\title{
An analytical framework to calibrate macroprudential policy
}

\section{Taryk Bennani, ${ }^{1}$ Cyril Couaillier, ${ }^{1}$ Antoine Devulder, ${ }^{2}$ Silvia Gabrieli, ${ }^{1}$ Julien Idier, ${ }^{1}$ Pier Lopez, ${ }^{1}$ Thibaut Piquard $^{3} \&$ Valerio Scalone $^{1}$}

October 2017, WP \#648

\begin{abstract}
This project presents the analytical framework for macroprudential policy (AFMaP) developed at the Financial Stability Directorate of the Banque de France that could be used to calibrate macroprudential instruments and to provide analytical support to macroprudential policy decision making. In this paper, we present and compare several possible methodologies to calibrate macroprudential capital buffers that rely both on structural models and macroprudential stresstesting tools. ${ }^{4}$
\end{abstract}

Keywords: Macroprudential policy; Countercyclical capital buffer; Systemic risk buffer JEL classification: G21, E44, C58, E32.

\footnotetext{
${ }^{1}$ Banque de France, DGSO-DSF-SMP.

${ }^{2}$ Banque de France, DGEI-DEMS-SEPS.

${ }^{3}$ Banque de France, DGSO-DSF-SMP, and Paris School of Economics.

${ }^{4}$ The views expressed here do not necessarily represent the opinions of the Banque de France. We would like to thank Raphaëlle Bellando, Agnès Bénassy-Quéré, Laurent Clerc, Vichett Oung and Hélène Rey for most useful comments, as well as Thibaut Duprey and David Gauthier for most useful research assistance in the development of some of the tools presented here.
}

\section{Working Papers reflect the opinions of the authors and do not necessarily express the views of the Banque} de France. This document is available on publications.banque-france.fr/en 


\section{NON-TECHNICAL SUMMARY}

The implementation of macroprudential policy poses a number of challenges to policymakers. A major one relates to the development of an analytical framework to inform the macroprudential decision-making process and guide the calibration of macroprudential buffers. This paper presents the tools developed at the Financial Stability Directorate of the Banque de France to guide the calibration of two macroprudential instruments of the CRD IV that are at the disposal of the French macroprudential authority: ${ }^{5}$ the countercyclical capital buffer $(\mathrm{CCyB})$ and the systemic risk buffer (SRB). Both buffers are Common Equity Tier 1 capital requirements. The CCyB is a time-varying buffer that aims to protect the banking sector from periods of excess aggregate credit growth as well as at leaning against the credit cycle. The SRB is a 'structural' capital requirement that aims at preventing or mitigating systemic risks of a non-cyclical nature.

We start by describing our framework for scenario design. Baseline and adverse scenarios are key ingredients to place a calibration exercise into the current and perspective macroeconomic context, and a crucial component of one of our strategies to macroprudential calibration - the "hybrid" approach that relies on stress testing tools. In particular, we describe how systemic risk analysis through early warning models [EWM] can be used to inform the design of the adverse scenario.

In addition to EWM, our analytical framework relies on several complementary models. A first class of models -at the heart of our "hybrid" calibration strategy- consists of a sequence of modules in the spirit of top down stress tests. Our framework builds on Henry and Kok (2013) and on Dees et al. (2017). It consists of several complementary modules that quantify the impact of an adverse scenario on individual banks' balance sheets through the calculation of first-round capital losses and the impact on riskweighted assets. We then aggregate the individual results and test whether projected systemwide capital ratios remain above a threshold level throughout the adverse event. Finally, the framework integrates a counterfactual analysis of the macroeconomic impact of any additional capital requirements that the policymaker may consider introducing based on the stress testing results.

A second class of models consists of contagion simulations. They can be used within the hybrid approach to quantify the systemic amplification that could follow after first-round bank losses in an adverse scenario, e.g., because of interbank contagion or asset fire sales.

A third class of models consists of dynamic stochastic general equilibrium (DSGE) models with costly financial intermediation, as in Clerc et al. (2015) or Gerali et al. (2010). These models are used for four distinct goals: (i) a structural calibration of the CCyB by the optimization of a given objective, e.g., the maximization of social welfare or the minimization of credit volatility; (ii) the design of adverse scenarios in the hybrid calibration strategy for the $\mathrm{CCyB}$; (iii) a counterfactual analysis of the macroeconomic

\footnotetext{
${ }^{5}$ In France, the Haut Conseil de Stabilité Financière (HCSF) was established in July 2013 as the authority in charge of macroprudential measures, upon the proposal of the Banque de France's governor.
} 
consequences of activating a $\mathrm{C} C \mathrm{BB}$ in the hybrid calibration approach; (iv) a structural calibration of the SRB, through identification of long-run costs and benefits to a permanent change in capital requirements.

We conclude with a quantitative illustration of the calibration strategies at our disposal: two structural strategies based on DSGE models (used to calibrate both the CCyB and the $\mathrm{SRB}$ ), and a hybrid strategy relying on our top-down stress test framework (used to calibrate the $\mathrm{C} C \mathrm{yB}$ ). The next figure provides a visual description of the two strategies. We conclude by emphasizing that expert judgment retains a crucial role for calibration. Expert judgment is central to the design of relevant scenarios as well as in the definition of the objective function of the macroprudential authority.

\section{A hybrid strategy for $\mathrm{CCyB}$ calibration based on top-down stress testing}

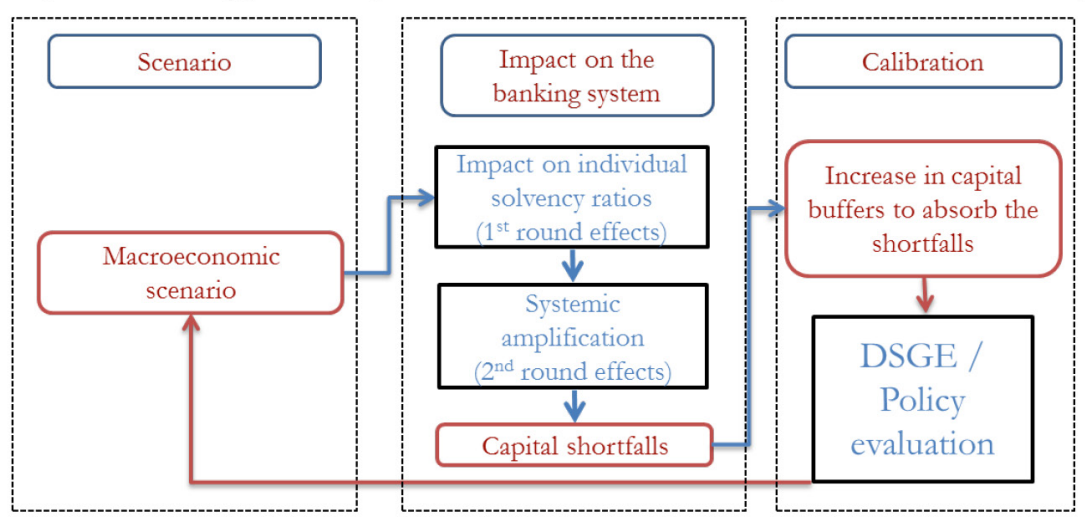

A strategy for $\mathrm{CCyB} \&$ SRB calibration based on a dynamic equilibrium model

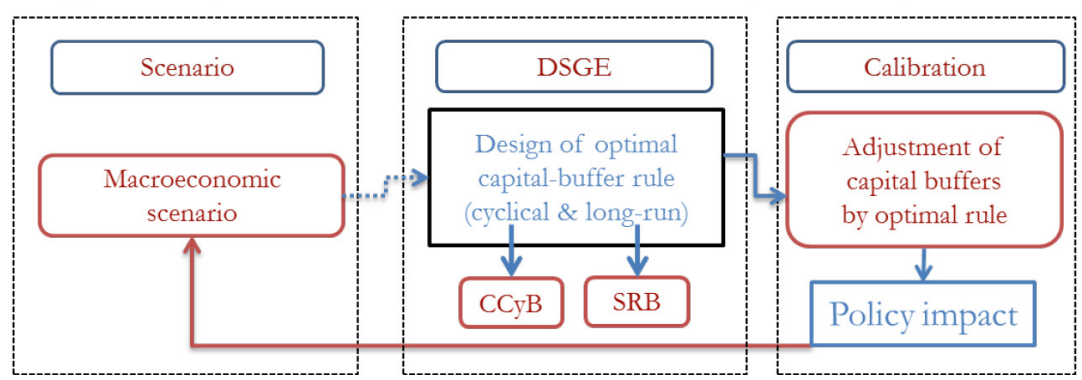

Representation of the DSF's strategies for calibrating macroprudential buffers

\section{Un cadre analytique pour la politique macroprudentielle}

Ce projet présente le cadre analytique pour la politique macroprudentielle (AFMaP) développé à la Direction de la Stabilité Financière de la Banque de France qui peut être mobilisé pour le calibrage des instruments macroprudentiels et qui fournit un support analytique d'aide à la décision aux autorités macroprudentielles. Dans ce papier, nous présentons et comparons les différentes méthodologies envisageables pour le calibrage des coussins de capital macroprudentiels basées à la fois sur des modèles structurels et sur des outils de stress-test macroprudentiels.

Mots-clés : Politique macroprudentielle; coussin contracyclique; coussin de risque systémique

Les Documents de travail reflètent les idées personnelles de leurs auteurs et n'expriment pas nécessairement la position de la Banque de France. Ce document est disponible sur publications.banque-france.fr 


\section{Introduction}

Top-down macro stress tests are therefore a powerful tool that can be employed in a range of exercises [...]. These would have the potential to assist macroprudential policy in the design, calibration and assessment of the impact of macroprudential tools. ${ }^{1}$ Vítor Constâncio, ECB Vice-President

The global financial crisis of 2007-2008 prompted reactions in international policy fora. Policymakers became increasingly aware of the need for a comprehensive approach to financial stability that focuses not only on the soundness of individual financial institutions but also on the resilience of the financial system as a whole, taking into account linkages among financial institutions and macro-financial feedback loops. Macroprudential policy, which aims at preventing systemic risk, "i.e. the risk of widespread disruptions to the provision of financial services that have serious consequences for the real economy" [CGFS, 2012], has since become one of the key goals of the G20 reform agenda.

The BCBS developed a set of regulatory reforms, referred to as Basel III, that combine a traditional micro-prudential approach - focused on individual institutions - with a macro-prudential perspective. At the European level, the Capital Requirements directive [CRD] IV / Capital Requirements Regulation [CRR] package, which entered into force in January 2014 (with a transition phase until 2019), contains a set of macroprudential instruments. In France, the Haut Conseil de Stabilité Financière [HCSF] was created in July 2013 as the French macroprudential authority with the legal ability to impose binding macroprudential measures on the financial system, upon the proposal of the Banque de France governor.

The calibration and the evaluation of the macroeconomic impact of macroprudential instruments are key challenges to which policymakers are confronted today. Besides state-of-the-art general equilibrium macroeconomic models, top-down stress test frameworks have become an increasingly popular tool for these purposes. To date, the European Central Bank and the Bank of England [BoE] rely on macro stress tests, usually complemented with other tools and models, to calibrate macroprudential instruments; for a discussion, see Henry and Kok [Eds.], BoE [2016], Dees et al. [2017].

In this paper we present the analytical framework developed at the Banque de France to inform macroprudential decision-making and to guide the calibration of macroprudential instruments in France. We focus on two specific buffers of the CRD IV that have been transposed into the French law and that are at the HCSF's disposal. First, the countercyclical capital buffer (CCyB), a time-varying Common Equity Tier 1 (CET1) capital requirement with a compound objective: a primary objective of increasing

\footnotetext{
1"The role of stress testing in supervision and macroprudential policy", keynote address at the London School of Economics, London 29 October 2015.
} 
the resilience of the banking sector against periods of excess aggregate credit growth, and a secondary objective of leaning against the build-up phase of the credit cycle (BCBS [2015]). Second, the systemic risk buffer (SRB), which is a CET1 capital buffer "for the financial sector or one or more subsets of that sector, in order to prevent and mitigate long term non-cyclical systemic or macroprudential risks" [CRD IV]. In our framework, we consider the $\mathrm{CCyB}$ as a tool to deal with cyclical risks and the SRB as a tool targeting risks that are not expected to abate naturally through the cycle (often referred to as 'structural' in the policy debate).

We start by describing our framework for scenario design. Baseline and adverse scenarios are a key ingredient of one of our approaches to macroprudential calibration - the stress testing approach - allowing to place the top-down stress test exercise into the current and perspective macroeconomic context. Scenario design is crucial for at least two reasons. First, a calibration exercise that builds on top-down stress testing requires both baseline projections of macro-financial variables as well as an additional, adverse event that adds to the original baseline. In our framework, we use the adverse scenario to quantify whether its impact would be systemic for the French banking sector. Second, the activation of macroprudential measures relies ultimately on the policymaker's views of macroeconomic and financial risks, and these can inform scenario design. In this context, we describe how systemic risk analysis through early warning models $[\mathrm{EWM}]^{2}$ can be used in the design of the adverse scenario.

Besides EWM, our analytical framework relies on several complementary modeling approaches. ${ }^{3} \mathrm{~A}$ first class of models consists of a sequence of modeling blocks in the spirit of top-down stress tests, labelled "hybrid approach" in our paper. Our framework builds on Henry and Kok [Eds.] and Dees, Henry, and Martin (Eds.) [2017]. It consists of several complementary modules (credit risk, market risk, and balance sheet satellites) that allow quantifying the impact of an adverse scenario on individual banks' balance sheets through the calculation of first-round losses, and the consequent impact on risk-weighted assets and capital ratios. We then aggregate the individual results and test whether the projected average capital ratio remains above a predefined threshold throughout the adverse event.

A second class of models consists of contagion simulations. These can be used within the hybrid approach to complement and amplify first-round losses by capturing realistic linkages across financial institutions. Contagion models can be particularly useful if the policymaker is concerned with risks stemming from interconnectedness and contagion externalities that are not duly internalised by financial

\footnotetext{
${ }^{2}$ More specifically, we rely on the model byCoudert and Idier [2016].

${ }^{3}$ In the same vein, CGFS [2016] illustrates the diversity of methods in operationalizing and, in particular, in calibrating macroprudential instruments. The CGFS report provides a useful overview of the practical experience and the analytical frameworks currently mobilized by central banks in assessing the costs and benefits of the implementation of macroprudential measures. It acknowledges that "there is no single preferred approach to ex-ante appraisals".
} 
institutions. We have two models in our toolbox that can be nested into the stress testing framework. ${ }^{4}$ Both include various channels of contagion, related to both solvency and liquidity dimensions. Importantly, one of the models takes into account several market-related channels of shock propagation, such as spirals of fire sales, margin calls and collateral depreciation, which have proved to be particularly dangerous for financial stability during the global financial crisis.

A third class of models consists of dynamic stochastic general equilibrium [DSGE] models that describe explicitly the behaviour of households, firms, and financial intermediaries. They are natural measurement tools for counterfactual analysis when implementing macroprudential policy. We rely on two DSGE models, both estimated on key French data and both including explicitly a banking sector. ${ }^{5}$ We use them for four distinct goals. The first is the structural calibration of the $\mathrm{CCyB}$, through optimization of a given objective - either the maximization of social welfare or the minimization of an ad hoc credit volatility function. The second is the design of scenarios in the hybrid calibration strategy for the CCyB (an alternative for scenario design are simple models in the vector autoregressive [VAR] class). The third is to integrate the policy impact in the hybrid calibration strategy for the CCyB; for this, a DSGE model is combined to our top-down stress test framework to run a counterfactual analysis of the macroeconomic consequences of activating a countercyclical capital requirement. The last goal is a structural calibration of the SRB, through identification of long-run costs and benefits to a permanent change in capital requirements.

In the remainder of the paper we describe our modeling approaches, focusing on their respective advantages and drawbacks, their differences and complementarities. We also provide a quantitative illustration of the different - structural and hybrid - calibration strategies for the CCyB and the SRB applied to the French economy.

The structure of the paper is as follows. Section 2 presents the objectives of the CCyB and the SRB. Section 3 discusses the design of baseline and adverse scenarios. Section 4 describes the different modeling approaches that can be used to guide the calibration of the buffers. Section 5 provides a quantitative illustration of the calibration strategies based on French data. Section 6 discusses some challenges in the calibration of macroprudential capital buffers. Tha last section concludes and indicates areas for future research.

\footnotetext{
${ }^{4}$ The models are: Gabrieli, Salakhova, and Vuillemey [2015] and Idier and Piquard [2017].

${ }^{5}$ We use the following DSGE models: the so called '3D model' by Clerc, Derviz, Mendicino, Moyen, Nikolov, Stracca, Suarez, and Vardoulakis [2015] and Mendicino, Nikolov, Suarez, and Supera [2016], and the model by Gerali, Neri, Sessa, and Signoretti [2010].
} 
Table 1: Overview of the paper

\begin{tabular}{|c|c|c|}
\hline Instrument & Countercyclical capital buffer (CCyB) & Systemic risk buffer (SRB) \\
\hline Institutional details & 2.1 .1 & 2.1 .2 \\
\hline \multirow[t]{5}{*}{ Risk analysis } & Structural: Unconditional (2nd moments) & Steady state \\
\hline & Hybrid: Conditional on scenario: & \\
\hline & o scenario design (baseline): 3.1 & \\
\hline & o systemic risk analysis: 3.2 & \\
\hline & o scenario design (adverse): 3.3 & \\
\hline \multirow[t]{2}{*}{ Calibration strategy } & Structural: 4.2 & 4.1 \\
\hline & Hybrid: 4.3 (incl. contagion: 4.5 ) & \\
\hline \multirow[t]{2}{*}{ Operational objective } & Structural: Welfare or volatility & Welfare \\
\hline & Hybrid: Solvency ratio threshold & \\
\hline Comparison of strategies & 4.4 & \\
\hline \multirow[t]{4}{*}{ Models in detail } & Structural: DSGE (Annexes 1, 2, 3) & DSGE (Annex 1) \\
\hline & Hybrid: Top-down stress testing (Annex 4) & \\
\hline & \& contagion analysis (Annex 5) & \\
\hline & \& policy impact analysis (Annexes $1-2$ ) & \\
\hline Quantitative example & $5.1,5.2,5.3$ & 5.4 \\
\hline Challenges in calibration & $6.1,6.2,6.3,6.4$ & $6.1,6.2,6.3,6.4$ \\
\hline
\end{tabular}

\section{Macroprudential capital buffers}

Several prudential buffers coexist in the current legislative environment at the European level, as shown in figure 1. Capital requirements include hard, non-cyclical requirements that banks must satisfy under all circumstances, currently set at $4.5 \%$ in terms of CET1 and $8 \%$ in terms of total capital, plus potential Pillar 2 requirements, which are of a microprudential nature hence under the discretion of the bank supervisory authority. The capital conservation buffer ( $\mathrm{CCoB})$, the systemic risk buffer (SRB) and buffers for systemically important institutions (G-SII and O-SII buffers) constitute additional non-cyclical requirements, whose violation would trigger automatic restrictions on dividend and bonus distribution. On top of these restrictions, the countercyclical capital buffer $(\mathrm{CCyB})$ constitutes a cyclical capital requirement. Finally, all additional capital retained by banks constitutes voluntary buffers, motivated for example by market forces, expectations of future changes in capital requirements or, when applicable, additional Pillar 2 guidance suggested by the supervisor.

The calibrations of the $\mathrm{CCyB}$ and of the SRB require an analysis able to account structurally for the dynamic interaction between the banking sector and the real economy. ${ }^{6}$

\footnotetext{
${ }^{6}$ Instruments such as the global systemically important institutions buffer or liquidity regulations that belong to the international standards of Basel III are typically set at the international level. The institutional framework for the adoption
} 


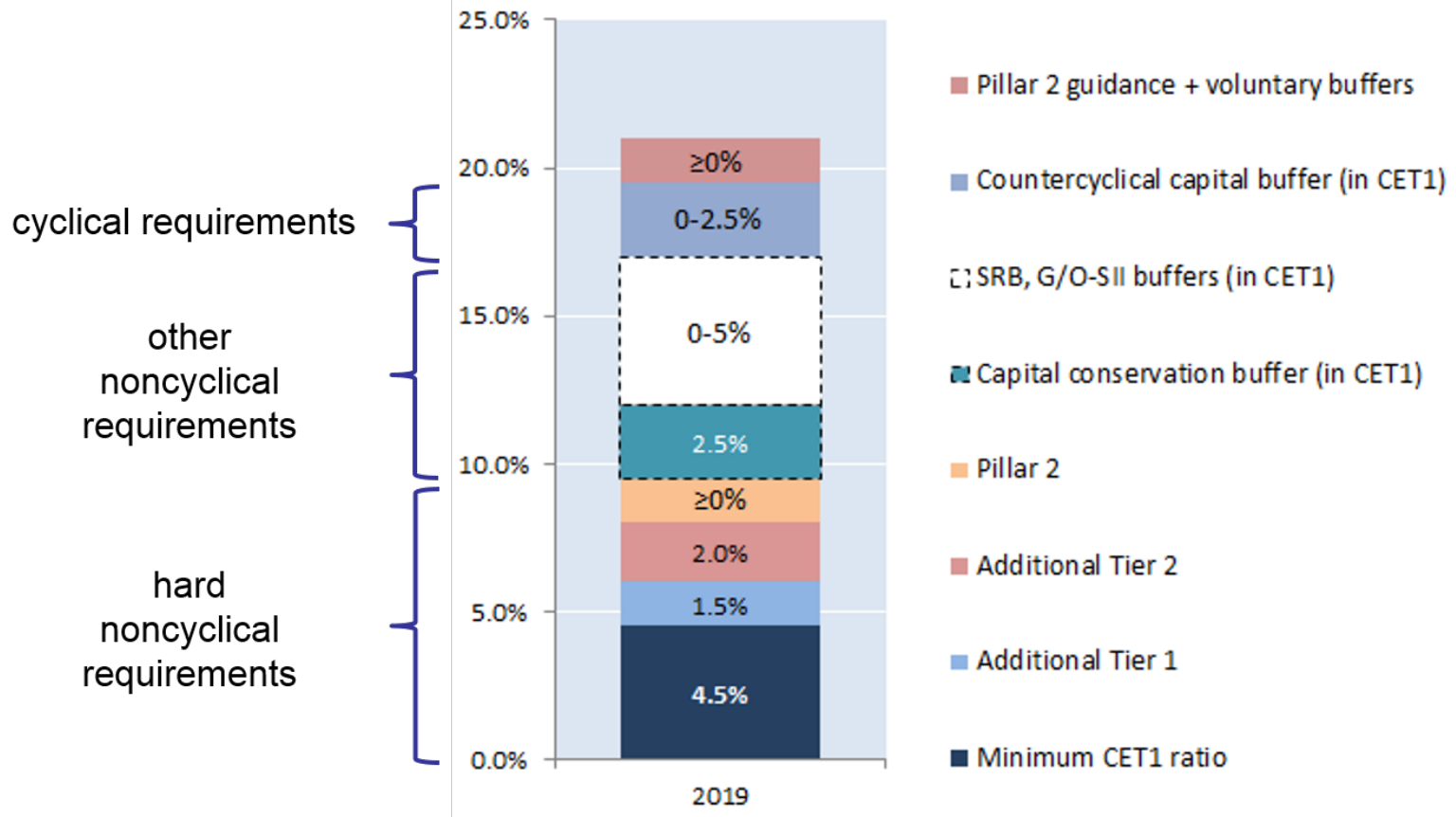

Figure 1: Capital requirements for 2019 in the current legislative environment in France.

\section{$2.1 \quad$ Objectives}

Capital buffers in general can be distinguished in their microprudential (undercapitalization putting at risk the solvency of individual institutions) and macroprudential (undercapitalization endangering the entire financial system and the real economy) target and in their long-run (steady-state) and short-run (cyclical) effects. In practice, the main example of macroprudential cyclical buffer at the HCSF's disposal is the countercyclical capital buffer, while instruments such as the systemic risk buffer address long-run stability issues.

\subsubsection{Countercyclical capital buffer (CCyB)}

The $\mathrm{CCyB}$ is intended to cover cyclical risks, thereby reflecting a financial cycle, in particular alternating phases of excessive credit and credit crunches, the former sowing the seeds of the latter. The BCBS attributes a compound objective to the CCyB:

of macroprudential policies in France inscribes in the recommendations by the Forum of Financial stability (FSB) and the European systemic risk board (ESRB) that their implementation be carried out by a specific national authority; in particular, the HCSF is the French authority that is responsible for activating the appropriate macroprudential instruments if systemic risks are identified. 
The primary aim of the countercyclical capital buffer regime is to use a buffer of capital to achieve the broader macroprudential goal of protecting the banking sector from periods of excess aggregate credit growth that have often been associated with the build up of system-wide risk. ${ }^{7}$ Protecting the banking sector in this context [...] [aims] to ensure that the banking sector in aggregate has the capital on hand to help maintain the flow of credit in the economy without its solvency being questioned, when the broader financial system experiences stress after a period of excess credit growth. This should help to reduce the risk of the supply of credit being constrained by regulatory capital requirements that could undermine the performance of the real economy and result in additional credit losses in the banking system. In addressing the aim of protecting the banking sector from the credit cycle, the countercyclical capital buffer regime may also help to lean against the build-up phase of the cycle in the first place. [BCBS, 2010a]

In terms of financial cycle, the CCyB's main focus is thus on the downturn period: it aims at improving banks' resilience to financial systemic shocks, so that they can provide the necessary credit flow to the real economy. The CCyB role in the rising phase comes only as an ancillary objective, with the so-called "leaning against the wind" policy of mitigating the buildup of risk by keeping a lid on (excessive) credit growth.

The design of the $\mathrm{CCyB}$ reflects this pecking order: by increasing capital requirements as a fraction of risk-weighted assets (RWA) when credit growth seems excessive and indicative of future stress in the financial system, the $\mathrm{C} C y B$ mechanically reinforces banks' resilience. On the contrary, the effect on credit growth comes from a trade-off between the two sides of the capital ratio: augmenting capital and reducing asset expansion.

In our models, this comes through an increase in lending spreads in order to increase margins and retain them as capital. This modeling assumption reflects the observed sluggishness of capital accumulation and, by ruling out fast adjustments, including in particular a direct access by banks to equity markets, the analysis presented here is particularly conservative. Since it takes times for banks to comply with the new requirements, the activation decision has to be taken sufficiently in advance before the economic situation deteriorates, not accounting for the legal delays (12 months in Europe). The capital requirements will be decreased accordingly when the adverse event occurs to mitigate the possibility that regulatory requirements further exacerbate the credit tightening.

\footnotetext{
${ }^{7}$ Systemic risk is defined in the European regulation CRD IV as "a risk of disruption in the financial system with the potential to have serious negative consequences for the financial system and the real economy."
} 
Our different models reflect this dual objective: the "hybrid" (i.e. stress test-based) approach focuses on bank resilience, calibrating the $\mathrm{CCyB}$ so that the average bank does not fall below a certain capital level threshold; the "structural" (i.e. DSGE-based) approach on the contrary focuses on the objective of smoothing the credit cycle and protecting the real economy, with a $\mathrm{CCyB}$ set to minimize credit volatility or otherwise remove the fluctuations that negatively affect social welfare. ${ }^{8}$

A benchmark CCyB rule When setting their rate of $\mathrm{CCyB}$, national authorities must compute and communicate a benchmark CCyB designed by the BCBS. According to this rule, the activation of the buffer depends on a unique indicator, namely the 'credit-to-GDP gap'. This indicator represents a detrended version of the ratio of credit to GDP at quarterly frequency, and uses a broad measure of outstanding credit, including all sources of debt funds for the private sector (even those originating from the non-bank financial sector) to compute a ratio relative to the sum of quarterly GDP over 4 quarters. The credit-toGDP gap is defined as the cyclical component of this ratio computed with a one-sided Hodrick-Prescott filter with smoothing parameter $\lambda=400,000$ [BCBS, 2010b].

In particular, the mechanical rule defines the size of the CCyB add-on $\left(\nu_{t}\right)$, in percent of RWA, as a function of the credit-to-GDP gap $\left(G A P_{t}\right)$ expressed in percentage points:

$$
\nu_{t}= \begin{cases}0 & \text { if } G A P_{t} \leq 2 \\ 0.3125\left(G A P_{t}-2\right) & \text { if } 2<G A P_{t} \leq 10 \\ 2.5 \% & \text { if } G A P_{t}>10\end{cases}
$$

Against this background, when risks materialize the BCBS guidelines suggest a prompt release of the countercyclical capital buffer to help banks absorb losses while complying with regulatory requirements. An interpretation of these guidelines is therefore that during an adverse scenario for the financial sector the macroprudential authority may choose not to commit to the rule described by equation (1) if the credit gap were not to drop immediately or otherwise remain above the $2 \%$ threshold level.

In the following, when describing our calibration strategies, we also include an evaluation of the effects of the BCBS's simple guiding rule for the activation and the calibration of the CCyB designed to serve as benchmark.

\footnotetext{
${ }^{8}$ We do not give more weight to the negative part of volatility, but consider it from a symmetric point of view. While a focus on removing negative skewness in the credit cycle is in principle possible, it remains a technically challenging and largely unexplored area in which we do not venture. We will discuss again the treatment of nonlinearities in Section 6 .
} 
Theoretical and empirical issues with the BCBS benchmark CCyB rule While the automatic BCBS rule (1) for the CCyB can be regarded as a useful benchmark, its motivation on the basis of a fullyfledged structural analysis so far still remains an open question. The alternative methodologies outlined in this paper provide alternative calibrations for capital buffers and help to gauge whether activations in line with the automatic rule can be justified through the lens of a structural analysis. From an empirical point of view, the BCBS buffer guide is weakened by the two empirical issues surrounding the computation of the credit to GDP gap: the measurement of credit and the calibration of the trend smoothing parameter. ${ }^{9}$

\subsubsection{Systemic Risk Buffer (SRB)}

According to Article 133 of CRD IV, "each Member State may introduce a systemic risk buffer of Common Equity Tier 1 capital for the financial sector or one or more subsets of that sector, in order to prevent and mitigate long term non-cyclical systemic or macroprudential risks [not covered by CRR Regulation], in the meaning of a risk of disruption in the financial system with the potential to have serious negative consequences to the financial system and the real economy in a specific Member State."

As such, the SRB is a flexible instrument aimed at correcting structural (i.e., permanent) systemic risks not addressed, or not sufficiently, by other specific instruments. Due to the lack of clear focus (targeted risks) and scope (i.e. applicability to the entire stock only or also to subsets of exposures) in the current regulatory definition, the $\mathrm{SRB}$ has so far been used to address a large spectrum of risks. The latter pertain to one or more subsets of bank exposures - located in the Member State only or also in a foreign country - and to all or a subset of institutions. ${ }^{10}$

For the purposes of this paper, we consider the SRB as a structural capital buffer covering all bank exposures (i.e. the models we consider do not allow for a distinction between domestic and foreign exposures) and the whole banking sector. The main objective of the SRB in the context of the long-run structural approach used in Section 4.1 is to improve welfare by addressing the following types of distortions: (i) banks' limited liability due to a sector-wide safety net from deposit insurance; (ii) banks' funding cost externalities due to the fact that the deposit premium depends on the average (rather than individual) bank risk behaviour; (iii) limited participation in equity markets, implying that equity as a form of funding is scarce and more expensive than debt. In practice, an SRB aims to limit the systemic

\footnotetext{
${ }^{9}$ A thorough discussion of the issues serrounding the BCBS buffer guide can be found in [Couaillier and Idier, 2017].

${ }^{10}$ For instance, Austria, Czech Republic, Denmark, Hungary, The Netherlands, Romania and Sweden have already applied an SRB only on selected banks and targeting all their exposures; on the contrary, the SRB introduced by Bulgaria and Estonia applies to all banks, but only to their domestic exposures. Structural risks addressed by the additional capital requirement vary from the domination and concentration of the banking sector, to risks stemming from foreign exposures due to the high degree of openness of the domestic economy, to sectoral risks, and banks' misaligned incentives.
} 
impact of misaligned incentives: the latter create moral hazard, hence excessive risk-taking or excessive leverage, possibly leading to a suboptimal level of capital in the long-run.

\section{Scenario design}

The evaluation of an activation of capital buffers depends on current macroeconomic perspectives, as reflected by a baseline macroeconomic scenario. Moreover, macroprudential stress-testing tools depend heavily on the averse scenario considered, and with it the hybrid calibration strategy presented in section 4.3. Scenario design is therefore an important exercise.

To construct the scenarios we rely on vector autoregressive time-series models for key macro-financial variables, either unrestricted (i.e. VAR), or featuring cross-equation restrictions imposed by theory (i.e. DSGE). On the one hand, DSGE models can build scenarios based on shocks with a clean economic interpretation, while the microfounded behavior of optimizing economic agents might mitigate overfitting via cross-parameter restrictions, at least in principle. On the other hand, the flexible structure of the unrestricted VAR-type models replicates more easily the in-sample dynamic properties of the data and, relative to the estimated DSGE models we use (see section 4), can easily include additional macro-financial variables typically found in stress testing exercises such as commodity prices, exchange rates or the slope of the term structure of interest rates.

We propose to use forecasts conditional on the official macroeconomic projection conducted by the Banque de France at Eurosystem level for the preparation of monetary policy decisions (the Broad Macroeconomic Projection Exercise [BMPE]) for a subset of the variables included in the VAR or DSGE models used for forecasting. We choose to include these projections in our information set as they reflect the view of the institution about future economic perspectives - the scenario used for the calibration of the CCyB is therefore consistent with the BMPE. We name the resulting scenario the "baseline scenario".

Under the structural approach, the baseline scenario can possibly trigger the activation of the $\mathrm{CCyB}$, for example if the BMPE associates with an expansion of credit. The role of the baseline scenario is different under the hybrid approach. In this case, by construction, the baseline scenario does not necessarily trigger any activation of the CCyB. In this context, we need to design an "adverse scenario", under which the macro-financial conditions of the economic environment trigger the activation of the CCyB before severely affecting the dynamics in the financial sector. To build the adverse scenario, we propose to extend the scenario beyond the horizon of the BMPE, and to add a one-year period corresponding to an adverse event; the two-year distance between the current date $t$ and the adverse event at $t+2$ spanned by the BMPE leaves sufficient time to account for transmission lags as banks adjust their capital levels to a potential 
macroprudential decision taken at date $t$ and coincides with the typical forecast horizons of early warning models.

Since the results of the hybrid approach depend crucially on the adverse shock, its design in terms of narrative and severity must be well communicated and agreed upon by decisionmakers. In particular, we emphasize the importance of linking scenario design to systemic risk monitoring. In turn, the stress testing tool offers a way to quantify the severity and systemicity of the event, whose stressful potential was suggested qualitatively by the tools discussed in section 3.2. The adverse shock should also be sufficiently likely to justify an activation of the buffer at the time of the analysis.

Summing up, we propose to build a scenario that includes two sub-periods: the baseline scenario covering a 2-year horizon, and the adverse event covering a 1-year horizon. The different calibration approaches considered are all tested over the whole horizon. Yet, the second downturn sub-period plays a role only in the determination of the size of the $\mathrm{CCyB}$ in the hybrid approach.

\subsection{Baseline scenario}

We rely on two alternative approaches to generate a forecast conditional on the BMPE (a.k.a. the baseline scenario): a DSGE and a VAR.

The DSGE approach relies on two alternative models: the GNSSFr model (described in Annex 2), which has been estimated using several quarterly time series of French data over the period 1993-2015, and the 3D model (described in Annex 1). The set of observable variables used to estimate the GNSSFr model includes the year-on-year growth rates of real GDP, CPI, real residential house prices and stock market index, the Basel III credit-to-GDP gap, the 3-month Euribor, the interest rate on 3-month deposits and lending rates on mortgages and corporate loans, and an aggregate bank capital ratio. The set of observable variables used to estimate the 3D model is instead more limited and the estimation strategy does not attempt to capture dynamic correlations in the data. While the use of the DSGE has the advantage of relying on the same model that will be subsequently used for counterfactual analysis, the GNSSFr model can produce projections only for a relatively limited subset of the macroeconomic and financial variables; this shortcoming is even stronger for our version of the 3D model, as it is more stripped-down model that includes only real variables; its ability to replicate observed dynamics is therefore limited.

Alternatively, we consider a VAR estimated over the period 1993Q1-2015Q4 using 10 quarterly time series that are typically found as the main macro-financial drivers in top-down stress testing models [see, for example, Henry and Kok , Eds.]. They include oil price year-on-year inflation, the EUR/USD real exchange rate, the 3-month EURIBOR, the credit-to-GDP gap, the year-on-year growth rate of real GDP, 
the year-on-year growth rate of real CAC40 dividends, the year-on-year inflation rate of the CPI deflator, the year-on-year growth rate of real estate prices deflated by CPI inflation, a spread computed as the difference between the 10-year interest rate on government bonds and the 3-month EURIBOR, and the year-on-year growth rate of the CAC40 index deflated by CPI inflation. All series are demeaned except for the credit-to-GDP gap which is defined as described in BCBS [2010b]. The VAR uses only one lag based on standard information criteria. ${ }^{11}$

As discussed, the first sub-period of the scenario is not a simple projection simulated with the dynamic macro model. It is adjusted to reflect at least the BMPE forecasts of the main macro-aggregates (in practice, those which are publicly available, including the annual growth rate of GDP and annual CPI inflation rates). The simulation may also depend on other information or projections available to the macroprudential authority, for example for growth rates of credit. In order to make the projection consistent with the desired information (BMPE or other), we use a standard Kalman smoother. The principle is well-known [e.g., Hamilton, 1994]: let $Y_{t}$ the vector of observable variables used in the simulation model (VAR or DSGE), $X_{t}$ a vector of so-called state variables and $\varepsilon_{t} \sim W N(0, I)$ the vector of structural shocks, and the state space representation of the model: ${ }^{12}$

$$
\begin{aligned}
X_{t} & =A X_{t-1}+B \varepsilon_{t} \\
y_{t} & =C X_{t-1}+D \varepsilon_{t}
\end{aligned}
$$

where $D$ is a matrix that represents the simultaneous response of observables to the structural innovation. We wish to impose the values of a subset of variables $w_{t} \subset y_{t}$ and of additional variables $z_{t}$ defined as linear combinations of the original variables $\left(z_{t}=Q y_{t}\right)$ over the projection horizon. Then we add the following equation to the previous state-space form of the model:

$$
\left[\begin{array}{c}
w_{t} \\
z_{t}
\end{array}\right]=\left[\begin{array}{c}
S \\
Q
\end{array}\right]\left(C X_{t-1}+D \varepsilon_{t}\right)
$$

where $S$ is a selection matrix with either 0 s or 1 s on its diagonal and 0 s elsewhere, and $Q$ reflects the definition of variables $z_{t}$. The Kalman smoother recovers the sequence of structural shocks which are

\footnotetext{
${ }^{11}$ While cointegration among a subset of variables (e.g., GDP and credit, stock prices and dividends, GDP and dividends) is justified from a theoretical perspective, statistical tests for cointegration over the relatively short estimation sample suggest a simple VAR representation in differences. Since we are interested in using the model for short-term forecasting, we stick to the $\operatorname{VAR}(1)$ representation.

${ }^{12}$ A linearized DSGE can be represented in the posed state-space form with particular restrictions on the coefficients of matrices $A, B, C, D$.
} 
consistent with the values imposed for $w_{t+h}, z_{t+h}$ and with the dynamics generated by the estimated statespace model 2 (either of VAR-type or DSGE). Our baseline scenario will be a set of projections for all the variables of the state space model, $\left\{\hat{X}_{T+1}, \ldots, \hat{X}_{T+h}\right\}$, given the entire set of observable information $\left\{X_{1}, \ldots, X_{T}, y_{T+1}, \ldots, y_{T+h}, z_{T+1}, \ldots, z_{T+h}\right\}$, where $T$ denotes the size of the estimation sample and $h$ the horizon of the scenario.

For future work, we aim at enriching the set of macroeconomic tools available in the production of the the baseline and the adverse scenarios. For example, we envisage the adoption of an alternative macrofinancial model, featuring disequilibrium equations and credit rationing, in order to describe the evolution of credit and its interaction with the macroeconomic environment in more depth. The introduction of this additional model goes in the direction of increasing the robustness of the scenarios designed and of the exercise as a whole.

\subsection{Systemic risk analysis to inform the design of adverse scenarios}

Systemic risk monitoring is ambitious given the diversity of risks that need to be monitored. It requires organizing the monitoring of all the components of the financial system (banks, insurance, markets, shadow banking sector, asset managers, etc.); to understand all the channels of transmission between the different players in the financial system that govern the possible propagation and amplification of individual shocks; to measure the contribution of the financial system to the financing of the economy and to assess the feedbacks between the real economy and the financial system.

There are numerous examples of the diversity of indicators that are followed by macroprudential authorities. For example, the European Systemic Risk Board (ESRB) in its Risk Dashboard uses a seven-pillar breakdown of risks: (1) interconnections and composite indicators of systemic risk; (2) macroeconomic risk; (3) credit risk; (4) risk of refinancing and liquidity; (5) market risk; (6) risk of profitability and solvency; (7) structural risks. In the United States, the Office of Financial Research (OFR) in charge of risk analysis for the US Federal Reserve's Financial Stability Oversight Council (FSOC) uses a more synthetic classification with (1) macroeconomic risk; (2) market risk; (3) credit risk; (4) risk of refinancing and liquidity; (5) risk of contagion.

Systemic risk analysis is thus a necessary prerequisite before running any calibration exercise. The detected risks should, as much as possible, feed into the scenarios we want to address in the calibration exercise. However, there is a need to consider a limited set of core indicators for making the exercise operational.

A first way to define core indicators, i.e. to be more specific regarding the monitoring, is to select a 
set of indicators that stick to the macroprudential instruments that we need to calibrate, namely the SRB and/or the $\mathrm{CCyB}$ in this paper. These two macroprudential instruments address different types of risks that have been described previously: as a consequence the systemic risk analysis should restrict and map to the specific objectives of the instruments. ${ }^{13}$

A second way to define core indicators is to evaluate the extent to which they would have helped in the past to detect systemic crises. To this end, early warning systems have been extensively developed by macroprudential authorities like in Banque de France (see Coudert and Idier [2016]). Key recent methodological references in this domain are Borgy et al. [2014]; Alessi and Detken [2011]; Alessi and Detken [2014]; Shin [2013]; Detken and group on CCyB [2014]; Ferrari and Pirovano [2015]; Kalatie et al. [2015].

Early warning approaches consist in defining optimal thresholds for some indicators that may signal the upcoming crises. Let us call $Z$ an economic indicator. We consider that an alert of crisis is emitted each time $Z$ exceeds the threshold $\theta$. To assess the relevance of $Z$ at a given $\theta$ threshold, the sample is decomposed into four categories of observations: (A) a signal is emitted and a crisis bursts at the $H$ horizon, the crisis is well predicted; (B) a signal is emitted and no crisis occurs within H horizon, it is a false alarm (Type II error); (C) no signal is emitted and a crisis bursts within the $H$ horizon, it is a missed crisis (Type I error); (D) no signal is emitted and no crisis occurs at the $H$ horizon, the tranquil period is well predicted. The number of observations in each category A, B, C and D can be then calculated. For each value of $\theta$ threshold, the performance of indicator $Z$ is then be assessed by two ratios : the percentage of missed crises $T_{1}(\theta, Z)=C /(C+A)$ and the percentage of false alarms $T_{2}(\theta, Z)=B /(B+D)$. The critical threshold is obtained by arbitrating between the two types of errors: (i) missing too many crises $\left(T_{1}\right)$ or (ii) wrongly predicting crises that do not exist (false alarms or $T_{2}$ ). This optimization consists in the minimization of the so-called policy-maker objective function that defines as:

$$
\operatorname{MinL}=\mu T_{1}+(1-\mu) T_{2}
$$

with $\mu$ the parameter gauging the aversion of the policy maker to miss a crisis. In our risk evaluation, we consider a balanced preference between $T_{1}$ and $T_{2}$ so we set $\mu=0.5$. The lower the threshold, the more frequent the signal. Hence, by setting the threshold sufficiently low, one can easily predict the whole set of crises, but this would generate numerous false alarms. Inversely the higher the threshold, the fewer signals the indicator emits, at the risk of missing more crises. All the indicators have no predictive power

\footnotetext{
${ }^{13}$ In this paper, we consider that the instrument selection has already been done, such that there is no trade-off between instruments given the risk analysis. However, this may not be always true in a macroprudential decision process since many macroprudential instruments overlap in terms of risks they are supposed to address.
} 
regarding past crises. This is why we tend to privilege the ones that would have been useful in detecting the growing imbalances that preceded past crisis events. This is especially the case for the Credit-to-GDP gap as shown in Drehmann and Juselius [2014]. The early warning corresponding critical thresholds may then help in designing risk scenarios. For example, Coudert and Idier [2016] have calculated a critical threshold for the credit-to-GDP gap of 6pp. This may be a trigger for a macroeconomic scenario that is compatible with such an increase of the indicator: (i) a surge in credit to private sector or (ii) a significant exogenous drop of GDP while credit is maintained in the economy. Finally, ex post, all these indicators may also inform experts if a specific calibration helps to reduce the risks these indicators tend to reveal.

One limit of this exercise is that many indicators that are followed in early warning systems (or more broadly in systemic risk monitoring) may not be part of the economic models we use to calibrate the macroprudential buffers. There is an obvious reconciliation to be done between the risk analysis performed on a plurality of indicators and what could be properly reflected in the stylized representation of the financial system we use in our models. This imperfect reconciliation between risk exhaustivity and modelling feasibility necessarily calls for some approximations and expert choices. ${ }^{14}$

A second limit is that to give robust estimates of the critical thresholds, the sample must include a sufficient number of crisis events in order to differentiate crisis periods from tranquil ones. Banking crises are rare events, this is why it requires that we work on a panel of countries that we have selected for being homogeneous in terms of financial structures. In this context, we have selected a panel of 10 countries in the euro area: AT, BE, DE, ES, FI, IE, IT, FR, NL, PT between 1985 and 2010. Coudert and Idier [2016] proposes to control (but not to correct) this statistical constraint by retaining only those indicators whose thresholds remain relevant for France, even if they have been ex-ante defined for a panel of countries. However, note that working on a panel makes it possible to consider that the origin of the major financial crises in the past can have similarities, whatever the country of origin, which allows with this approach to (i) learn from our errors over time, by monitoring indicators that might have been useful in the past; (ii) learn from the mistakes of our country-neighbors.

All these indicators cannot, however, consider the "new" possible sources of future financial crises. Therefore, monitoring via the warning system can not be mechanical in that it cannot cover all the possible risks.

Regarding the specific case of the CCyB, many indicators other than the Credit-to-GDP gap may be used to help in the design of a scenario (see Coudert and Idier [2016] paper for a detailed list of variables

\footnotetext{
${ }^{14}$ Another limit related to early warning systems is that crises being rare events, critical thresholds are defined on a panel of countries to have a sufficient number of crisis observations. This leads to critical thresholds that are equal across countries.
} 
and thresholds). ${ }^{15}$. The Basel Credit-to-GDP gap has proved to be a signal for past crises as soon as it had reached 6pp. Note this threshold is higher than the $2 \mathrm{pp}$ of the buffer guide in the CCyB dedicated recommendation of the ESRB (ESRB/2014/1). Many indicators reflect credit dynamics for households, non-financial corporations or the private sector in general: when total credit to households grows by more than $7 \%$ yoy it may signal a growing vulnerability in the financial system. Debt sustainability is also important for the different sectors: if a aggregate debt service ratio for households is greater than 13,7\%, there may be a financial stability issue. Regarding real-estate, prices of residential real-estate goods or mortgage dynamics proved to be good indicators. Finally, interest rates indicators as the slope of the yields curve or the gap between GDP growth and interest rates could also be useful.

Taking into account these results, designing scenarios that are coherent with these potential signals or based on story-telling that could be related to these proxies of cyclical systemic risks are key in our macroprudential stress-testing framework.

\subsection{Adverse scenario}

The adverse event includes an economic downturn that is assumed to follow from an adverse shock to the economy. To generate the event we need a structural representation of the model, so we can simulate the effects of a particular set of shocks and we can attach an economic interpretation to it.

We rely on two alternative approaches. First, we rely on a simple recursive-ordering approach to shock identification (i.e., to obtain the matrix $B$ in equation (2) when $y_{t}=X_{t}$ ) based on a Cholesky decomposition of the covariance matrix of the VAR innovations under a given Wold ordering of the vector of variables. For that purpose, variables are ordered as described in table 2. Each variable is associated with a specific shock to which we try and give an economic interpretation. The shocks associated with variables at the top of the table affect contemporaneously the variables ordered after them (in this sense the top variables are more exogenous), whereas shocks associated with variables at the bottom of the table only affect the other variables with a lag (and in this sense those variables are more endogenous). To choose the ordering presented above, we base our economic reasoning on the lag structure of shock effects. Specifically, we assume an environment in which oil prices, the EUR/USD real exchange rate and the short term interest rate do not react immediately to shocks specific to the French economy, as they are set effectively exogenous from a French viewpoint; then come the real variables (credit, GDP and dividends); and lastly come prices (consumer price, housing price, interest-rate spread on bonds and stock prices),

\footnotetext{
${ }^{15}$ Regarding the analysis of structural risks addressable by a SRB, a broad set of indicators is provided to national macroprudential authorities in ESRB [2014]
} 


\begin{tabular}{ll}
\hline$\pi_{o}$ & oil price yoy inflation \\
$e$ & EUR/USD real exchange rate \\
$i$ & 3m Euribor \\
$b y$ & credit-to-GDP gap \\
$\Delta y$ & real GDP qoq growth rate \\
$\Delta d$ & real CAC40 dividends qoq growth rate \\
$\pi$ & consumer price qoq inflation \\
$\Delta q_{h}$ & real house price qoq inflation \\
$i_{10}-i$ & 10y-3m interest-rate spread \\
$\Delta c a c$ & real stock price index (CAC40) yoy growth rate \\
\hline
\end{tabular}

Table 2: Triangular ordering of VAR variables: from more to less endogenous

which are assumed to adjust immediately to real shocks to ensure equilibrium in markets, while they are expected to have only lagged consequences on the real economy. An implicit assumption, therefore, is that the structural shock in equation (2) can be backed out from the innovations to a VAR representation of the observable variables. ${ }^{16}$

Alternatively, we can rely on dynamic general equilibrium models. Under this option, structural shocks have a more straightforward economic interpretation relative to the SVAR approach as their identification is based on an explicit economic theory. However, the DSGE models at our disposal can produce the adverse event only on a subset of the macroeconomic and financial variables included in the VAR (notably, they do not include oil prices, the exchange rate or the slope of the term structure).

Thus, the complete scenario (at quarterly frequency) consists of a projection from the current date $t$ to three years (or twelve quarters) from now (i.e. to $t+12$ ), in turn divided into a first sub-period given by the projections $\left\{\hat{X}_{s}\right\}_{s=t}^{t+8}$ and a second sub-period in which we add a linear combination of impulse responses to the projected $\left\{\hat{X}_{s}\right\}_{s=t+9}^{t+12}$. These impulse responses simulated with the structural model (be it SVAR or DSGE) are chosen consistently with a narrative scenario based on expert judgment and on the risk assessment surrounding the baseline projections. It is worth to stress that both approaches provide great flexibility in the design of the adverse scenario and allow for tailoring the exercise according to different types of macro-financial risks that the policymaker may want to address. An example is provided in the illustrative implementation of the hybrid approach (see section 5).

\footnotetext{
${ }^{16}$ See Fernández-Villaverde, Rubio-Ramírez, Sargent, and Watson [2007] for a detailed discussion of the (particularly strong) required regularity conditions.
} 


\section{Strategies for calibration of macroprudential buffers}

In this section, we develop tools and methods to inform the decision-maker in the calibration of a macroprudential capital buffer. As discussed in section 2, the current legal framework distinguishes between buffers in place to correct the cyclical pattern of the economy and buffers in place to correct steady-state inefficiencies in the economy that originate in the financial sector. Accordingly, we separate the prescribed interventions into transitory and permanent components, thereby associating the CCyB to the short-run objective and the SRB to the long-run objective.

For concreteness, our approach aims at calibrating the components of a Basel-III-type capital buffer rule:

$$
\nu_{t}=\underbrace{\nu}_{\text {non-cyclical }}+\underbrace{\phi_{\nu}}_{\begin{array}{c}
\text { cyclical } \\
\text { (rule) }
\end{array}}\left(\frac{\text { Credit }_{t}}{\sum_{j=0}^{3} G D P_{t-j}}-\frac{\text { Credit }}{4 * G D P}\right)+\underbrace{\epsilon_{t}^{\nu}}_{\begin{array}{c}
\text { cyclical } \\
\text { (unexpected) }
\end{array}}
$$

where $\nu$ is the steady-state level of required capital, $\phi_{\nu}$ is the systematic reaction coefficient to developments in credit-to-gdp ratio deviations from the steady-state level, and $\epsilon_{t}^{\nu}$ represents discretionary unanticipated deviations from the rule. While other families of rules can be considered, the advantage of this simple rule is that it is directly comparable with the evolution suggested by the automatic Basel-III method in equation (1). ${ }^{17}$

Considering the dual objectives of the $\mathrm{CCyB}$ and the inherent limits of state-of-the-art models, the calibration of the $\mathrm{CCyB}$ should be based on multiple analyses. Since the conclusions drawn from each of them depend on different assumptions, the purpose of these analyses is to provide rich information to decisionmakers, who ultimately will have to attach a discretionary weight to the different prescriptions. This paper proposes two approaches to guide the calibration of the SRB and the CCyB. For ease of exposition, we first present the structural, DSGE-based, approach to calibration (for both the SRB and the $\mathrm{CCyB}$ ). We then illustrate the hybrid approach and its use to calibrate a countercyclical capital requirement. We conclude by discussing advantages and drawbacks of the two approaches.

\subsection{SRB - A structural calibration strategy}

As discussed in section 2, the SRB aims at addressing long-run vulnerabilities of the banking system. The structural calibration of the SRB relies on a general equilibrium macroeconomic model (the 3D model by

\footnotetext{
${ }^{17}$ The time-invariance of the SRB component should not of course be taken at face value - it can include a low-frequency component reflecting permanent changes in the economy, for example as more information becomes available to the econometrician concerning the underlying model parameters that determine the optimal coefficients of rule (4).
} 
Clerc et al. [2015]; see Annex 1) that accounts for the possibility of equilibrium defaults in the banking sector and the resulting negative spillovers onto real activity. This DSGE model is thus able to explain permanent vulnerabilities in the banking sector and potential benefits to a change in the steady-state level of regulatory capital requirements (see figure 2).

In the model, bank defaults imply costly liquidations and cause welfare losses that agents fail to internalize because of the existence of safety net guarantees and of depositors' inability to command bankspecific risk premia. Higher capital requirements reduce deadweight losses of defaults, which occur in equilibrium, but at the same time increase reliance on expensive, scarce equity. Therefore, higher capital requirements reduce loan supply and tighten lending standards but can increase economic activity and social welfare, as they reduce the implicit subsidy to banks and depositors provided by government as a consequence of limited liability and deposit insurance.

In this context, the optimal steady-state level of bank capital trades off (i) the cost related to the rise in borrowing costs that reduces the welfare of indebted households and (ii) the benefit of the reduction in the frequency of bank defaults and the associated resources lost in bankruptcy. The ability of permanently higher capital requirements to increase the welfare of both savers and borrowers is however limited, as after a threshold level the benefits from a lower incidence of bank defaults are outweighed by the costs imposed on borrowing households of a higher cost of credit [Mendicino, Nikolov, Suarez, and Supera, 2016].

To guide the calibration of the capital buffer, we compute in the 3D model the level of the solvency ratio of banks that produces Pareto improvements in welfare for both savers and borrowers in the long run; in particular, we find a target solvency ratio that maximize welfare of borrowing households, as they are the ones that can be worse off from high capitalization levels, while the welfare of saving households is increasing in the steady-state capitalization level of banks [OMRTF, 2017]. Accordingly, if current noncyclical requirements -from a micro and from a macro perspective- are below this threshold level then we can make unambiguously the case for higher non-cyclical requirements, while we would not be able to do so for non-cyclical capital requirements beyond the threshold level.

Summing up, the structural approach based on the model by Clerc et al. [2015] estimated on French data (see Annex 1) focuses on the net benefits of a change in the steady-state level of regulatory capital requirements. Since this approach identifies non-cyclical reasons for macroprudential interventions, it can mainly be used for the calibration of non-cyclical macroprudential buffers such as the SRB. 


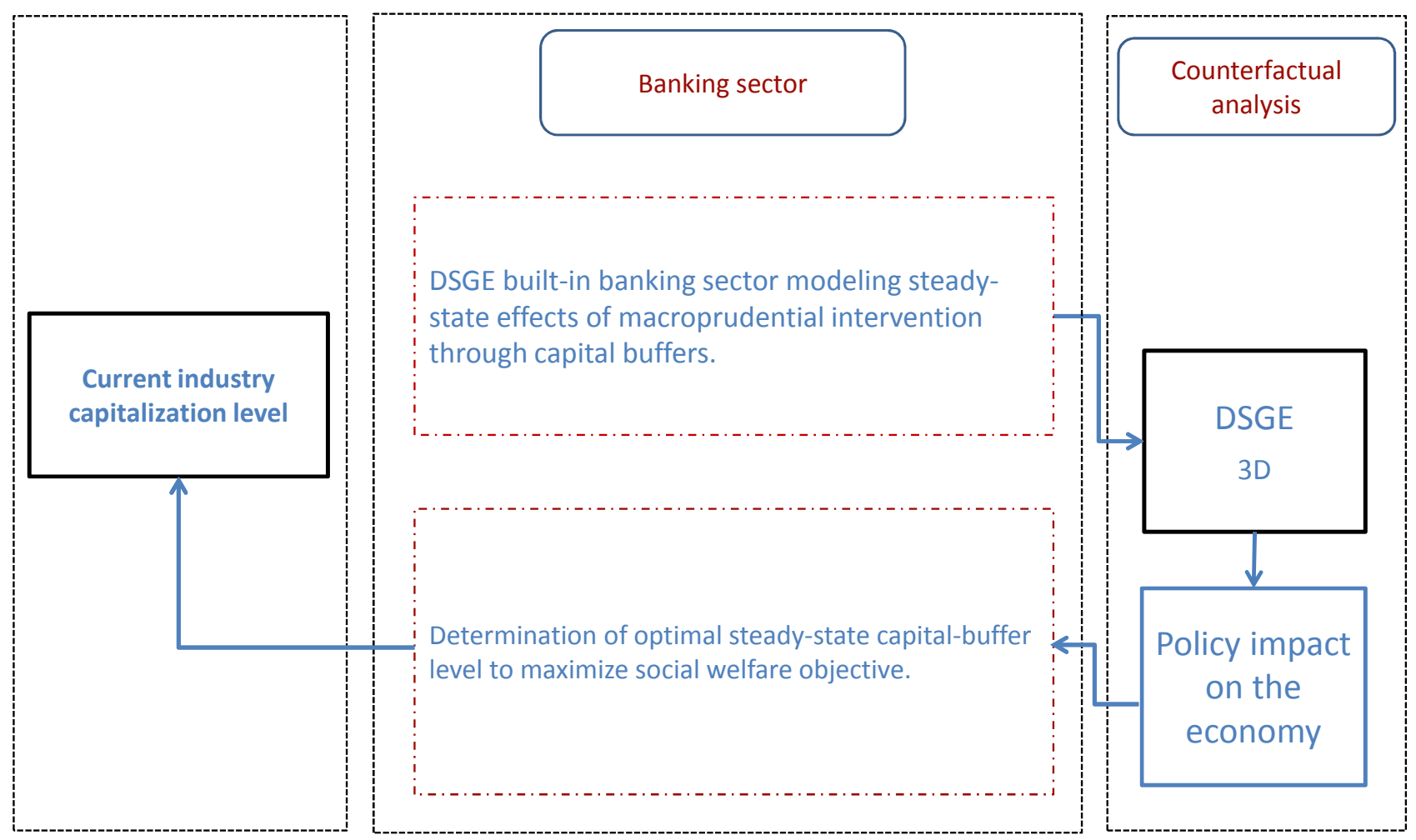

Figure 2: Schematic representation of the long-run structural approach for the calibration of the SRB.

\subsection{CCyB - A structural calibration strategy}

The structural calibration of the $\mathrm{CCyB}$ aims at calibrating the cyclical component of the rule depicted in equation (4) by relying on dynamic general equilibrium models of the French economy that capture several features of key French macrofinancial variables. We deploy two alternative DSGE models that emphasize different linkages between the macroeconomy and the banking sector (see Annex 3). Both models make explicit the link between saving and borrowing households, entrepreneurs and banks, as well as the transmission channels onto the French economy of a systematic CCyB Basel-III-type rule of form (4) targeting the volatility of the credit cycle by affecting agents' expectations.

A first DSGE model at our disposal is the 3D model described in the previous section (see Clerc et al., 2015). Our version is developed and summarized in Annex 1.

A second DSGE model builds on Gerali, Neri, Sessa, and Signoretti [2010]; the central friction to bank intermediation is that banks pay a cost each time their leverage deviates from the regulatory target and can adjust their equity level only sluggishly by retaining earnings. Our version is developed and summarized 
in Annex 2. While this model has no default in the banking sector in equilibrium, it offers a rich structure with nominal and real rigidities, thanks to which it is able to replicate a number of dynamic properties observed in the data. Cyclical adjustments in the regulatory target can help dampen the credit cycle, as they can reduce the required capital level in states of the economy in which it is particularly costly to impose higher lending margins on borrowers by forcing banks to retain more capital. ${ }^{18}$

Independently of the model used, the structural approach chooses a capital buffer rule to maximize an objective function by choosing the reaction parameter $\phi_{\nu}$ in the Basel-III-type rule (4). The objective function is either model-implied social welfare maximization (which implies attributing priorities to the welfare of the various agents in the economy - e.g., saving and borrowing households), or an ad-hoc criterion in line with the declared, intermediate objectives of the CCyB.

For example, in line with the social welfare function specified for the steady-state structural approach of subsection 4.1 we may maximize the welfare of borrowing households; behind this approach is implicit that the capitalization level chosen by the banking sector subject to market forces is suboptimal, thereby justifying macroprudential interventions implemented via additional capital buffers. These sources of market failure are modeled as explicit externalities in the 3D model.

As another example, we can formalize the structural approach for the CCyB according to the declared intermediate objectives (to eliminate 'abnormal' credit expansions and to prevent credit restrictions in recessions) by considering the problem for the macroprudential authority of finding the slope of the CCyB rule that minimizes the ad hoc loss function [see also Angelini, Neri, and Panetta, 2014]:

$$
\phi_{\nu}=\arg \min \left\{\sigma_{\text {credit growth }}^{2}+\lambda_{y} \sigma_{\mathrm{GDP} \text { growth }}^{2}+\lambda_{\nu} \sigma_{\nu}^{2}\right\}
$$

where $\sigma_{x}^{2}$ denotes the unconditional variance of variable $x$ and the parameters $\lambda_{y}$ and $\lambda_{\nu}$ reflect the policymaker's priorities when trading off a reduction in credit and GDP volatility and a variation in the instrument of an acceptable magnitude (for example, BCBS, 2010b envisages a CCyB that moves within the interval $[0,2.5 \%])$. In fact, the macroprudential authority is also concerned with keeping changes and the size of the $\mathrm{CCyB}$ moderate (see section 2), so the objective of the CCyB rule associates with a maximal volatility of the instrument viewed as acceptable, and represents effectively a trade-off with respect to the main objective. ${ }^{19}$

\footnotetext{
${ }^{18}$ This model is however unable to explain long-run benefits to capital requirements, so we do not rely on it for the calibration of the SRB.

${ }^{19}$ Heuristically, the reduction in volatility is viewed as a proxy for reducing the welfare cost of fluctuations. We use the shortcut objective (5) because targeting an explicit welfare-theoretic objective may lead to fragile results-mainly in the GNSSFr model, which lacks a statement of the explicit externalities justifying an intervention, to the different weights attached to welfare of the three types of households.
} 


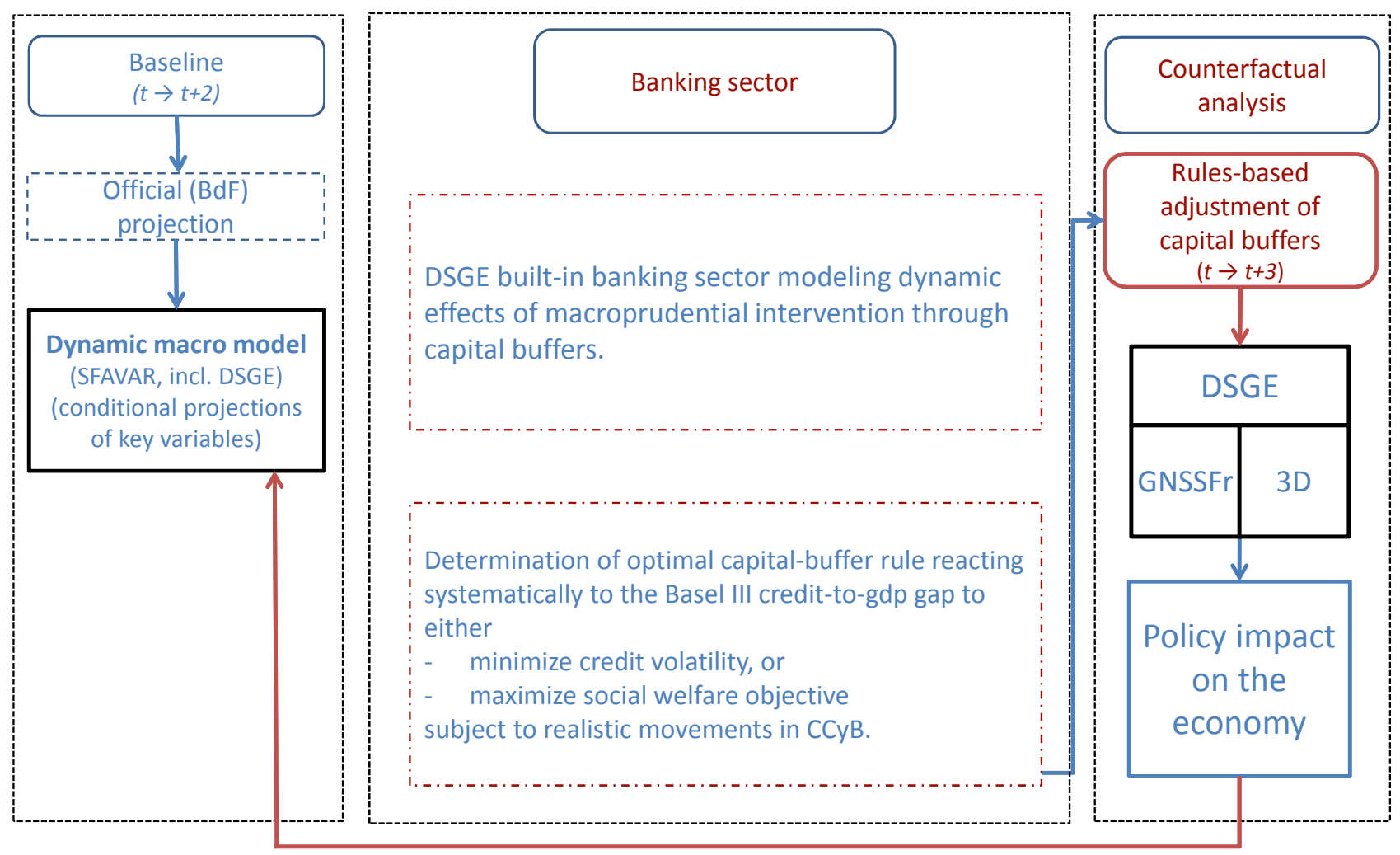

Figure 3: Schematic representation of the structural approach for the calibration of the CCyB.

CCyB calibration can therefore be derived by determining the current and prospective juncture of the business and credit cycles and the associated cyclical trajectory according to the CCyB rule in (4) that optimizes the objective function. The implementation of the structural approach for the CCyB consists in simulating the GNSSFr model over the scenario horizon under the assumption that the macroprudential authority follows such an optimal CCyB rule.

This process is done in two steps. First, we use the estimated version of the GNSSFr or 3D model to recover the structural shocks that best replicate the period covering historical data and the scenario; this 'inversion' of the model is done using a Kalman smoother. These shocks are interpreted as the deep causes of the business cycles independently of an optimized cyclical macroprudential policy. These shocks are subsequently fed into a version of the structural model that includes a CCyB rule to simulate the optimized response of the capital buffer and the associated counterfactual responses of the main endogenous variables.

The use of a structural model is critical for this exercise because the rule can be explicitly embedded in the model along with behavioral and equilibrium equations. In particular, structural DSGE models 
account for how agents form expectations and the role of expectations in current agents' decisions. In this simulation, expectations determine to a large extent the endogenous reactions of agents to changes in the $\mathrm{CCyB}$. Specifically, agents internalize the policy rule as well as the rest of the economic environment but they do not anticipate the exogenous shocks that hit the economy in the future. In particular, if the scenario features a persistently high credit-to-GDP gap explained by the occurrence of repeated shocks pushing credit upwards, then agents anticipate a quicker return of credit to its long term level accompanied by an activation and then release of the $\mathrm{CCyB}$. This reaction by agents mitigates the response of the economy to the CCyB as compared to what happens when the buffer is activated in an unexpected, discretionary fashion and for an uncertain period of time. ${ }^{20}$

Summing up, the output of the structural approach for the calibration of the CCyB is (i) a proposed trajectory for the $\mathrm{CCyB}$, and (ii) a simulation of the associated effects on the real economy. In practice the trajectory obtained for the $\mathrm{CCyB}$ needs to be translated into a feasible one-shot activation of the CCyB; the macroprudential authority may not want to change the buffer in each quarter or by unconstrained amounts. Rather, the profile of the obtained $\mathrm{CCyB}$ response provides an indication about the magnitude of the rise in the buffer that is consistent with the policymakers' objectives expressed in terms of credit volatility. Realistic prescriptions that may be drawn from this analysis require inevitably the use of expert judgment.

\subsection{CCyB - A hybrid strategy}

Besides the structural approach to calibration, we also rely on a hybrid approach to identify a systemic undercapitalization due to cyclical reasons. Our hybrid approach combines a top-down stress-testing tool, to quantify individual and sectoral vulnerabilities to the adverse event constructed in Section 3, with a DSGE model for counterfactual analysis if a macroprudential capital buffer were activated at the current date. ${ }^{21}$ This approach has the advantage of exploiting the rich cross-sectional information of macro stress testing tools popular among financial stability practitioners, yet it can easily give rise to contradictions if misused, as it combines a partial-equilibrium model (the macro stress testing tool) with general-equilibrium models (the dynamic model underlying the construction of the scenario and the DSGE model for counterfactual analysis). We discuss these difficulties in subsection 4.4.

The rationale for $\mathrm{CCyB}$ activation in this exercise is the resilience of the banking sector to systemic events - the increase in the buffer should prevent a substantial number of banks to fall below a threshold

\footnotetext{
${ }^{20}$ This alternative case corresponds to the policies considered in the hybrid approach (section 4.3).

${ }^{21}$ See also Henry and Kok [Eds.] for a seminal contribution on the idea of hybridizing stress testing tools and general equilibrium models.
} 


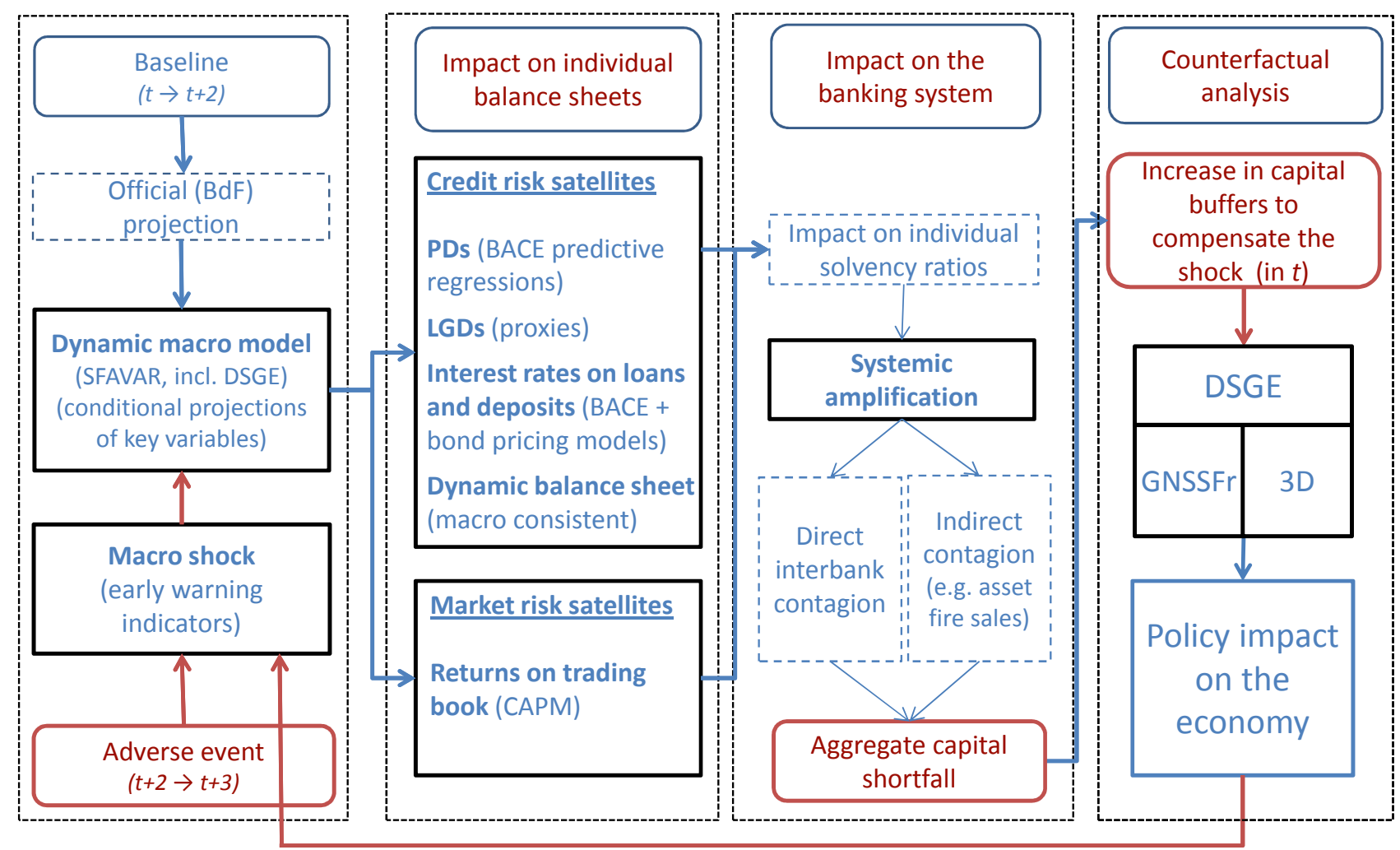

Figure 4: Schematic representation of the hybrid approach for the calibration of the CCyB.

solvency ratio during the adverse event. In this context, the macro stress testing tool allows for observing the impact of the scenario on each individual bank and may point out the macro-prudential tool that is most suitable to respond to the modeled risk. ${ }^{22}$

Starting from the scenario - whose design should build on indicators of risks in line with the goal of the $\mathrm{CCyB}$ - the hybrid approach relies on the following building blocks (see figure 4):

- Impact of the scenario on individual banks' balance sheets: satellite models are used to project the macro trajectories under the baseline scenario and the adverse event into credit and market risk indicators, which are in turn mapped into banks' capital ratios; the impact is measured in terms of equity losses as well as new risk weights and capital levels (see Annex 4);

\footnotetext{
${ }^{22}$ The tool may also reveal whether a microprudential reply may be more appropriate to address the risk. For example, since the $\mathrm{CCyB}$ applies to all banks, mobilizing the stress testing framework may reveal that the banking system shortfall (given the CCyB risk scenario) is mainly due to a specific bank. In this context, one may prefer to interpret the adverse event not as a systemic event that could motivate the introduction of a CCyB but rather as an issue more of a microprudential nature.
} 
Table 3: Basel III phase-in arrangements. Source: BCBS.

\begin{tabular}{lrrr}
\hline & 2017 & 2018 & 2019 \\
\hline Minimum common equity capital ratio & $4.5 \%$ & $4.5 \%$ & $4.5 \%$ \\
Capital conservation buffer (CCoB) & $1.25 \%$ & $1.875 \%$ & $2.5 \%$ \\
Minimum common equity plus CCoB & $5.75 \%$ & $6.375 \%$ & $7.0 \%$ \\
Minimum tier 1 capital & $6.0 \%$ & $6.0 \%$ & $6.0 \%$ \\
Minimum total capital & $8.0 \%$ & $8.0 \%$ & $8.0 \%$ \\
Minimum total capital plus CCoB & $9.25 \%$ & $9.875 \%$ & $10.5 \%$ \\
\hline
\end{tabular}

- Impact on the banking system: contagion models are used to amplify the losses of individual banks due to a combination of interbank contagion effects and fire sales of assets (i.e. accounting for both direct and indirect contagion mechanisms, see Annex 5); at this stage individual capital shortfalls relative to some threshold level (e.g., existing hard non-cyclical requirements; see table 1) are aggregated at the banking system level;

- Counterfactual analysis: after aggregation of the prospective capital shortfalls to quantify the common, additional capital buffer that would be required to protect the banking system against the scenario, the prescribed calibration is fed into a DSGE model to evaluate the consequences on the real economy of the preemptive introduction of the capital buffer.

The hybrid approach specifies as the objective function of the macroprudential authority that aggregate banks' capital to risk-weighted assets ratios at the end of the stress test horizon do not fall below a prespecified distress threshold that is viewed as likely to influence credit supply adversely based on expert judgment. As for the scenario, the choice of a threshold is critical to the results; it should be consistent with policymakers' objectives. In application (section 5), we will take a legal criterion and set the capitalization threshold to $7.95 \%$ of risk weighted assets that corresponds to the minimum CET1 requirement plus capital conservation buffer plus average SII buffers that banks will be required to retain by regulation at the end of 2019, as shown in figure 1 and table $3 .^{23}$

These calculations suggest an activation of the $\mathrm{CCyB}$ equal to the difference between the chosen threshold and forecast capital to risk-weighted assets ratios at the end of the stress-testing horizon. The buffer would be kept constant until the occurrence of the adverse event and then released back to zero. The immediate activation of the $\mathrm{CCyB}$ leads banks to start adjusting their capital to risk-weighted assets

\footnotetext{
${ }^{23}$ We do not use a threshold as low as in usual stress testing exercises for individual banks (for example, up until 2014 the European Banking Authority commonly referred to a 5.5\% hurdle rate for CET1 ratios in its EU-wide stress testing exercises), as the risk of individual bank default is the purpose of other prudential requirements.
} 
ratio through increases in credit spreads. When the negative shocks hit the economy, banks' capital to risk-weighted assets ratios are in line with the requirements even accounting for the observed sluggishness of bank equity capital; the existence of such transmission lags motivates our choice of having the adverse event hit only at date $t+2$ years. Then, as the adverse event materializes, the macroprudential authority immediately releases the $\mathrm{CCyB}$ to reduce the banks' recapitalization efforts needed to comply with prudential requirements.

While the banking industry now weathers through the downturn without falling below the critical capitalization threshold, the activation of the $\mathrm{CCyB}$ prescribed by the macro stress testing tool has an additional impact on banks in that it has a contractionary effect on economic activity during the whole scenario that precedes the adverse event. Any of the DSGE models available in our toolkit (GNSSFr or 3D) can be used to simulate the macroeconomic effects of this policy. Since the activation of the CCyB alters the initial scenario, the calibration is refined by an iteration between the DSGE model and the stress testing module. In practice, this iteration process converges very quickly.

Assumptions regarding expectations are needed for this simulation: in the model, the view of economic agents about the level of the $\mathrm{CCyB}$ in future periods matters for their current decisions. We assume that agents consider that the activation is permanent; although they know that the CCyB is a cyclical instrument and that it will be released in difficult times, they do not anticipate the negative shocks leading to the economic downturn. Therefore, they behave as if the CCyB were to be maintained over a long period of time in the future. When the negative shock occurs and is observed by all economic agents, the buffer is released by the macroprudential authority, and economic agents immediately revise their projections as the release of the $\mathrm{CCyB}$ is now believed to last for the foreseeable future. Accordingly, the effects of the full path of the instrument over the scenario horizon are given by the reaction of the model to an unexpected positive $\mathrm{CCyB}$ shock during the baseline period followed by a negative shock of the same magnitude at the date of the adverse event. While the former shock reduces growth in the first sub-period of the scenario, the latter shock dampens the drop in credit and output in the second sub-period. ${ }^{24}$

Finally, one has to address the potential contradictions that may arise when hybridizing a partialequilibrium model (the macro stress testing tool) and general-equilibrium models. In fact, one cannot simply stitch together these different models. The next subsection discusses these issues.

\footnotetext{
${ }^{24}$ One would ultimately not want to consider movements in the CCyB as a sequence of unexpected shocks but rather as a systematic rule, more in line with the treatment of the $\mathrm{CCyB}$ in the structural approach. However, as long as the construction of the stress scenario, its link to macroeconomic risk factors and to banks' capital ratios remains non-systematic, it seems hard to make the case for considering a $\mathrm{CCyB}$ calibration based on macro stress testing tools as a rules-based framework.
} 
Table 4: Comparative table of the three strategies

\begin{tabular}{|c|c|c|c|}
\hline & $\begin{array}{l}\text { Structural } \\
\text { (long-run) }\end{array}$ & $\begin{array}{l}\text { Structural } \\
\text { (cyclical) }\end{array}$ & $\begin{array}{l}\text { Hybrid } \\
\text { (cyclical) }\end{array}$ \\
\hline Models & DSGE & DSGE & $\begin{array}{l}\text { Top-down stress testing tool } \\
+ \text { network }+ \text { DSGE }\end{array}$ \\
\hline Objective & Welfare & Welfare / Volatility objective & Solvency ratio threshold \\
\hline Target buffer & SRB & $\mathrm{CCyB}$ & $\mathrm{CCyB}$ \\
\hline
\end{tabular}

\subsection{Comparison and complementarity of the different approaches}

Relative to an as yet unreachable general equilibrium model with heterogeneous banks with granular balance sheets, the structural calibration strategy looks like a stylized macro stress testing tool that delivers predictions only about aggregate capital ratios, while our hybrid strategy looks like a complex partial equilibrium model complemented by structural macroeconomic features. Thus, the two approaches (hybrid and structural) complement each other. Table 4 sketches a comparison of the structural versus hybrid strategy for the calibration of the SRB and the CCyB.

\subsubsection{Pros and cons of the structural approach for the calibration of the CCyB}

Contrary to the hybrid approach, the structural approach seeks to evaluate a rule for the $\mathrm{CCyB}$ that describes the behavior of the macroprudential authority as a systematic response to the credit-to-GDP gap - as envisaged by the Basel Committee [BCBS, 2010b], and paralleling the usage of Taylor-type rules by the monetary authority. Recommendations resulting from this approach are optimal from a welfaretheoretic viewpoint, or otherwise beneficial provided the exogenous objective that they reduce the magnitude of fluctuations in some predefined variable such as credit growth. The main transmission mechanism of macroprudential policies of this form acts by managing agents' expectations.

The rich economic structure that characterizes the structural approach allows for an optimal calibration of the $\mathrm{CCyB}$ while explicitly considering its effect on agents' expectations, thereby addressing Lucas [1976] critique, as well as optimizing behavior by households, firms and banks. However, the link from macroeconomic developments to banks' balance sheets is highly stylized, as balance sheets display liabilities that include only undifferentiated deposits and one type of equity capital, and assets are limited to a few loan categories. These considerations call for complementary prescriptions for the CCyB. 


\subsubsection{Pros and cons of the hybrid approach}

A macro stress testing module, which models in partial equilibrium the impact of macroeconomic shocks on richer bank balance sheets, allows for more heterogeneity and granular information and can be a useful complement to the structural analysis. In particular, the model allows to analyze what is happening to individual banks and can thus be tailored to each bank's business model and vulnerability to specific shocks. However, the greater ability to characterize individual balance sheets in the hybrid approach comes at the cost of a less rigorous treatment of the interaction between the banking sector and the real economy. In particular, relative to a general equilibrium approach, our macro stress testing tool misses the dynamic behavior of banks and macroeconomic feedback loops.

The partial-equilibrium nature of macro stress testing tools complicates their use to produce meaningful macroeconomic feedback loops as well as normative prescriptions. On the one hand, macro stress testing tools start from a time-series model (including VAR and DSGEs discussed in section 3) of the joint distribution of key macroeconomic variables to construct a macroeconomic scenario. Since the macroprudential literature starts from the premise that the observed movement of variables is in part explained by the presence of a banking system (for example, financial intermediation plays a role in amplifying the shocks that hit the economy), it follows that some feedback from the movement of banking sector variables onto macroeconomic variables is already included in the scenario that is fed into the stress testing tool. ${ }^{25}$ This is explicit if the scenario of section 3 is constructed via DSGE models, and it is implicit in a VAR-type model as we interpret it as the reduced-form representation of a structural model in which banks play a nontrivial role. In this sense, nothing guarantees that the behavior of the banking system implicit in the projected macroeconomic variables can be reconciled with the behavior of banks' modeled by the stress testing tool. ${ }^{26}$

On the other hand, state-of-the-art stress testing tools are silent on the structural relation between regulatory capital requirements and the macroeconomy, i.e., they are unable to tell us how people's, firms' and banks' behavior would change after a macroprudential policy intervention. We partially bypass this issue by using stress testing tools as an indication of capital needs (i.e., as an alternative ad-hoc objective function to the ones we met under the structural approach), to then resort to a dynamic general equilibrium model based on optimizing behavior to study the impact of policy intervention on the scenario and update

\footnotetext{
${ }^{25}$ For this reason we refrain from trying to incorporate into this approach a study of the effects of banks' losses on the macroeconomy, as suggested for example by Henry and Kok [Eds.] and Dees et al. [2017]; the scenario must already accounts to some extent for such a feedback loop.

${ }^{26} \mathrm{~A}$ dynamic balance sheet strategy could reconcile individual banks' decisions as modeled by the macro stress testing tool with the aggregate decisions implied by the scenarios. More deeply, aggregate scenarios have implications for aggregate capital ratios - implications that can be made explicit if the scenarios are constructed by a DSGE.
} 
the capital needs identified by the stress testing tool. This idea lies at the heart of our hybrid methodology.

\subsubsection{Transmission mechanisms and rules vs. discretion}

A first effect of changes in banks' required capitalization levels, as captured by the majority of DSGE models that include a banking sector (including the two DSGE used in this paper), is that an increase in capital buffers induces a contraction of credit supply with negative effects on final demand, at least in the short run. Banks adapt to higher capital-to-assets ratio requirements by a mix of retaining earnings and shedding assets, thereby increasing lending spreads and/or reducing credit in the transition phase. As a result, credit and economic activity contract. Symmetrically, the release of the buffer in bad times can have a positive effect on credit, and hence on GDP growth.

A second effect of higher capital requirements is captured by models exemplified by the 3D model, in which some banks choose to default in equilibrium. Since higher levels of capitalization reduce the default frequency and a positive default probability increases banks' funding costs as well as they consume resources, permanently higher requirements can have a positive effect not only on welfare but also on economic activity. In this model, the contractionary effect of higher requirements typically dominates in the short run, while the long-run expansionary effect prevails in the long run.

Another key aspect in the modeling of the transmission mechanism of time-varying capital requirements relates to whether such time-variation follows a systematic rule or acts as a policy surprise - an unpredictable kind of discretionary policy behavior. For example, our hybrid methodology implements the discretionary approach as a fully unpredictable decision to activate or release a regulatory capital buffer, and hence would generically be ruled out as an optimal policy stance by a fully structural, welfare-theoretic perspective. However, as stressed in the previous subsection, the hybrid approach conveys information from stress testing tools to complement a structural analysis with richer cross-sectional details. Only an ideal (but so far unattainable) general equilibrium model with heterogeneous banks with granular balance sheets would allow for a welfare-theoretic analysis with the same rich representation of banks' balance sheets as stress testing models.

While long transmission lags, demanding data requirements, and model uncertainty are reasons to sympathize with a discretionary approach, a rules-based approach is most likely the ideal form of an optimal cyclical macroprudential policy. A rules-based approach will reduce uncertainty as to when the macroprudential authority will act and by how much. The structural approach goes in this direction, while the hybrid approach remains a discretionary approach. In this context, it is tempting to view top-down stress tests as a tool to cross-check the appropriateness of required capital levels determined within a 
rules-based framework, and based on a different objective function.

\subsection{Contagion mechanisms to complement first round losses}

Network models can be used within the hybrid approach to amplify the initial shock to the banking system due to one or more contagion mechanisms. Contagion occurs due to financial interconnections: while these allow for a better diversification of financial institutions, thus contributing to well-functioning financial markets in calm times, they can also be channels that propagate tail risks when these materialize, spreading financial vulnerabilities across institutions and across countries. Interconnections may thus amplify a given cyclical shock and weaken the financial system as a whole, pushing the aggregate capital shortfall to a higher level than it would have otherwise been the case.

Network models take into account both direct and indirect channels of shock propagation. Direct contagion arises if a bank defaults on its contractual obligations, thus triggering distress (insolvency and/or illiquidity) at its counterparties and potentially leading to a default cascade. On the other hand, indirect contagion goes on even in the absence of direct contractual linkages between banks: in this case, distress is not necessarily triggered by a bank's default, but may spread e.g. because of overlapping portfolios of securities holdings, margin calls and asset fire sales, information spillovers. ${ }^{27}$ Indeed, the 2007 financial crisis was characterized mainly by (various forms of) indirect contagion, which occurs when banks' actions generate externalities that affect other firms through non-contractual channels.

In the hybrid approach for the calibration of the $\mathrm{CCyB}$, the policymaker can be interested in assessing the systemic amplification that follows the impact on individual balance sheets by considering both direct and indirect contagion effects. Direct effects can be quantified relying on the network model of interbank contagion by Gabrieli, Salakhova, and Vuillemey [2015], where the impact on individual solvency ratios is magnified because of banks' bilateral credit obligations in the network (bank solvency contagion) coupled with banks' liquidity hoarding behavior in the short-term money market (bank liquidity contagion). However, focusing only on capital losses due to direct contagion can underestimate the aggregate capital shortfall at the banking system level. This is why we also have in our toolbox a more comprehensive numerical simulation framework, developed by Idier and Piquard [2017], allowing to quantify the losses that would stem from interbank contagion combined with asset fire sales, margin calls and collateral depreciation. The two contagion set up are illustrated in more detail in Annex 5.

\footnotetext{
${ }^{27}$ Clerc et al. [2016] identify two fundamental channels of indirect contagion: the market price channel, in which scarce funding liquidity and low market liquidity reinforce each other, generating a vicious spiral; and information spillovers, in which bad news can adversely affect a broad range of financial firms and markets.
} 


\section{Illustrative quantitative exercise}

This section shows an application of the calibration strategies presented in Section 4. We construct a scenario over 2017-2019 by relying on the VAR model described in Section 3. We use the VAR to build forecasts for 10 macro-financial variables (see list in table 2), conditional on the available BMPE projections, and to simulate the response of the economy to negative shocks. The adverse event presented here is meant to be merely illustrative.

Preview of results In this illustrative example, the analysis would not make the case for a permanent increase in major French banks' capital buffers, but it would suggest a moderate increase in transitory capital buffers by around 0.2-0.4pp, in line with the prospective developments in credit indicators as well as with the automatic capital buffer guide (see Annex 6). Table 5 summarizes the results of the different analysis as well as the reasons for the main differences among them, which lie on the objective of each calibration strategy.

Table 5: Summary of results of the illustrative exercise

\begin{tabular}{lll}
\hline Instrument & CCyB & SRB \\
\hline Calibration strategy & Structural (3D model): $+.4 \mathrm{pp}$ & $+0 \mathrm{pp}$ \\
& Structural (GNSSFr model): $+.2 \mathrm{pp}$ & \\
& Hybrid (3D model for policy impact): $+.25 \mathrm{pp}$ & \\
& Hybrid (GNSSFr model for policy impact): $+.19 \mathrm{pp}$ & \\
& Automatic: $+.6 \mathrm{pp}$ & \\
Objective & Structural (3D): Borrowers' welfare & Borrowers' welfare \\
& Structural (GNSSFr): Credit volatility & \\
& Hybrid: Solvency ratio threshold & \\
\hline
\end{tabular}

\subsection{The scenario}

The baseline scenario matches the published Banque de France baseline projections of annual growth rates of GDP and inflation over 2017 and 2018. These projections, used as a basis for monetary policy decisions in the Euro area, reflect medium-run economic outcomes that are viewed as sufficiently credible and likely by the Eurosystem. Conditional on these projections, we simulate the variables included in the VAR over 2017 and 2018 using standard filtering techniques. The scenario is completed by constructing an economic downturn occuring in 2019Q1. As the CCyB calibration obtained with the hybrid approach is very sensitive 
to this downturn episode, it should be carefully designed to reflect risks identified in particular with early warning models. Above all, it should be discussed and validated by the decisionmaker.

The adverse event is assumed to originate from an abrupt broad-based hike in global risk premia due to a change in investor preferences. The initial shock would propagate to European stock market indexes, including an adverse effect on CAC40 valuations. In this environment of financial stress, future interest rates remain low, while the perspectives about economic activity weaken. In practice, this narrative is implemented as a negative shock to the CAC40 stock price index of magnitude $-40 \%$ which corresponds to a 3-standard deviation shock, occurring in 2019Q1. ${ }^{28}$ The probability associated with this event is less than $.5 \%$ at a yearly frequency using Gaussian disturbances.

The responses of the main macroeconomic aggregates are plotted in figure 5. Output declines sharply by $0.5 \%$ relative to the baseline after one quarter. A weaker response of credit results in a slightly increasing credit-to-GDP gap during the year. House prices and the level of interest rates are affected negatively while the model identifies a minor increase in inflation.
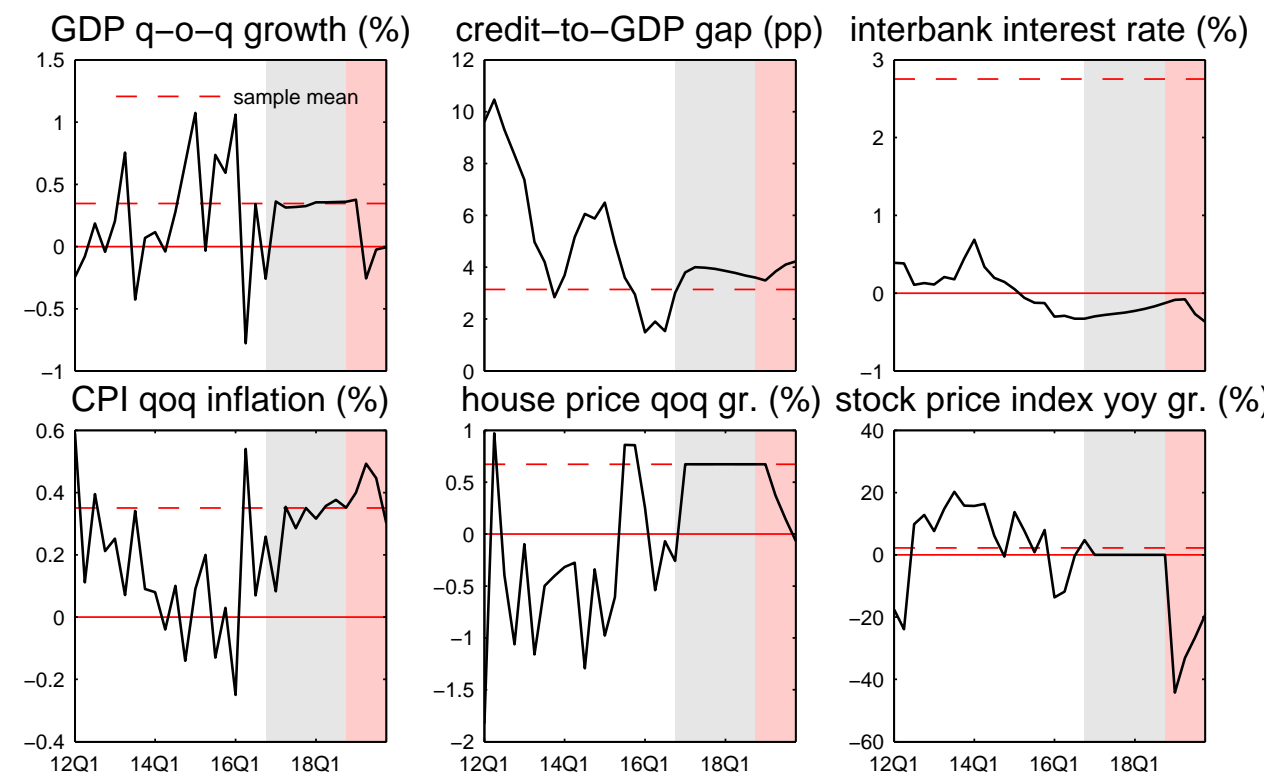

Figure 5: Illustrative scenario for key macro-financial variables. The scenario is consistent with the BMPE for 2017 and 2018 for French yoy inflation and GDP growth. In 2019 a 3-standard deviation shock to CAC40 valuations is assumed to occur. The adverse event relies on a SVAR.

\footnotetext{
${ }^{28}$ Note how the recent crisis is included in the historical data from which we infer the empirical distribution of macrofinancial variables.
} 


\subsection{Structural approach for the calibration of the $\mathrm{CCyB}$}

The structural approach for the $\mathrm{CCyB}$ can be formalized by considering the problem for the macroprudential authority of finding the slope of the $\mathrm{CCyB}$ rule either that maximizes borrowers' welfare (in which case we consider a second-order accurate solution of the model), or that minimizes the ad hoc loss function

$$
\phi_{\nu}=\arg \min \sigma_{\text {credit }}^{2}+\lambda \sigma_{\nu}^{2}
$$

where the parameter $\lambda$ reflects the policymaker's priorities coming from trading off a reduction in credit volatility and a variation in the instrument of an acceptable magnitude. For example, both the GNSSFr and 3D models predict an inverse relation between the reaction of the $\mathrm{CCyB}$ rule to developments in the credit-GDP gap and the volatility of credit, GDP and the credit-GDP gap, as well as a direct relation with unconditional borrowers' welfare. Intuitively, countercyclicality in capital requirements implies that more credit is available in bad states of nature, which provides borrowers with greater opportunities for intertemporal smoothing [see Mendicino et al., 2016, for more details]. ${ }^{29}$

Accordingly, we simulate a counterfactual scenario under the assumption that the $\mathrm{CCyB}$ follows a linear rule in the credit-to-gdp gap with respective slopes $\phi_{\nu}=0.28$ (GNSSFr model with rule (A.2.35) under the ad-hoc objective criterion) and $\phi_{\nu}=0.35$ (3D model with rule (A.1.6) and borrowers' welfare as the objective) that optimize the objective function while keeping a standard deviation of the $\mathrm{CCyB}$ under $1.25 \mathrm{pp}$. The response of the buffer and of the main variables are shown in figure 6 .

When the rule is active, the $\mathrm{CCyB}$ jumps up because the gap is above its historical mean in 2016Q4. The contraction of credit supply results in an unnoticeable drop in GDP while the credit-to-GDP gap is slightly reduced by end-2019. Credit growth is slightly dampened initially and but remains strong until the end of the horizon. Note that the CCyB is not released at the date of the adverse shock, because the credit-to-GDP gap remains positive. So the $\mathrm{CCyB}$ rule does not yield benefits in terms of mitigation of this particular economic contraction. As reflected by the optimized objective, the explicit benefit is to dampen the credit cycle. Moreover, the 3D model, with its explicit modeling of the probability of banking crises, shows the reduction in banks' default probabilities associated with the increase in required capital; the implied positive effects on the economy of the reduction in default probability (that reduces banks debt funding costs) may even outweigh the negative effects of an increase in buffers (that forces banks to move to a more costly source of funding) through an expectations channel; consequently, we see a tiny

\footnotetext{
${ }^{29}$ In both models, however, the found nonzero reaction is not Pareto optimal if we start from the optimized steady-state level of capital (a joint optimization could of course change the picture in terms of Pareto optimality); optimization of the welfare-theoretic criterion can be therefore sensitive, even qualitatively, to changes in Pareto weights.
} 
GNSSFr model - ad-hoc objective ( $\phi_{\nu}=.28$, credit volatility reduced by 11.7\%):
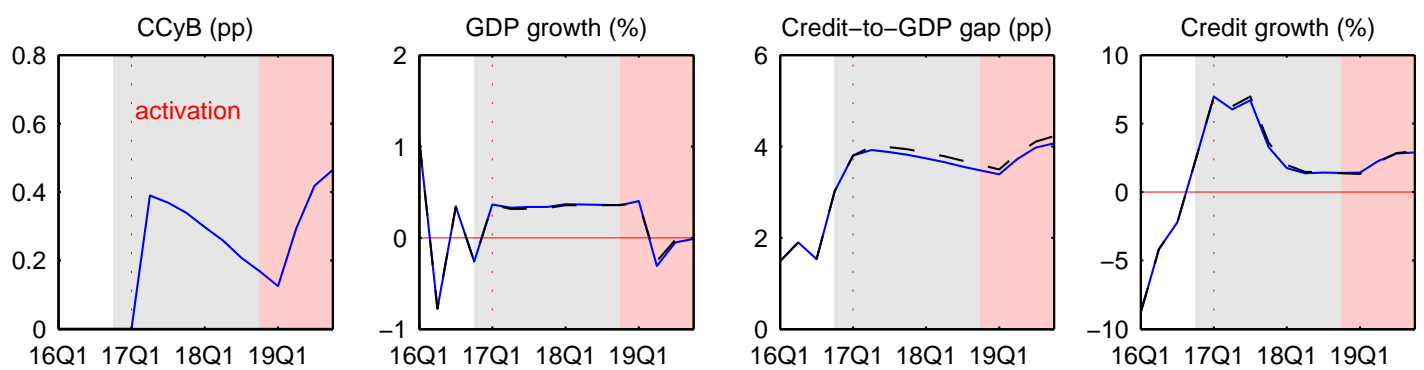

$3 D$ model - social welfare objective $\left(\phi_{\nu}=.354\right)$ :
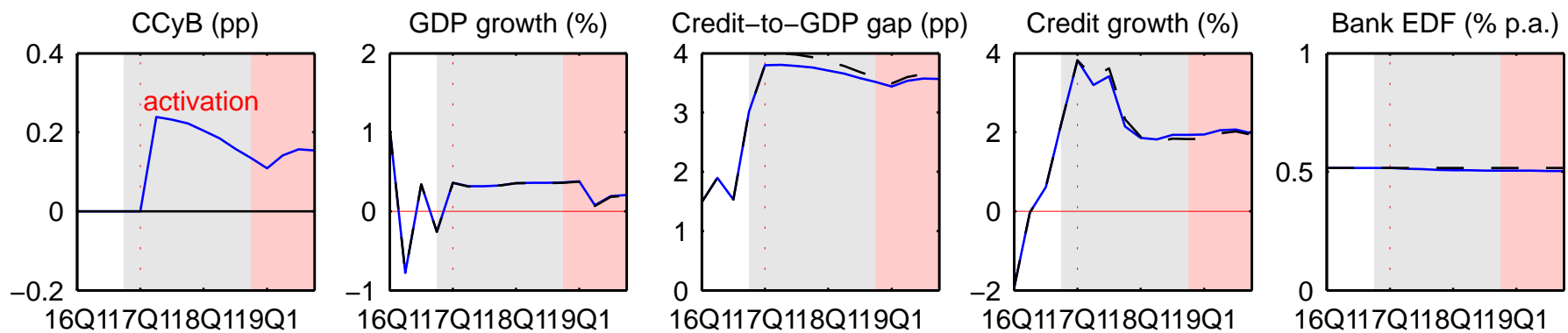

Figure 6: Counterfactual analysis under the structural approach for the calibration of the CCyB in the illustrative scenario. The ad-hoc objective minimizes credit fluctuations subject to a 2-s.d. range of the $\mathrm{CCyB}$ of less than $2.5 \%$. The welfare objective maximizes borrowers' unconditional welfare subject to a 2-s.d. range of the CCyB of less than $2.5 \%$. 
expansionary effect on credit in 2019.

The recommendation that results from this analysis is of an immediate activation of the CCyB by $0.2-$ .4pp. The DSGE model provides a quantitative link between unconditional objectives in terms of credit growth or welfare and the current magnitude of the rise in the CCyB.

\subsection{Hybrid approach}

Using the stress testing module described in Annex 4, we simulate the effect of the adverse macroeconomic episode assumed in 2019Q1 on the capital to risk-weighted assets ratio of six major French banks over the twelve-month period following the adverse event (Table 6). We rely on the top-down stress testing tool discussed in Annex 4. Banks' capital ratios remain relatively stable until end-2018 around their value recorded in 2016Q4 and they deteriorate during the economic downturn. In this exercise, banks are not allowed to adjust their balance sheets. This is another conservative behavioral assumption, as it prevents any protective behavior on the part of banks that would limit their losses during the stressful period.

\begin{tabular}{lrrrrrr}
\hline & bank 1 & bank 2 & bank 3 & bank 4 & bank 5 & bank 6 \\
\hline end-2017 & -0.0031 & 0.0110 & -0.0048 & -0.0032 & -0.0053 & -0.0044 \\
end-2018 & -0.0021 & 0.0118 & -0.0048 & -0.0020 & -0.0043 & -0.0035 \\
end-2019 & -0.0189 & -0.0134 & -0.0167 & -0.0198 & -0.0206 & -0.0175 \\
end-2019+contagion & -0.0921 & -0.0768 & -0.0599 & -0.0996 & -0.0800 & -0.0793 \\
\hline
\end{tabular}

Table 6: Average losses in capital-to-risk-weighted-assets ratios relative to the 2016Q4 level for the main 6 French banks under the illustrative scenario. The 6 banks have been made anonymous (we report losses rather than the level of capital ratios to avoid revealing the identity of each bank). Note: the losses in 2017 and 2018 are due to the activation of a CCyB by $.25 p p$ (column 1 of table 7 ), which has a negative effect on the economy. Contagion amplification at end-2019 is calculated using a calibrated version of Idier and Piquard [2017].

For illustrative purposes, we also report in Table 6 the losses due to systemic amplification at end2019. We use a calibrated version of Idier and Piquard [2017]. Contagion develops through the following channels: direct losses on interbank equity and debt, indirect losses due to fire sales (which may set off upon bank failures) and margin calls on collateralized interbank debt as soon as the market value of assets is depleted. ${ }^{30}$ This amplification scenario is designed to report extreme market stress and very conservative losses, as shown by the figures in table 6 .

It is important to note that modeled contagion losses do not just depend on the size of direct losses but also on the absolute value of the capital ratio at which banks find themselves in. This contagion module

\footnotetext{
${ }^{30}$ In Annex 5 we report the key parameters that play a role in this amplification phenomena, especially the way to approximate interbank exposure matrices using public data and Amihud [2002] statistics to gauge the market impact of asset liquidation.
} 
can therefore be used as a way to revise upwards the required capital buffer - a route we do not explore here - if the modeler attributes a nontrivial probability to the event that initial losses turn into a pandemic crisis because of systemic amplification.

As expected, banks capital to risk-weighted-assets ratios are negatively affected across all six banks. The adverse event appears of a systemic nature as quantified by the macro stress testing tool. Naturally, the activation of the $\mathrm{CCyB}$ should respond to the undercapitalization of the banking industry during an adverse episode such as the one considered here. There is a need to define a threshold under which banks are considered as undercapitalized. This level is defined based on expert judgment and should correspond to a situation in which the fear of possible solvency issues is likely to influence credit supply adversely.

In this example, we set the undercapitalization threshold to $7.95 \%$ of risk weighted assets + existing Pillar 2 requirements. This level corresponds to the minimum CET1 requirement (4.5\%), plus capital conservation buffer (phased in at $2.5 \%$ in 2019) that banks will be required to retain by regulation at the end of 2019, plus an average $0.95 \%$ extra SII requirement, and whose violation would trigger the mechanisms described in section 2. Of course, this calibration is illustrative and should be discussed carefully but has the advantage of being consistent with current regulation. To this threshold level we compare the projected CET1 ratios of the six banks at the end of 2019 and compute the associated maximum capital shortfall. Although the prescription is driven by the worst capitalized bank at the end of the stress horizon, table 6 quantifies the systemicity of the event by showing how the banking sector would be reacting to a systemic event, i.e., to a macroeconomic event that affects banks across the board.

\begin{tabular}{lcc}
\hline iteration & prescription (GNSSFr model) & prescription (3D model) \\
\hline 0 & .190 & .190 \\
1 & .212 & .191 \\
2 & .222 & .192 \\
3 & .223 & .192 \\
4 & .253 & .192 \\
$\vdots$ & $\vdots$ & $\vdots$ \\
$\infty$ & .253 & .192 \\
\hline
\end{tabular}

Table 7: Convergence of CCyB prescriptions in the hybrid approach.

The approach suggests a vulnerability with respect to the adverse event that justifies an activation of the $\mathrm{CCyB}$ of .25pp. The prescription for an increase in the CCyB suggested by the macro stress testing tool will in general have a mild contractionary effect on the macroeconomy over the eight quarters that precede the adverse event. Our iterative procedure for deriving the calibration with a CET1 ratio threshold of $7.95 \%$, converges rapidly, as depicted in table 7 . 
GNSSFr model:
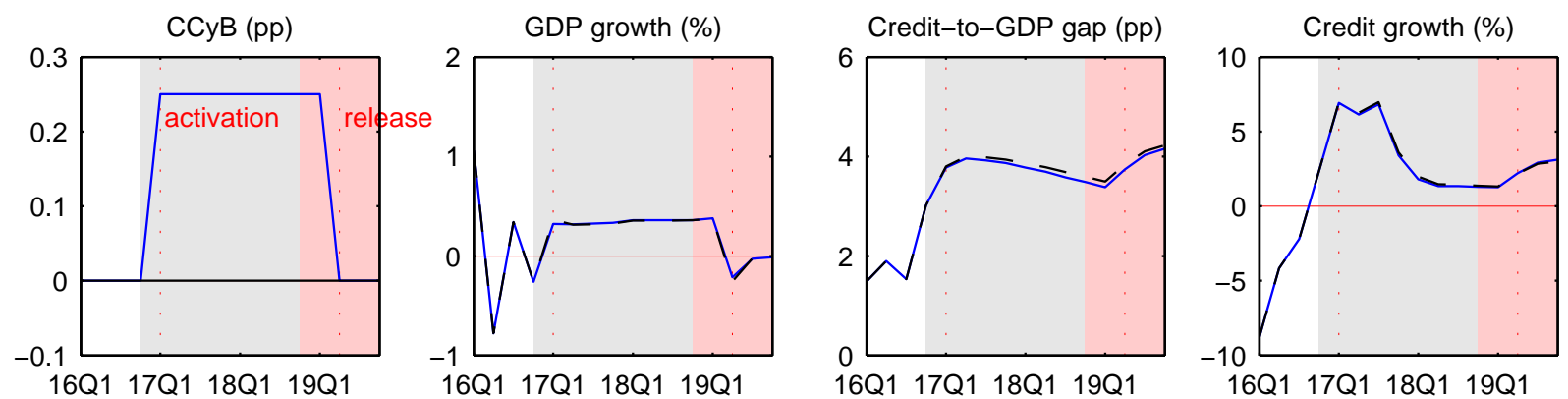

$3 D$ model:
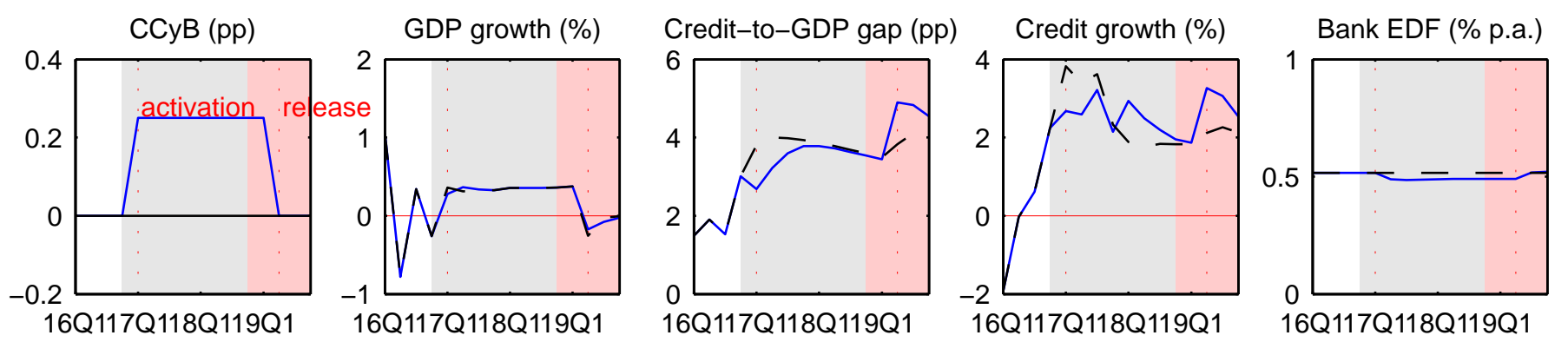

Figure 7: Counterfactual analysis under the hybrid approach in the illustrative scenario.

Implicitly, the immediate activation of the CCyB (in 2017) prompts banks to progressively adjust their ratio by a similar amount over 2017 and 2018. As a result, when the adverse shock occurs the average solvency ratio at the end of the stress test horizon (end-2019) would be limited to a minimum of $7 \%$ plus respective SII buffers and Pillar 2 requirements. Of course, at that date, the CCyB should be lifted to relax regulatory pressures on banks' capitalization that would otherwise restrain credit supply; accordingly, we see an expansionary effect on credit in the figure. The successive activation and release of the $\mathrm{CCyB}$ would have general equilibrium effects on the economy - first contracting credit supply and growth then dampening the economic downturn. Accordingly, the iteration between DSGE and the stress testing models help us refine the calibration of the CCyB.

The macroeconomic impact of the policy suggested by this approach is shown in figure 7 . The activation brings GDP growth down on activation (with a rebound in the following quarter). Credit slows down in annualized terms in 2017, and the credit-to-GDP gap is reduced in 2018. 

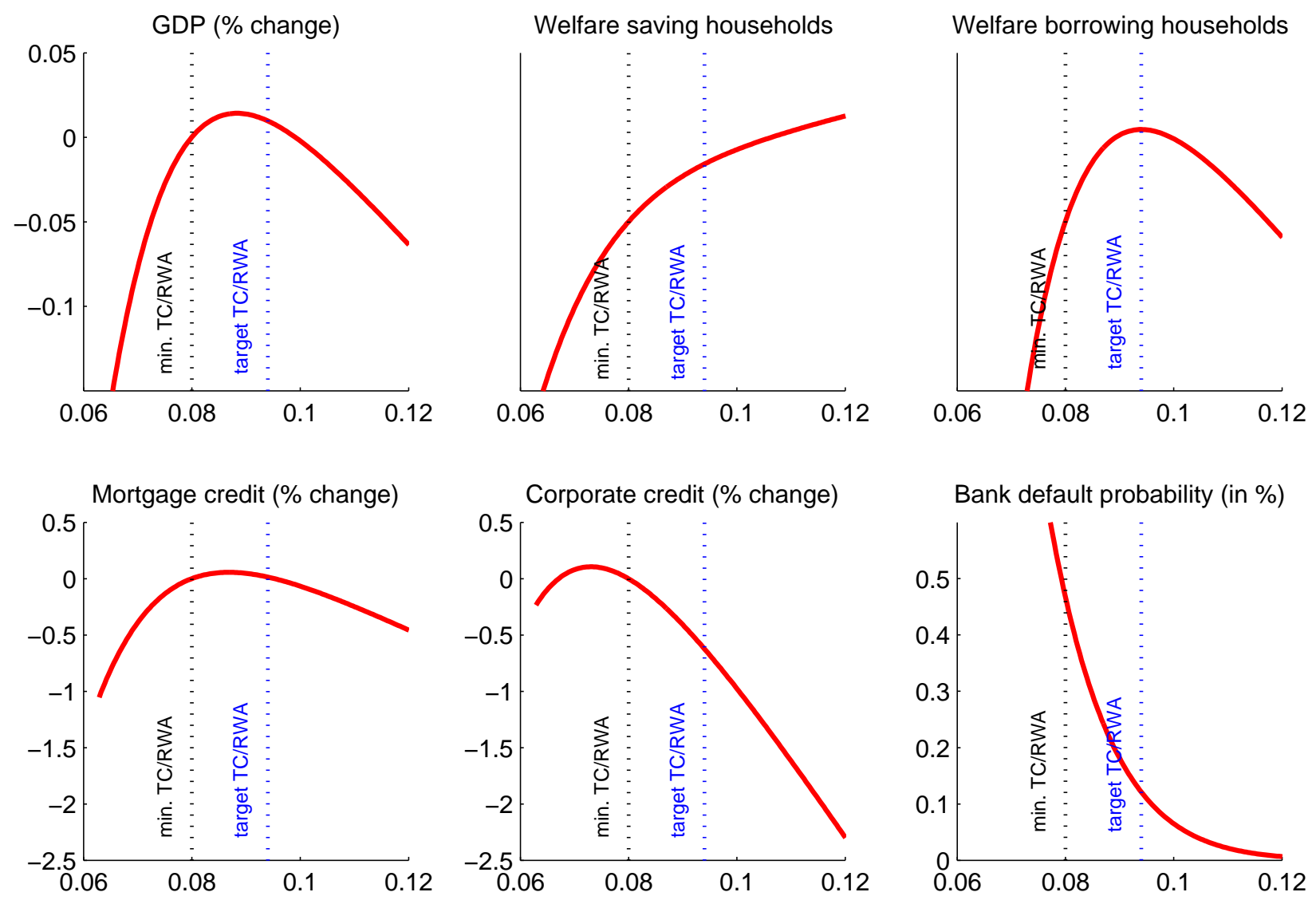

Figure 8: Steady-state effects of different levels of non-cyclical bank (total) capital requirements in the 3D model.

\subsection{Structural approach for the calibration of the SRB}

As explained in subsection 4.1, we focus for this analysis on the observed capital ratio, including both the minimum capital requirement and excess voluntary buffers in banks balance sheets. Building on the 3D model, figure 8 quantifies the cost-benefit trade-off of non-cyclical capital requirements by plotting the steady-state effect of different levels of non-cyclical bank capital requirements on key macro-financial variables and welfare measures, which aggregate the effect on variables that determine social welfare (durable and non-durable consumption and hours worked).

Notice in particular how there is a target capitalization level below which an increase in capital increases everybody's welfare but beyond which will produce welfare losses for borrowers. This thresholds is located at a total capital to risk-weighted assets ratio of around 9.5\%, which coincides with the level that 
maximizes the welfare of borrowing households. ${ }^{31}$ Thus, from a Paretian perspective, while we can make unambiguously the case for higher non-cyclical requirements if we find ourselves below the target level, we would not be able to do so beyond the target level of $9.5 \%$.

Since current non-cyclical requirements in terms of total capital are already larger than $9.5 \%$ for each of the major 6 French banks, the model does not suggest a long-run structural undercapitalization of the French banking system, and hence the need to activate a SRB.

\section{Challenges in the calibration of capital buffers}

\subsection{Distinguishing between prudential buffers}

We start by discussing the distinction between microprudential and macroprudential buffers in practice; we then turn to how to distinguish when a risk calls for activating the CCyB or the SRB. Broadly, microprudential buffers target an identified undercapitalization linked to the solvency of individual institutions, whereas macroprudential buffers target insufficient capitalization having the potential to impact the entire financial sector and the real economy. While, from a positive perspective, the impact on the real economy of an increase in buffers does not of course depend on whether the increase was micro or macroprudential (capital is fungible after all), the distinction is relevant normatively. For example, in the structural analysis presented here, all reasons for correcting bank capital requirements identified by our DSGE models are due to the negative impact of banking sector losses on the real economy; or, in the contagion analysis presented below, the reason for any identified correction to bank capital requirements would be due to banks' interlinkages and consequent amplification of first-round losses. The resulting requirements are therefore macroprudential in nature. ${ }^{32}$

The distinction remains, however, more subtle than it may appear. In particular, it seems hard to guarantee that a microprudential analysis does not take into consideration macroprudential aspects. For example, consider the following exquisitely microprudential exercise: we consider a balance sheet and we shock the return on a specific asset in isolation from the macroeconomic context and from any network considerations. Even in this simple context, the difficulty comes from the fact that we have to choose the size of the shock. The size is typically derived from the empirical distribution, and observed shocks are

\footnotetext{
${ }^{31}$ See also OMRTF [2017].

${ }^{32}$ To take an extreme example, imagine that bank defaults had no consequences on the real economy. In this context, while an analysis focused on limiting individual bank default may find some strictly positive microprudential requirements, an analysis based on limiting undesirable effects of the banking sector on the real economy would find no need for extra requirements from a macroprudential perspective.
} 
reduced-form. For example, a micro shock of $1 \%$ probability and with an impact of $-10 \%$ on returns could become amplified into a $-20 \%$ shock in reality due to network effects or macro feedback loops; hence, we would observe a $-20 \%$ shock with $1 \%$ probability, and we would carry out our analysis on the basis of that figure. Effectively, therefore, the effect we considered as microprudential would already take into account some macroprudential mechanisms.

In the context of macroprudential buffers, the distinction between the application of the $\mathrm{CCyB}$ and of the SRB manifests both at a positive and a normative level. In particular, we regard them respectively as transitory and permanent movements in capital requirements. While this economic distinction may not fully overlap with the legal distinction outlined in 2.1.1 and 2.1.2, it retains a clear conceptual appeal. On the one hand, a transitory capital requirement would focus on removing inefficient or otherwise unwanted fluctuations in the business and credit cycles by some policy objective function (be it welfare-theoretic or ad-hoc). On the other hand, a permanent activation of a capital buffer (for example the SRB) would address a steady-state distortion, thereby mitigating the associated long-run inefficiencies in the economy. For example, structural models such as the dynamic general equilibrium models used in later sections can point to a long-run suboptimal capitalization due to excessive risk-taking by banks. In this context, there is a well-defined optimal long-run capital level that optimizes a social welfare function by trading off the benefits from a lower incidence of bank defaults and the costs of having banks shift towards equity, which represents a particularly costly source of funding in the model. In any event, it is important that the decisionmaker is aware of the rationale behind the undercapitalization to judge the appropriate frequency of prescribed movements in capital buffers.

\subsection{The difficulty in assessing transmission channels}

A first difficulty that arises when one seeks to assess the transmission of changes in macroprudential buffers to the real economy is the limited insight into this mechanism we can gain from past experience. In Europe, the arguably most relevant experience with a countercyclical capital buffer is the dynamic provisioning policy of Spain between 2000 and 2008 documented in Jiménez, Ongena, Peydró, and Saurina [2013]. Historically, bank capitalization requirements did change both for regulatory and market reasons, yet these events do not constitute a sufficiently long time series of observations to be reliably exploited with standard econometric techniques.

In this context, we choose to rely on general equilibrium models to shed light onto the transmission of a $\mathrm{CCyB}$ activation to the real economy through explicit optimization mechanisms. In particular, dynamic equilibrium models describe optimal decisions of representative economic agents facing limited resources 
and have been enriched in recent research to account for the role of the banking sector in the economy. Regulatory capital requirements are explicitly characterized and play a role in the behavior of banks. For this reason, these models are a natural measurement tool to gauge the dynamic effect of a change in macroprudential buffers on the real economy, as well as the effect of macroeconomic shocks on the banking sector as whole.

Regarding the SRB, we may expect similar channels of transmission with the main difference that the risk triggers behind activation are not cyclical but steady-state distortions.

\subsection{Capturing highly non-linear effects}

A second challenge is related to the objective of the $\mathrm{CCyB}$, which is to mitigate vulnerabilities in the banking sector resulting from excessive credit growth and with the potential to cause real activity to plummet because of highly non-linear disruptions in the financial sector.

In this respect, the available cyclical DSGE models have one major limitation: imperfections in the banking sector do amplify shocks, however, the typical low-order perturbations used to represent the solution of these models have a difficult time in modeling periods of excessive credit growth that endogenously build up the conditions that amplify the subsequent contraction. For example, to a typical first-order perturbation, the role of banks in the amplification of shocks is modelled as state independent, so one would miss likely nonlinearities that would materialize during low-probability events, the most typical case being a bank failure triggering financial markets freeze, as happened with Lehmann Brothers in September 2008. Symmetrically, systematic policy responses to shocks can dampen fluctuations by reducing the amplifying role of banks, however, low-order perturbations have a difficult time in describing whether the policy response has a larger effect during tail events relative to normal times.

Thus, the consequences of the financial crises that macroprudential buffers aim at defusing must be considered at least in part in the following analysis as out-of-model events; there most likely is some unquantified implicit benefit in the activation of capital buffers in the fact that such highly nonlinear episodes are mitigated. The modeling of such nonlinear effects is left for further research.

\subsection{The dependence on 'extreme' scenarios}

The evaluation of an activation of capital buffers (the CCyB in particular) has to be placed in the context of the current juncture of the business and credit cycles, and hence has to be done in the context of specific scenarios. In our applications we consider a baseline and an adverse scenarios. 
The baseline scenario, in order to provide useful policy guidance, serves to tell to what extent the CCyB increase would impact on the economy given current medium-run macroeconomic perspectives. Therefore, the design of the baseline scenario is key for the conclusions. Specifically, it has to correspond very closely to a projection that the policymaker considers as relevant. That is the reason why we use in the following analysis a scenario that reflects as closely as possible the central projection used and made by the Banque de France (and other Eurosystem Central Banks in the context of the Broad Macroeconomic Projection Exercise [BMPE]) in the preparation of monetary policy decisions, at least in the short term. Optimized $\mathrm{CCyB}$ rules from an unconditional perspective (see the structural approach for the calibration of the $\mathrm{CCyB}$ of section 4.2) depend on the baseline projection to evaluate whether a current activation is justified.

The adverse scenario should build on this starting point but be augmented with potential heightened risks to the financial system. Risks in the financial system are very broad, of diverse natures, and their materialization as crises are rare events. This challenge of spotting the right risk, design the right proxy and anticipate the variation of such indicators as a consequence of risk materialisation makes the design of the adverse scenario challenging. The strategy adopted for buffer calibration should then be flexible enough to incorporate indicators (macrofinancial variables) that are relevant in the design of the adverse scenario. ${ }^{33}$ The hybrid approach to CCyB calibration presented in section 4.3 relies heavily on the adverse scenario as it deploys a macro stress testing tool to identify prospective capital shortfalls when the banking system is faced with downside risk.

\section{Concluding remarks}

In this paper, we explore and design a flexible and comprehensive analytical framework consisting of various classes of models (VAR, early warning models, DSGE models, top-down stress tests, contagion models) which allows us to calibrate both cyclical (CCyB) and structural (SRB) capital buffers. We show that each buffer requires a scenario carefully designed and a calibration strategy consistent with the macroprudential objective targeted by the buffer. Our framework relies on macroeconomic and financial forecasts consistent with official forecasting exercises (as the BMPE in the Euro area) and complemented, when needed, by an adverse shock drawing from our systemic risk assessment.

Depending on the precise calibration goal, we can opt for one or another analytical tool at our disposal. For instance, in the scenario design phase, we may use the VAR if we want to put more emphasis on replicating the dynamics of more key variables. On the opposite, if we want to give priority to theoretical

\footnotetext{
${ }^{33}$ Against this background, the purpose of this paper is to present the tools and methodology under an illustrative scenario. The quantitative results reported below should not be viewed as formal policy recommendations in the current situation.
} 
underpinnings, we may choose a DSGE model. Another example is the possibility to switch on and off the network module, according to whether we consider it relevant or not to simulate second-round losses for a given stress testing exercise.

In this paper we implemented two calibration strategies: a structural strategy, based on DSGE models, and a hybrid strategy, based on a top-down stress testing framework. The first strategy is naturally suited for the calibration of the SRB, given the long-run, non-cyclical nature of the risks targeted by this buffer. We rely on both the structural and the hybrid strategies for the calibration of the CCyB. Our analytical framework provides direct operational policy applications since it is meant to support the decision-making process of macroprudential authorities when making their calibration decisions. It is however important to emphasize that we do not intend to establish an automatic or mechanical relationship between the outcome of our modeling approaches and the calibration level eventually set for macroprudential capital buffers. One key ingredient that should never be disregarded when dealing with macroprudential policy in general and calibration in particular is expert judgment. As rightly pointed out in CGFS [2016]: "independently of the approach taken to appraisals, expert judgment retains an overriding role".

Finally, several areas for future research are left open. On scenario design, the development of an empirical macro-financial model that would encompass a more elaborate simulation for credit and its interactions with macroeconomic variables. On policy design, the development of a DSGE model with granular balance sheets and heterogeneous banks that matches key cross-sectional features of the banking industry and the time-series behavior of the main macro-financial variables. Lipinski [2016] represents a recent step in that direction. On the overall structure of all approaches, a challenge left for further research is a better account of rare but highly disruptive financial crises. 


\section{References}

V. Acharya, C. Brownlees, R. Engle, F. Farazmand, and M. Richardson. Measuring systemic risk. In Roggi and Altman, editors, Managing and Measuring Risk: Emerging Global Standards and Regulation After the Financial Crisis, Series in Finance. World Scientific, 2013.

P. Alessandri, P. Gai, S. Kapadia, N. Mora, and C. Puhr. Towards a framework for quantifying systemic stability. International Journal of Central Banking, 5(3), 2009.

L. Alessi and C. Detken. Quasi real time early warning indicators for costly asset price boom/bust cycles: A role for global liquidity. European Journal of Political Economy, 27(3):520-533, 2011.

L. Alessi and C. Detken. Identifying excessive credit growth and leverage. ECB Working paper Series, 1723, 2014.

Y. Amihud. Illiquidity and stock returns: cross-section and time-series effects. Journal of Financial Markets, 5:31-56, 2002.

P. Angelini, S. Neri, and F. Panetta. The interaction between capital requirements and monetary policy. Journal of Money Credit and Banking, 46(6):1073-1112, 2014.

Basel Committee on Banking Supervision BCBS. An explanatory note on the Basel II IRB Risk Weight functions. BCBS Paper, 189, 2005.

Basel Committee on Banking Supervision BCBS. Guidance for national authorities operating the countercyclical capital buffer. BIS Communications, 2010a.

Basel Committee on Banking Supervision BCBS. Basel III: A global regulatory framework for more resilient banks and banking systems. BCBS Paper, 189, 2010b.

Basel Committee on Banking Supervision BCBS. Frequently asked questions on the basel iii countercyclical capital. BIS Communications, 2015.

Bank of England BoE. The financial policy committee's approach to setting the countercyclical capital buffer. BoE Policy Statements, 2016.

V. Borgy, L. Clerc, and J.P. Renne. Measuring aggregate risk: Can we robustly identify asset-price boom-bust cycles? Journal of Banking \&3 Finance, 46:132-150, 2014.

Committee on the Global Financial System CGFS. Operationalising the selection and application of macroprudential instruments. CGFS Publications, 48, 2012.

Committee on the Global Financial System CGFS. Experiences with the ex-ante appraisal of macroprudential instruments. CGFS Publications, 56, 2016.

L. J. Christiano, M. Eichenbaum, and C. L. Evans. Nominal rigidities and the dynamic effects of a shock to monetary policy. Journal of Political Economy, 113(1):1-45, 2005.

L. Clerc, A. Derviz, C. Mendicino, S. Moyen, K. Nikolov, L. Stracca, J. Suarez, and A. Vardoulakis. Capital regulation in a macroeconomic model with three layers of default. International Journal of Central Banking, 2015.

L. Clerc, A. Giovannini, S. Langfield, T. Peltonen, R. Portes, and M. Scheicher. Indirect contagion: the policy problem. ESRB Occasional Paper Series, 9, 2016. 
C. Couaillier and J. Idier. Measuring excess credit using the basel gap: relevance for setting the countercyclical capital buffer and limitations. Banque de France Quarterly Selection of Articles, 46, 2017.

V. Coudert and J. Idier. An early warning system for macroprudential policy in france. Banque de France Working Paper Series, 609, 2016.

V. Curdia and M. Woodford. Credit frictions and optimal monetary policy. Manuscript, 2009.

V. Curdia and M. Woodford. Credit spreads and monetary policy. Journal of Money, Credit and Banking, 42(6):3-35, 2010.

M. Darracq-Paries, C. Kok Sorensen, and D. Rodriguez-Palenzuela. Macroeconomic propagation under different regulatory regimes: Evidence from an estimated DSGE model for the Euro Area. International Journal of Central Banking, 7(4): 49-113, 2011.

S. Dees, J. Henry, and R. Martin (Eds.). STAMPE: Stress-test analytics for macroprudential purposes in the euro area. $E C B$ Publication, 2017.

C. Detken and X ESRB Working group on CCyB. Operationalising the countercyclical capital buffer: indicator selection, threshold identification and calibration options. ESRB Occasional paper, 5, 2014.

M. Drehmann and M. Juselius. Evaluating early warning indicators of banking crises: Satisfying policy requirements. International Journal of Forecasting, 30(3):759-780, 2014.

M. Drehmann, S. Sorensen, and M. Stringa. The integrated impact of credit and interest rate risk on banks: A dynamic framework and stress testing applications. Journal of Banking and Finance, 34:710-29, 2010.

European Systemic Risk Board ESRB. The esrb handbook on operationalising macro-prudential policy in the banking sector. ESRB Occasional Paper Series, 2014.

J. Fernández-Villaverde, J. F. Rubio-Ramírez, T. J. Sargent, and M. W. Watson. ABCs (and Ds) of understanding VARs. American Economic Review, 97(3):1021-6, 2007.

S. Ferrari and M. Pirovano. Early warning indicators for banking crises: a conditional moments approach. MPRA Paper 62406, University Library of Munich, 2015.

S. Gabrieli, D. Salakhova, and G. Vuillemey. Cross-border interbank contagion in the european banking sector. Banque de France Working Paper, 545, 2015.

A. Gerali, S. Neri, L. Sessa, and F. M. Signoretti. Credit and banking in a DSGE model of the euro area. Journal of Money Credit and Banking, 42(6):108-141, 2010.

C. Gourieroux, J.C. Heam, and A. Monfort. Bilateral exposures and sytemic solvency risk. Canadian Journal of Economics, 45(4), 2012.

R. Greenwood, A. Landier, and D. Thesmar. Vulnerable banks. Journal of Financial Economics, 115(3):471-485, 2015.

J. D. Hamilton. Time Series Analysis. Princeton University Press, Princeton, 1994.

J. Henry and C. Kok (Eds.). A macro stress testing framework for assessing systemic risks in the banking sector. ECB Occasional Paper Series, 152, 2013.

M. Iacoviello. House prices, borrowing constraints, and monetary policy in the business cycle. American Economic Review, 95(3):739-64, 2005. 
M. Iacoviello and S. Neri. Housing market spillovers: Evidence from an estimated DSGE model. American Economic Journal: Macroeconomics, 2:125-64, 2010.

J. Idier and T. Piquard. Pandemic crises in financial systems: a simulation-model to complement stress-testing frameworks. Banque de France Working Paper, 621, 2017.

U. Jermann and V. Quadrini. Macroeconomic effects of financial shocks. American Economic Review, 102(1):238-71, 2012.

G. Jiménez, S. Ongena, J. Peydró, and J. Saurina. Macroprudential policy, countercyclical bank caital buffers and credit supply: Evidence from the Spanish dynamic provisioning experiments. Manuscript, 2013.

A. Justiniano, G. E. Primiceri, and A. Tambalotti. Credit supply and the housing boom. Manuscript, 2014.

S. Kalatie, H. Laakkonen, and E Tölö. Indicators used in setting the countercyclical capital buffer. Discussion Papers 8/2015. Bank of Finland, 2015.

F. Lipinski. Risky financial intermediation, aggregate risk, cross-sectional risk, and macroeconomic fluctuations. Manuscript, 2016.

P. Lopez. A model of optimal macroprudential and monetary policies. Mimeo, 2015.

R. E. Jr. Lucas. Econometric policy evaluation: A critique. In K. Brunner and A. Meltzer, editors, The Phillips Curve and Labor Markets, volume 1 of Carnegie-Rochester Conference Series on Public Policy, pages 19-46. Elsevier, New York, 1976.

C. Mendicino, K. Nikolov, J. Suarez, and D. Supera. Designing capital regulation in a quantitative macroeconomic model. ECB working paper, forthcoming, 2016.

T. Monacelli. Optimal monetary policy with collateralized household debt and borrowing constraints. In J. Y. Campbell, editor, Asset Prices and Monetary Policy, pages 103-46. University of Chicago Press, Chicago, 2008.

OMRTF. Operationalization of the 3d model: A quantitative assessment of macroprudential policies in euro area countries. ECB working paper series, forthcoming, 2017. Report of the MPPG Task Force for Operationalising Macroprudential Research.

X. Sala-i Martin, G.I. Doppelhofer, and R. Miller. Determinants of long-term growth: A bayesian averaging of classical estimates (bace) approach. American Economic Review, 2004.

H. Shin. Procyclicality and the search for early warning indicators. IMF Working Paper No. 13/258, 2013.

F. Smets and R. Wouters. Shocks and frictions in US business cycles. A Bayesian DSGE approach. American Economic Review, 97(3):586-606, 2007.

H. Suh. Dichotomy between macroprudential policy and monetary policy on credit and inflation. Economics Letters, 122: $144-9,2014$.

M. Woodford. Inflation targeting and financial stability. Sveriges Riksbank Economic Review, 2012. 


\section{Annex 1 The 3D model}

The 3D model [Clerc, Derviz, Mendicino, Moyen, Nikolov, Stracca, Suarez, and Vardoulakis, 2015, Mendicino, Nikolov, Suarez, and Supera, 2016] is a real dynamic general equilibrium model that links saving and borrowing households, firms and banks and explicitly models the possibility of default by all borrowing agents as a consequence of aggregate and idiosyncratic shocks.

The version of the model estimated on French data that we rely on in the present paper is based on the output of the work stream 1 of the Task Force for Operationalizing Macroprudential Research [OMRTF, 2017]. Most model parameters are calibrated to match key first and second moments of real, banking and financial variables, including total bank capital ratios, returns on equity, bank default probabilities, and mortgage and corporate loan write offs.

Furthermore, since we are interested in building counterfactual trajectories for nominal variables and for volatile house and stock prices, we specify an exogenous inflation process and include exogenous disturbances in stock and house prices to capture more flexibly the historical volatility over the sample of interest. Finally, to capture the dynamic relationship among GDP growth, the credit-to-GDP gap, and average bank default frequency - in particular the role of the credit-GDP ratio as a leading indicator of negative developments in economic activity and bank default frequency - we estimate by maximum likelihood a dynamic component in total capital ratios as an ad-hoc device to generate the dynamic correlations of interest.

\section{A.1.1 The model}

Infinitely-lived borrowing households consume nondurable and housing goods and supply labor. Overlapping generations of two-period-lived entrepreneurs retain earnings from corporate activity as corporate equity capital and distribute part of them as dividends to households. Analogously, an overlapping generation of two-period-lived bankers retain earnings from banking activity as bank equity capital and distribute part of them as dividends to households. Banks finance mortgage and corporate loans funded through equity from bankers and deposits from households. In the model all borrowing agents (impatient households, entrepreneurs and banks specialized in either corporate or mortgage loans) have limited liability and their strategic defaults imply costly liquidations.

The government levies lump-sum taxes to fund a deposit safety net that insures depositors, albeit imperfectly in that depositors still lose a fraction of their deposits proportional to average bank defaults. This imperfection produces a nontrivial deposit premium while implying the depositors' inability to command bank-specific risk premia, and hence welfare losses that agents fail to internalize because of the existence of deposit guarantees. Moreover, the assumed limited participation in the market for bank equity implies a higher cost of bank equity relative to deposits. Therefore, since individual banks' cost of funding becomes detached from individual risk taking, banks have incentives to lever up as much as possible and ultimately default too much. It follows that the amount of defaults and the cost of funding are inefficient.

The rest of the economy is characterized by producers of consumption goods, by producers of productive and housing capital goods subject to stock adjustment costs, and by a government that sets (cyclical) capital requirements that constrain banks' leverage state by state and that balances its budget to finance 
the deposit insurance agency.

For more details about the modeled structure, the reader is referred to the original papers [Clerc et al., 2015, Mendicino et al., 2016].

We include three extra sources of exogenous disturbances to produce nontrivial forecasts for the inflation rate and to better match stock and house price volatility, which is substantial over the sample used in application, which extends beyond the sample used in calibration. Moreover, notice that observed total bank capital ratios $(\nu)$ are determined exclusively by the maximum amount of leverage they are allowed to take, in turn determine by a mixture of market and regulatory factors. In particular, we specify a time-varying ratio:

$$
\nu_{t}=\left(1-\rho_{\nu}\right) \nu+\rho_{\nu} \nu_{t-1}+\phi_{\nu}\left[\ln \left(\frac{B_{t}}{\sum_{j=0}^{3} y_{t-j}}\right)-\ln \left(\frac{B}{4 y}\right)\right]
$$

with $B_{t}$ and $y_{t}$ being respectively credit and output, and letters without a time subscript denote the respective values at the deterministic steady state. This ad-hoc inclusion of a cyclical component controlled by coefficient $\phi_{\nu}$ is crucial in capturing the role of the credit-GDP ratio as a leading indicator of a heightened probability of systemic crises (here meant as an increase in banks' default frequency). ${ }^{34}$

\section{A.1.2 Estimation on French data}

We use a linear approximation of the policy functions around the deterministic steady state to characterize key theoretical moments and the likelihood of the model. As detailed in OMRTF [2017], we calibrate most parameters to capture first and second moments of key French macro-financial variables.

We rely on quarterly French data over the 2001-2014 period. In particular, we match the share of borrowing households and their share of housing wealth, the average leverage of households, the average realized return on equity, the average observed total capital ratio, the mean write-off rates for mortgage and corporate loans, the average housing investment to GDP ratio, the volatility of GDP, inflation, residential house prices and CAC40 index, as well as the mean and volatility of Moody's banks' expected default frequency, corporate and mortgage loans and spreads. Finally, we estimate the capital ratio rule (A.1.6) by using the Basel III credit-to-GDP gap in its dynamic relationship with GDP and Moody's bank expected default frequency. Table 8 reports the estimates of the structural parameters in equation (A.1.6).

Table 8: Parameter Estimates

\begin{tabular}{ccc}
\hline & point estimate & st.dev. \\
\hline$\phi_{\nu}$ & -0.0256 & 0.0119 \\
$\rho_{\nu}$ & 0.9201 & 0.0630 \\
\hline
\end{tabular}

Table 9 shows the ability of the model to reproduce the unconditional volatilities of the observable time series. Figure 9 shows a set of dynamic correlations to gauge the ability of the model to capture the

\footnotetext{
${ }^{34}$ Intuitively, a negative coefficient $\phi_{\nu}$ implies that high credit-gdp signals lower future capitalization rates, and hence higher future vulnerabilities.
} 
Wold representation of the observed time series that we use in the exercises of section 5 , thereby clarifying all dimensions along which the model is likely to have counterfactual implications.
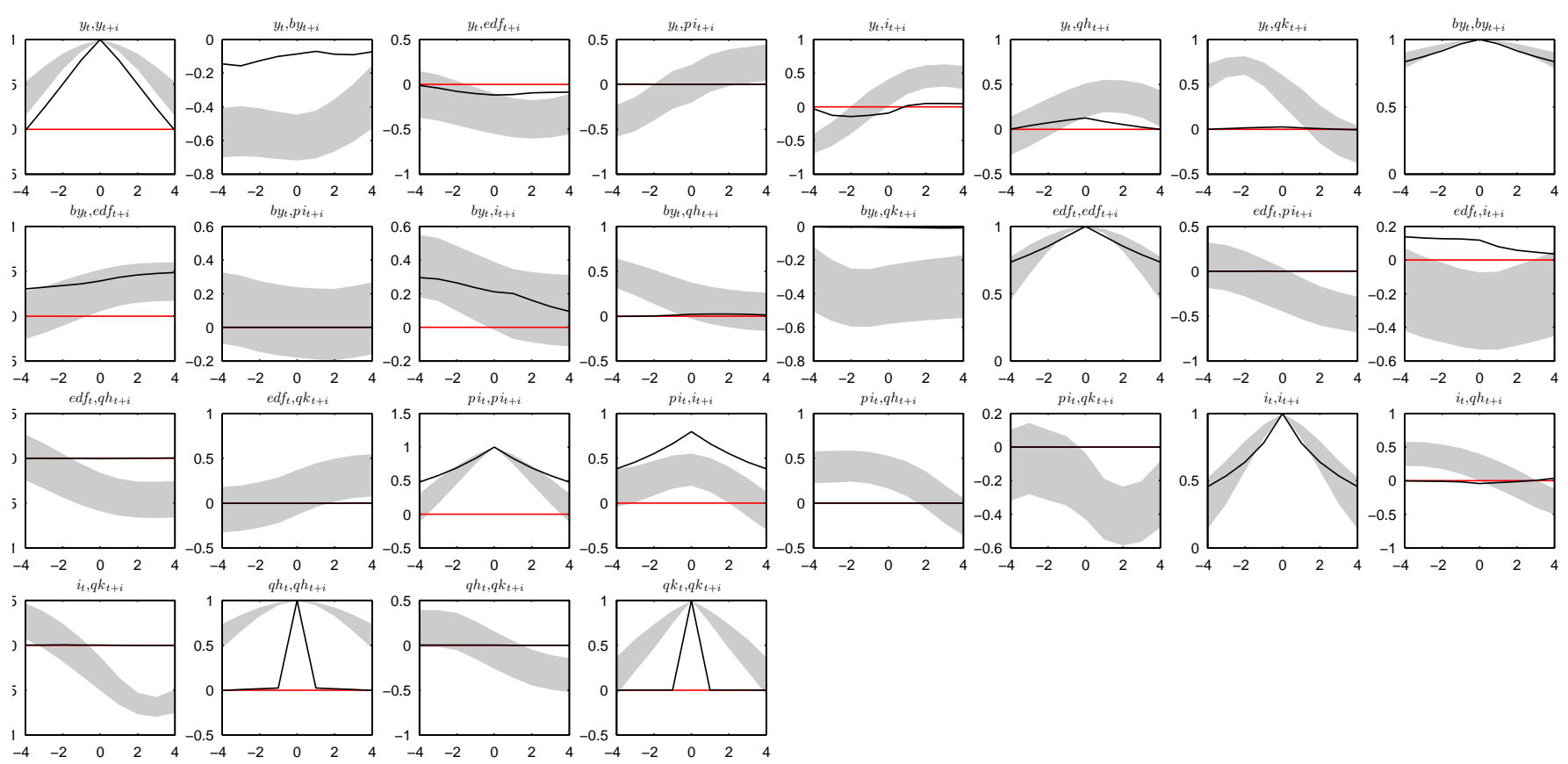

Figure 9: Dynamic cross-correlations of the observable variables: empirical 90\% confidence intervals (shaded areas) and model-implied mode (solid black lines).

Table 10 reports the approximate variance decomposition of the main macro-financial variables of the model.

\section{A.1.3 Macroprudential policy experiments}

After having estimated the drivers of business-cycle fluctuations (table 14), we are now able to conduct counterfactual policy analysis and to study two main questions related to the macroeconomic effect of shocks originating in the banking system: i) the impact on the macroeconomy of an unanticipated increase in bank capital requirements; and ii) the effect of the introduction of a capital buffer rule on the credit and output cycles conditional on the main macroeconomic shocks that drove the endogenous variables historically.

Unexpected (permanent) increase in regulatory capital ratios Figure 10 shows the response of the economy to a permanent increase in total capital ratios. 
Table 9: Unconditional standard deviations

\begin{tabular}{lrrr}
\hline Observable & Model st.dev. & Data st.dev. mean & [90\% confidence interval] \\
\hline GDP yoy growth & $0.29 \%$ & $0.40 \%$ & {$[0.35 \% ; 0.47 \%]$} \\
credit-GDP gap & $4.19 \%$ & $4.51 \%$ & {$[3.84 \% ; 5.18 \%]$} \\
Moody's banks' EDF & $0.20 \%$ & $0.18 \%$ & {$[0.15 \% ; 0.21 \%]$} \\
yoy inflation rate & $0.20 \%$ & $0.20 \%$ & {$[0.17 \% ; 0.23 \%]$} \\
nominal interest rate & $0.25 \%$ & $0.26 \%$ & {$[0.22 \% ; 0.30 \%]$} \\
house price yoy growth & $1.63 \%$ & $1.91 \%$ & {$[1.63 \% ; 2.20 \%]$} \\
CAC40 yoy growth & $5.66 \%$ & $5.95 \%$ & {$[5.07 \% ; 6.83 \%]$} \\
\hline
\end{tabular}

Table 10: Variance decomposition

\begin{tabular}{lrrrrrrr}
\hline variance decomp. & $\epsilon^{a}$ & $\epsilon^{S e}$ & $\epsilon^{S m}$ & $\epsilon^{S b}$ & $\epsilon^{\pi}$ & $\epsilon^{h}$ & $\epsilon^{k}$ \\
\hline GDP yoy growth & 87.03 & 11.54 & 0.40 & 1.03 & 0.00 & 0.00 & 0.00 \\
credit-GDP gap & 3.29 & 85.80 & 10.20 & 0.71 & 0.00 & 0.00 & 0.00 \\
Moody's banks' EDF & 1.21 & 31.64 & 1.07 & 66.08 & 0.00 & 0.00 & 0.00 \\
yoy inflation rate & 0.00 & 0.00 & 0.00 & 0.00 & 100.00 & 0.00 & 0.00 \\
nominal interest rate & 11.61 & 21.31 & 2.26 & 1.21 & 63.61 & 0.00 & 0.00 \\
house price yoy growth & 2.60 & 0.67 & 0.01 & 0.03 & 0.00 & 96.69 & 0.00 \\
CAC40 yoy growth & 0.03 & 0.07 & 0.00 & 0.00 & 0.00 & 0.00 & 99.89 \\
\hline
\end{tabular}

Note: Exogenous shocks are technology $\left(\epsilon^{a}\right)$, corporate risk $\left(\epsilon^{S e}\right)$, mortgage risk $\left(\epsilon^{S m}\right)$, bank risk $\left(\epsilon^{S b}\right)$, inflation $\left(\epsilon^{\pi}\right)$, house price $\left(\epsilon^{h}\right)$ and stock price shocks $\left(\epsilon^{k}\right)$.

There are two externalities in the model that are responsible for constrained-inefficient competitive outcomes. First, the existence of a deposit guarantee implies that depositors do not internalize the cost of bank defaults; even if they lose a fraction of deposits when banks default, they still do not command a bank-specific risk premium as the fraction depends on average bank default. Second, participation in equity markets is limited, so capital is scarce, hence costly.

In this context, permanently tighter capital requirements (holding market-required buffers fixed) reduce loan supply and tighten lending standards but can increase economic activity and social welfare if the increases are permanent, as they reduce banks' bad incentives. In fact, in addition to the traditional channel whereby higher bank leverage reduces bank funding costs through a higher option value of default (due to the fact that deposit premia are not bank-specific) and a smaller reliance on expensive equity, a deposit premium channel implies higher funding costs (due to imperfect deposit guarantees) through a higher bank default frequency. The effect of higher capital requirements on economic activity depends on whether the traditional channel dominates the deposit premium channel. A high steady-state return on equity emphasizes the traditional channel, while a high steady-state bank default frequency emphasizes the deposit premium channel.

In terms of welfare, however, the role of average bank defaults is crucial, as households have to bear the 

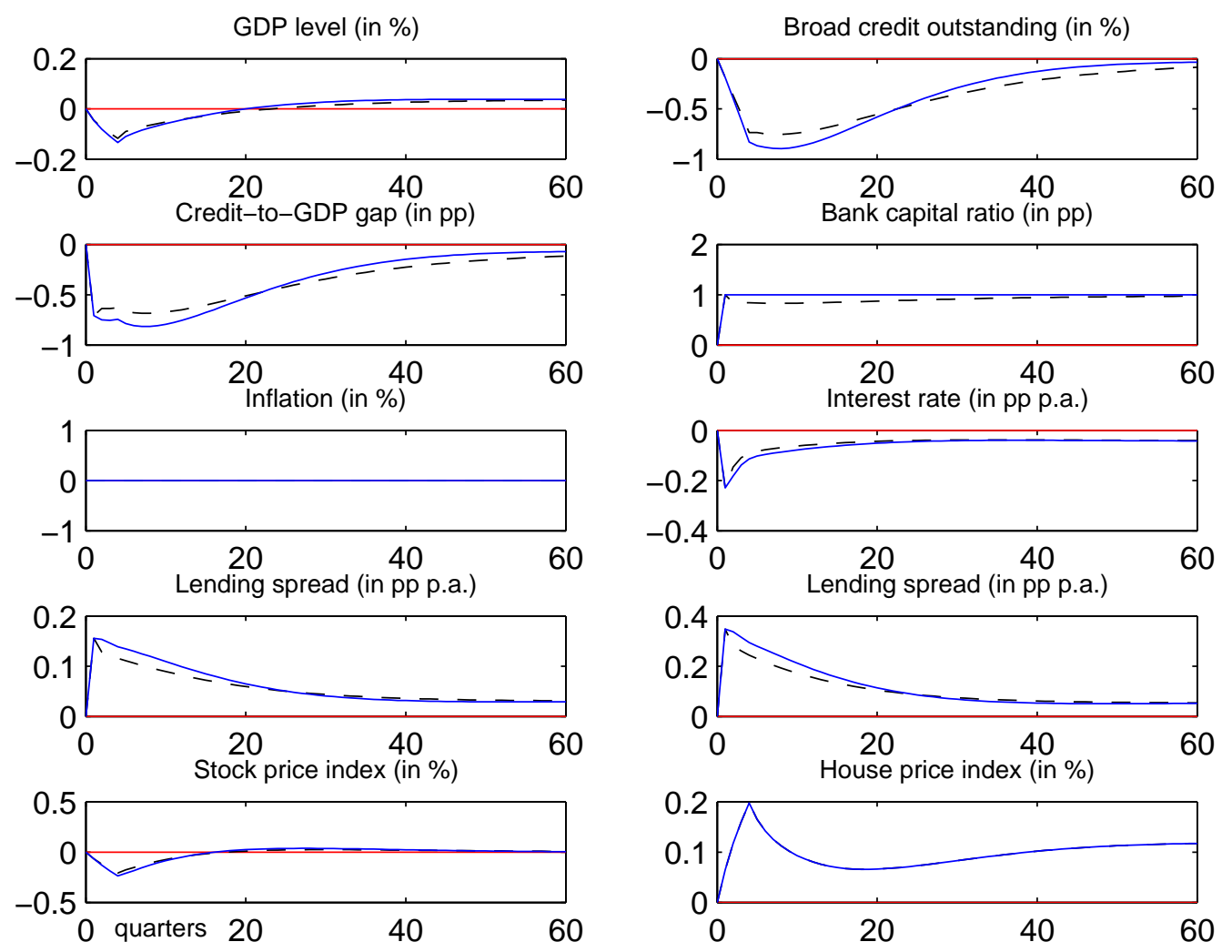

Figure 10: Reaction of the main variables to a 100bp permanent increase in regulatory capital ratio target; dashed lines represent counterfactual responses in the presence of a $\mathrm{CCyB}$ (slope of reaction to the broad credit gap $\left.\phi_{\nu}=.25\right)$. Impulse responses are computed using a parametrization at the posterior mode.

cost of bank defaults through lump-sum taxation. The ability of higher capital requirements to increase the welfare of both savers and borrowers is however limited, as after a threshold level the benefits from a lower incidence of bank defaults (lower tax burden on households to finance the deposit insurance, less resources lost in bankruptcy) are outweighed by the costs imposed on borrowing households of higher credit spreads (higher capital requirements increase the scarcity of bank equity, and hence the return commanded by bank equity owners). Any welfare criterion that assigns a positive Pareto weight to the borrowing households, including a strict Pareto optimality criterion, implies a hump-shaped welfare function with an optimum capital ratio [OMRTF, 2017].

Despite the potentially positive long-run effects on output of a permanent increase in regulatory capital requirements, the effects on GDP are typically contractionary in the short run. In fact, capital accumulation remains sluggish as bank shareholders take time to retain earnings; it follows that in the meantime banks have to shed loans to comply with the higher capital requirements, thereby tightening economic activity. 

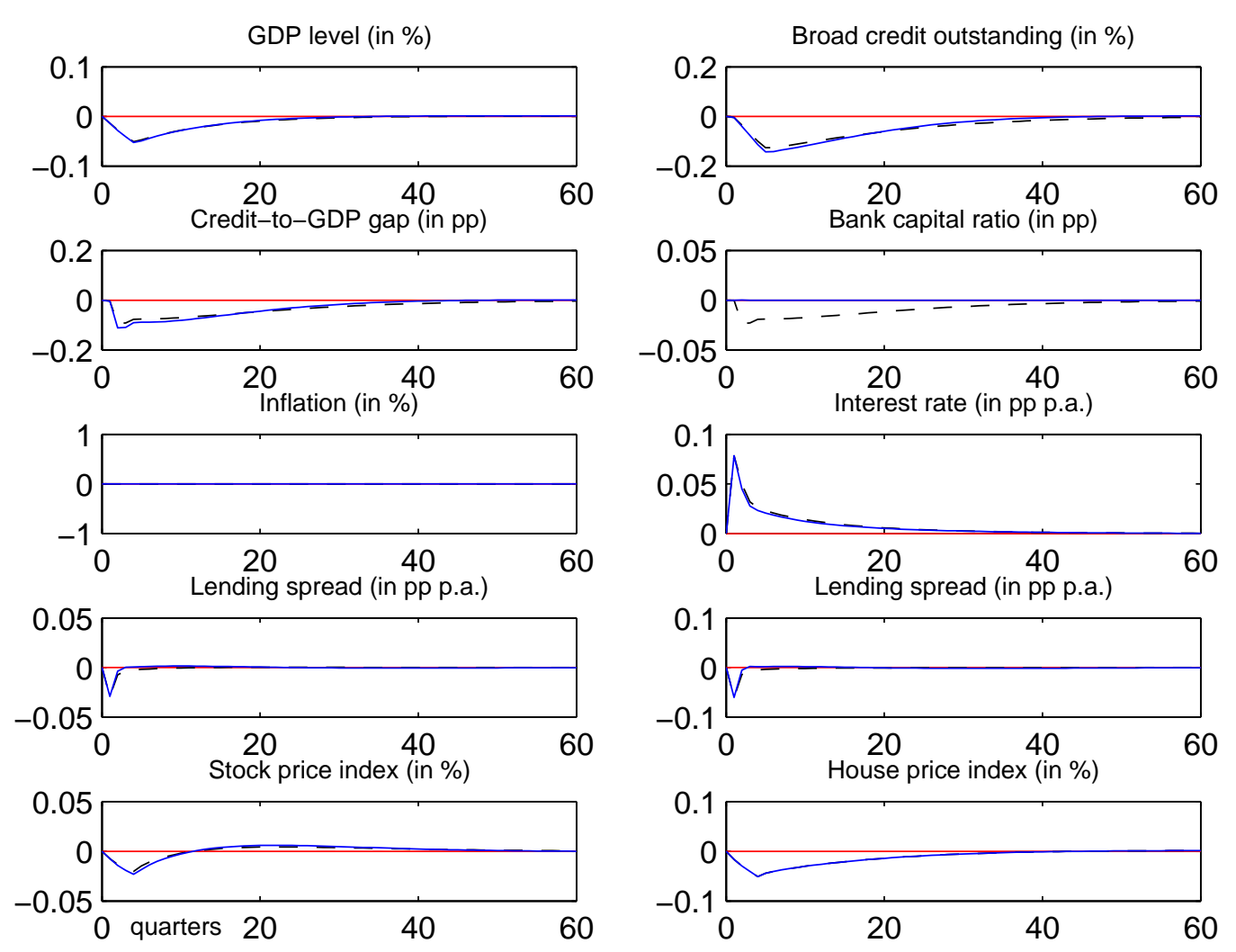

Figure 11: Reaction of the main variables to a 1-s.d. unexpected loss suffered by the banking system; dashed lines represent counterfactual responses in the presence of a $\mathrm{CCyB}$ (slope of reaction to the broad credit gap $\phi_{\nu}=.25$ ). Impulse responses are computed using a parametrization at the posterior mode. 
Systematic macroprudential reaction to credit developments By construction, our CCyB is not exactly identical to the instrument envisaged on paper [BCBS, 2010b]. To get magnitudes consistent with the automatic Basel III rule we choose $\phi_{\nu}=0.25$, so a deviation of the credit-to-GDP gap of $10 \%$ from its long-term trend associates to 2.5 percentage points of additional capital. Figures 10 and 11 also describe the reaction of the economy after a bank risk shock (a shock to the dispersion of banks' idiosyncratic shocks) in the presence of a $\mathrm{CCyB}$ rule. In the case of these financial shocks that originate in the banking sector the effect of the different shocks on credit is generally dampened by the CCyB rule, in line with the declared objective. In the case of the permanent increase in the capital target, the economy eventually converges to the higher capital target but does so with smoother transitional dynamics. The dampening effect of the CCyB for the relatively small coefficient of .25 is, however, quite limited.

\section{Annex 2 The GNSSFr model}

The GNSSFr model builds on a framework originally proposed by Gerali, Neri, Sessa, and Signoretti [2010] and that incorporates a nontrivial banking sector into a model with borrowing constraints (similar to Iacoviello [2005]) and nominal frictions [similar to Christiano, Eichenbaum, and Evans, 2005, Smets and Wouters, 2007]. ${ }^{35}$ In particular, our setting features imperfect financial intermediation, as banks incur into equity adjustment costs whenever their sluggish capital levels differ from an exogenous target level, and liquidity constrained agents that face LTV-type constraints to borrowing. ${ }^{36}$ Thus, we explicitly integrate in the estimated model a specific macroprudential instrument for counterfactual analysis - a CCyB - because it is an instrument that can be activated by the French national authority.

Relative to the original framework by Gerali et al. [2010], we make two minor extensions that are necessary to evaluate meaningful macroprudential policies and to capture the volatility of house prices. First, we follow Angelini et al. [2014] in conducting a counterfactual local analysis in which we interpret the time-varying bank leverage target as a cyclical regulatory capital requirement. The capital buffer takes the form of additional capital requirements in the banking sector which, by being countercyclical, relax the regulatory capital constraints imposed on the banking sector during a downturn. This interpretation matches the use in the Basel III framework of the credit-to-GDP gap as a trigger for the activation/deactivation, although in estimation the time-varying target level picks up undifferentiated movements in both market and regulatory bank leverage requirements. Second, we depart from a fixed housing supply; adjustment costs in the production of housing goods, which uses up consumption goods, allows the model to match the observed volatility of house prices.

We estimate the model with Bayesian techniques on French macrofinancial data. After recovering a measure of the structural effects on the economy of unexpected changes in bank equity capital and in leverage targets, we carry out a counterfactual analysis and find that the CCyB affects the credit market,

\footnotetext{
${ }^{35}$ See also Darracq-Paries, Kok Sorensen, and Rodriguez-Palenzuela [2011] and Angelini, Neri, and Panetta [2014] as examples of frameworks that build on a similar specification of the banking structure.

${ }^{36}$ The bank equity adjustment costs are introduced in an ad hoc fashion to force banks to finance their activity through capital. Lopez [2015] offers a microfoundation of convex bank equity adjustment costs at the aggregate bank level from financial frictions in the form of leverage constraints and heterogeneity in loan monitoring costs at the individual bank level.
} 
decreasing its volatility across a broad range of macroeconomic shocks, although its quantitative effect appears limited.

\section{A.2.1 The Model}

The model embeds two main sources of frictions both linked to the credit market. On the supply side, imperfectly competitive banks set a time-varying markup on loans that increases credit costs for households and limits the production possibilities of entrepreneurs, and face convex costs from retaining capital ratios that deviate from a target requirement determined by market and regulatory motives; banks adjust equity slowly through earnings retention and adjust lending and deposit rates sluggishly.

On the demand side, the borrowing of both households and entrepreneurs is subject to collateral requirements. The exogenously imposed LTV constraint acts as the binding constraint on mortgage and corporate loans. Also, there is no direct finance and all transactions are intermediated by the banking sector.

\section{A.2.1.1 Non-financial sector}

The economy is populated by three types of agents - patient households, impatient households and entrepreneurs, who maximize their utilities subject to the respective resource constraints. Both patient households, indexed by $(P)$, and impatient households, indexed by $(I)$, work, consume and save/borrow. The last class of agent, the entrepreneurs, consume, borrow and combine labour and capital to produce a homogeneous good which is later differentiated and sold as a final consumption good. Households and entrepreneurs differ in their discount factors $\left(\beta^{I}<\beta^{P}\right.$ and $\left.\beta^{E}<\beta^{P}\right)$ to ensure that locally around the deterministic steady state patient households are savers and impatient households and entrepreneurs are borrowers. $^{37}$

Patient households Patient households choose their levels of consumption $c_{t}^{P}$, housing stock $h_{t}^{P}$ and labour supply $l_{t}^{P}$ in order to maximize their expected utility: ${ }^{38}$

$$
U_{P}\left(c_{t}^{P}, h_{t}^{P}\right)=\mathbb{E}_{0} \sum_{t=0}^{\infty} \beta_{P}^{t}\left[\left(1-a^{P}\right) \epsilon_{t}^{z} \log \left(c_{t}^{P}-a^{P} c_{t-1}^{P}\right)+\epsilon_{t}^{h} \log \left(h_{t}^{P}\right)-\frac{\left(l_{t}^{P}\right)^{1+\phi}}{1+\phi}\right]
$$

where $\phi$ is the inverse Frisch-Waugh elasticity of labour supply and parameters $a^{P}$ and $a^{I}$ define the degree of (external) consumption habits for each household type. Disturbances $\epsilon_{t}^{z}$ and $\epsilon_{t}^{h}$ are introduced to represent shocks to households' preferences for consumption and housing, respectively.

\footnotetext{
${ }^{37}$ To avoid dealing with occasionally binding constraints, which would considerably complicate the solution of the model, we follow Iacoviello [2005], Gerali et al. [2010] and Angelini et al. [2014] in assuming that the shocks to the economy are local, so patient households always remain savers and and impatient households and entrepreneurs always remain borrowers.

${ }^{38}$ In the utility function, we weigh consumption by $1-a^{P}$ to produce the same deterministic steady-state marginal utility of consumption as in a model without habits.
} 
Patient households earn a wage $w_{t}^{P}$ for each unit of labour supplied $l_{t}^{P}$. Last period deposits of patient households $d_{t-1}$ are paid $\left(1+r_{t-1}^{d}\right) / \pi_{t}$ per unit, where $\pi_{t}=P_{t} / P_{t-1}$ defines the current rate of inflation. The patient households' budget constraint is:

$$
c_{t}^{P}+q_{t}^{h}\left(h_{t}^{P}-\left(1-\delta^{h}\right) h_{t-1}^{P}\right)+d_{t}=w_{t}^{P} l_{t}^{P}+\frac{1+r_{t-1}^{d}}{\pi_{t}} d_{t-1}+\operatorname{Tr}_{t}^{P}
$$

where $q_{t}^{h}$ is the real price of the housing good, which depreciates at rate $\delta^{h}$, and $\operatorname{Tr}_{t}^{P}=J_{t}^{R}+\omega^{b} J_{t-1}^{B}+$ $J_{t}^{h}$ corresponds to lump-sum transfers that include dividends from firms and banks owned by patient households.

Impatient households A continuum of identical impatient households maximise their inter-temporal utility:

$$
U_{I}\left(c_{t}^{I}, h_{t}^{I}\right)=\mathbb{E}_{0} \sum_{t=0}^{\infty} \beta_{I}^{t}\left[\left(1-a^{I}\right) \epsilon_{t}^{z} \log \left(c_{t}^{I}-a^{I} c_{t-1}^{I}\right)+\epsilon_{t}^{h} \log \left(h_{t}^{I}\right)-\frac{\left(l_{t}^{I}\right)^{1+\phi}}{1+\phi}\right]
$$

Because they are impatient, these households are borrowers at the margin, at least in a neighborhood of the deterministic steady state [Iacoviello, 2005]. We denote their borrowing by $b_{t}^{I}$, which they obtain by pledging their housing stock $h_{t}^{I}$ as collateral. An exogenous LTV constraint limits the borrowing capabilities of households. Namely, we assume that their borrowing is limited by a multiple of the expected value of their housing stock used as collateral,

$$
\left(1+r_{t}^{b I}\right) b_{t}^{I} \leq m^{I} E_{t}\left[\pi_{t+1} q_{t+1}^{h}\left(1-\delta^{h}\right) h_{t}^{I}\right]
$$

where $m^{I}$ is the LTV ratio for mortgages, i.e., the total amount of credit households can get for one unit of collateral, set by the regulator or determined by the market based on liquidity considerations. ${ }^{39}$

Thus, the ex-ante borrowing household's budget constraint is:

$$
c_{t}^{I}+q_{t}^{h} h_{t}^{I}+\frac{1+r_{t-1}^{b I}}{\pi_{t}} b_{t-1}^{I}=w_{t}^{I} l_{t}^{I}+b_{t}^{I}+q_{t}^{h}\left(1-\delta^{h}\right) h_{t-1}^{I}
$$

Entrepreneurs When maximizing utility, each entrepreneur is only concerned with the deviations of his own consumption $c_{t}^{E}$ from an external habit level controlled by parameter $a^{E}$ :

$$
U_{E}\left(c_{t}^{E}\right)=\mathbb{E}_{0} \sum_{t=0}^{\infty} \beta_{E}^{t} \log \left(c_{t}^{E}-a^{E} c_{t-1}^{E}\right)
$$

\footnotetext{
${ }^{39}$ Given the size of the model, we do not explore a global solution method and stick to the more common local approach [Iacoviello, 2005, Monacelli, 2008, Gerali et al., 2010, Angelini et al., 2014]. See Lopez [2015] for a global solution of a stripped down general equilibrium model with a similar banking structure.
} 
In addition to the individual consumption and borrowing choices, each entrepreneur chooses his labour and capital inputs $k_{t}^{E}$ and $l_{t}^{E}$. The budget constraint is given by:

$$
c_{t}^{E}+w_{t}^{P} l_{t}^{E, P}+w_{t}^{I} l_{t}^{E, I}+\frac{1+r_{t-1}^{b E}}{\pi_{t}} b_{t-1}^{E}+q_{t}^{k} k_{t}^{E}=\frac{y_{t}}{x_{t}}+b_{t}^{E}+q_{t}^{k} k_{t-1}^{E}\left(1-\delta^{k}\right)+J_{t}^{k}
$$

where $J_{t}^{k}$ are profits realized by the capital goods producers, $r_{t}^{b E}$ is the interest rate paid by entrepreneurs for each unit of loan $b_{t}^{E}$. The capital good is purchased at price $q_{t}^{k}$ and depreciates at rate $\delta^{k}$, while $x_{t} \equiv \frac{P_{t}}{P_{t}^{W}}$ corresponds to the relative price of the wholesale good $y_{t}$ which is produced by each entrepreneur according to the technology:

$$
y_{t}=a_{t}^{E}\left(k_{t-1}^{E}\right)^{\alpha}\left(l_{t}^{E}\right)^{1-\alpha}
$$

Here $l_{t}^{E}$ is a measure of aggregate labour, combining labour from both types of households:

$$
l_{t}^{E}=\left(l_{t}^{E, P}\right)^{\mu}\left(l_{t}^{E, I}\right)^{1-\mu}
$$

In symmetry with the case of impatient households, an exogenous LTV constraint limits the borrowing capabilities of entrepreneurs:

$$
\left(1+r_{t}^{b E}\right) b_{t}^{E} \leq m^{E} E_{t}\left[\pi_{t+1} q_{t+1}^{k}(1-\delta) k_{t}^{E}\right]
$$

where $m^{E}$ is the loan-to-value (LTV) ratio for corporate loans set by the regulator or by the market.

Loans and deposit demand The three types of agents interact differently with the monopolistically competitive financial intermediaries. Namely each bank has a certain degree of market power and is able to differentiate its customers depending on their type. Assuming a Dixit-Stiglitz structure for the credit market, we denote by $\epsilon^{d}, \epsilon^{b I}$, and $\epsilon^{b E}$ the elasticities of substitution among different loan types for patient households, impatient households and entrepreneurs. Individual demands for loans to households $b_{t}^{I}(j)$, loans to entrepreneurs $b_{t}^{E}(j)$ and deposits $d_{t}(j)$ hinge on overall volumes and on individual prices charged relative to their average counterparts:

$$
b_{t}^{I}(j)=\left(\frac{r_{t}^{b I}(j)}{r_{t}^{b I}}\right)^{-\epsilon_{t}^{b I}} b_{t}^{I}, \quad b_{t}^{E}(j)=\left(\frac{r_{t}^{b E}(j)}{r_{t}^{b E}}\right)^{-\epsilon_{t}^{b E}} b_{t}^{E}, \quad d_{t}(j)=\left(\frac{r_{t}^{d}(j)}{r_{t}^{d}}\right)^{-\epsilon_{t}^{d}} D_{t}
$$

where in estimation we allow for stochastic elasticities of substitution to better fit the data.

\section{A.2.1.2 Banking sector}

The structure of the banking system follows closely the one in Gerali et al. [2010]. It allows studying shocks originating from the supply side of the credit market. There is a continuum of identical bank holdings, $j \in(0,1)$, constituted of three branches each. Each perfectly competitive bank holding distributes loans to an amount, $B_{t}$, and obtains funds by collecting deposits, $D_{t}$, from patient households or by issuing bank 
equity, $k_{t}^{b}$, subject to the balance-sheet constraint:

$$
B_{t}=D_{t}+k_{t}^{b}
$$

The two retail branches, namely the deposit and the loan branch, operate under monopolistic competition and fix the interest rates for deposits and loans relative to the elasticities of substitution $\epsilon^{d}$, $\epsilon^{b I}$ and $\epsilon^{b E}$.

Wholesale branch Each wholesale branch operates as a link between the two retail branches and combines bank capital and deposits in order to issue loans. Bank equity capital is sluggish in that bank capital $k_{t}^{b}$ accumulates only through retained earnings as:

$$
k_{t}^{b}=\left(1-\delta^{b}\right) \frac{k_{t-1}^{b}}{\pi_{t}}+\left(1-\omega^{b}\right) \frac{J_{t-1}^{b}}{\pi_{t}}+\epsilon_{t}^{k}
$$

where $\delta^{b}$ is the cost for managing bank equity, $J_{t}^{b}$ corresponds to the profits of the bank, and $\epsilon_{t}^{k}$ is a disturbance introduced that represents unanticipated bank losses or exogenous capital adjustments (e.g., equity issuance to foreign investors). To motivate the banks' objective function a fraction of profits, $\omega^{b}>0$, is distributed each period as a dividend to equity owners. ${ }^{40}$ As in Angelini et al. [2014], the parameter $\delta^{b}$ can be interpreted as a fixed cost to managing equity and it prevents capital from growing without bound while allowing strictly positive steady-state profits. While this structure captures the slowmovement of bank equity capital in the data, it is important to note how it also rules out other options for recapitalization that may be available to the bank. The absence of other sources of equity financing most likely overstates the sluggishness of bank equity capital.

As both $D_{t}$ and $k_{t}^{b}$ are perfect substitutes, the choice of each bank is determined by the existence of $\nu_{t}$, an exogenous capital-to-asset target ratio from which it is costly to deviate. In the data this target is most likely a mixture of market and regulatory bank leverage requirement, depending on whichever of the two binds more on a given juncture of the business cycle; in estimation we will not attempt at disentangling the two components, however, we will subsequently investigate the effect of a regulatory increase in capital requirements as an exogenous increase in $\nu_{t}$, irrespective of other movements in the target due to exogenous market forces.

A wholesale banking branch chooses $D_{t}$ and $B_{t}$ according to the program:

$$
\begin{gathered}
\max _{\left\{B_{t}, D_{t}\right\}} \mathbb{E}_{0} \sum_{t=0}^{\infty} \Lambda_{0, t}^{P}\left[\left(1+R_{t}^{b}\right) B_{t}-B_{t+1}+D_{t+1}-\left(1+R_{t}^{d}\right) D_{t}+\Delta k_{t+1}^{b}-\frac{\kappa_{k b}}{2}\left(\frac{k_{t}^{b}}{B_{t}}-\nu_{t}\right)^{2} k_{t}^{b}\right] \\
\text { s.t. } B_{t}=D_{t}+k_{t}^{b}
\end{gathered}
$$

where both $R_{t}^{b}$ the net wholesale loan rate, and $R_{t}^{d}$ the net wholesale deposit rate are taken as given. Finally, $\kappa_{k b}$ represents the cost of deviating from the regulatory capital-to-asset ratio.

\footnotetext{
${ }^{40}$ For simplicity, we consider the limit as $\omega^{b} \downarrow 0$.
} 
The first order conditions of the wholesale branch give the following relation between the funding costs for the wholesale branch and the price set for loans:

$$
R_{t}^{b}=R_{t}^{d}-\kappa_{k b}\left(\frac{k_{t}^{b}}{B_{t}}-\nu_{t}\right)\left(\frac{k_{t}^{b}}{B_{t}}\right)^{2}
$$

As we assume an unlimited source of finance for a given monetary policy rate $r_{t}$, the wholesale deposit rate $R_{t}^{d}$ is pinned down in the interbank market $R_{t}^{d}=r_{t}$.

Using (14) we obtain a definition for the spread $S_{t}^{w}$ :

$$
S_{t}^{w} \equiv R_{t}^{b}-r_{t}=-\kappa_{k b}\left(\frac{k_{t}^{b}}{B_{t}}-\nu_{t}\right)\left(\frac{k_{t}^{b}}{B_{t}}\right)^{2}
$$

As a result, the wholesale branch chooses its capital-to-asset ratio and its distance from the regulatory requirement only relative to the difference between the rate paid by loan branches $R_{t}^{b}$ and the rate paid to the deposit branch $r_{t}$. That is to say the interest rate spread is here the key variable which drives banks' decision to tighten lending conditions in case it fails to be sufficient to cover payout commitments to depositors or equity holders.

Loan branch Loan branches operate under monopolistic competition and determine rates for entrepreneurs $r_{t}^{b E}$ and rates for households $r_{t}^{b I}$. All branches are subject to adjustment costs to rate changes, to model persistence in rate movements that will be necessary to fit the data in estimation.

Intertemporally, each loan branch faces the following problem:

$$
\begin{aligned}
\max _{\left\{r_{t}^{b I}(j), r_{t}^{b E}(j), m_{t}^{E}, m_{t}^{I}\right\}} & \mathbb{E}_{0} \sum_{t=0}^{\infty} \Lambda_{0, t}^{P}\left[\left[1+r_{t}^{b I}(j)\right] b_{t}^{I}(j)+\left[1+r_{t}^{b E}(j)\right] b_{t}^{E}(j)-\left(1+R_{t}^{b}\right) B_{t}(j)\right. \\
& \left.-\frac{\kappa_{b I}}{2}\left(\frac{r_{t}^{b I}(j)}{r_{t-1}^{b I}(j)}-1\right)^{2} r_{t}^{b I} b_{t}^{I}-\frac{\kappa_{b E}}{2}\left(\frac{r_{t}^{b E}(j)}{r_{t-1}^{b E}(j)}-1\right)^{2} r_{t}^{b E} b_{t}^{E}\right]
\end{aligned}
$$

subject to the loan demand schedule in equation (A.2.17) and the balance sheet constraint of the loan branch

$$
B_{t}(j)=b_{t}^{E}(j)+b_{t}^{I}(j)
$$

As we impose a symmetric equilibrium condition, we obtain a unique pricing equation for mortgage and corporate loans, $s=\{I, E\}$ :

$$
\epsilon_{t}^{b s} \frac{1+R_{t}^{b}}{r_{t}^{b s}}-\kappa_{b s}\left(\frac{r_{t}^{b s}}{r_{t-1}^{b s}}-1\right) \frac{r_{t}^{b s}}{r_{t-1}^{b s}}+\beta_{p} E_{t}\left\{\frac{\lambda_{t+1}^{P}}{\lambda_{t}^{P}} \kappa_{d}\left(1-\epsilon_{t}^{b s}-\frac{\epsilon_{t}^{b s}}{r_{t}^{b s}}\right)+\kappa_{b s}\left(\frac{r_{t+1}^{b s}}{r_{t}^{b s}}-1\right)\left(\frac{r_{t+1}^{b s}}{r_{t}^{b s}}\right)^{2} \frac{b_{t+1}^{s}}{b_{t}^{s}}\right\}=0
$$


Deposit branch Deposit branches operate in a similar way compared to retail branches, collecting deposits from households at rate $r_{t}^{d}$ and selling them to the wholesale branch at rate $r_{t}$.

Deposit branches solve the following program:

$$
\max _{\left\{r_{t}^{d}(j)\right\}} \mathbb{E}_{0} \sum_{t=0}^{\infty} \Lambda_{0, t}^{P}\left[r_{t} D_{t}(j)-r_{t}^{d}(j) d_{t}(j)-\frac{\kappa_{d}}{2}\left(\frac{r_{t}^{d}(j)}{r_{t-1}^{d}(j)}-1\right)^{2} r_{t}^{d} d_{t}\right]
$$

subject to the deposit schedule of equation (A.2.17) and the balance sheet constraint $D_{t}(j)=d_{t}(j)$. In a symmetric equilibrium we find a pricing equation for the deposits:

$$
-1+\epsilon_{t}^{d}-\epsilon_{t}^{d} \frac{r_{t}}{r_{t}^{d}}-\kappa_{d}\left(\frac{r_{t}^{d}}{r_{t-1}^{d}}-1\right) \frac{r_{t}^{d}}{r_{t-1}^{d}}+\beta_{p} E_{t}\left\{\frac{\lambda_{t+1}^{P}}{\lambda_{t}^{P}} \kappa_{d}\left(\frac{r_{t+1}^{d}}{r_{t}^{d}}-1\right)\left(\frac{r_{t+1}^{d}}{r_{t}^{d}}\right)^{2} \frac{d_{t+1}}{d_{t}}\right\}=0
$$

With no adjustment costs, the pricing equations boil down to:

$$
r_{t}^{b s}=\frac{\epsilon_{t}^{b s}}{\epsilon_{t}^{b s}-1} R_{t}^{b s} \quad r_{t}^{d}=\frac{\epsilon_{t}^{d}}{\epsilon_{t}^{d}-1} r_{t}
$$

In such a setup interest rates on loans or deposits are simply set as markup over the marginal cost.

Finally, the consolidated real profits of banks $J_{t}^{b}$ (with $J_{t}^{b}>0$ to ensure the participation of the bank) are defined as the sum of net earnings from the retail branches and the wholesale branch.

\section{A.2.1.3 Rest of the economy}

Central bank. Monetary policy is introduced via a standard Taylor rule which sets the interest rate $r_{t}$ on the interbank market:

$$
1+r_{t}=(1+r)^{\left(1-\phi_{r}\right)}\left(1+r_{t-1}\right)^{\phi_{r}}\left(\frac{\pi_{t}}{\pi}\right)^{\phi_{\pi}\left(1-\phi_{r}\right)}\left(\frac{y_{t}}{y_{t-1}}\right)^{\phi_{y}\left(1-\phi_{r}\right)} \exp \left(\epsilon_{t}^{m}\right)
$$

where $\epsilon_{t}^{m}$ is a white noise for the monetary policy shocks.

Labour unions. Individual workers provide slightly differentiated labor types $m$, so that it has to be aggregated, say by perfectly competitive labour unions, respectively for patient and impatient households $s=\{P, I\}$. Labour unions set the nominal wage $W(m)$ of each individual worker by maximising the utility derived by labor income versus the cost of effort subject to adjustment costs and price stickiness:

$$
\max _{\left\{W_{t}^{s}(m)\right\}} \mathbb{E}_{0} \sum_{t=0}^{\infty} \beta_{s}^{t}\left\{U_{C_{t}^{s}(m)}\left[\frac{W_{t}^{s}(m)}{P_{t}} l_{t}^{s}(m)-\frac{\kappa_{w}}{2}\left(\frac{W_{t}^{s}(m)}{W_{t-1}^{s}(m)}-\pi_{t-1}^{\iota w} \pi^{1-\iota_{w}}\right)^{2} \frac{W_{t}^{s}}{P_{t}}\right]-\frac{l_{t}^{s}(m)^{1+\phi}}{1-\phi}\right\}
$$


where the real wage is given by $w_{t}^{s}=\frac{W_{t}^{s}}{P_{t}}$ and wage inflation $\pi_{t}^{w s}=\frac{w_{t}^{s}}{w_{t-1}^{s}} \pi_{t}$. The standard downward-sloping demand function from labour unions is:

$$
l_{t}^{s}(m)=\left(\frac{W_{t}^{s}(m)}{W_{t}^{s}}\right)^{-\epsilon_{t}^{l}} l_{t}^{s}
$$

Thus, the symmetric equilibrium leads to the following hybrid wage Phillips curve:

$$
\kappa_{w}\left(\pi_{t}^{w s}-\pi_{t-1}^{\iota w} \pi^{1-\iota_{w}}\right) \pi_{t}^{w i}=\beta_{s} \frac{\lambda_{t+1}^{s}}{\lambda_{t}^{s}} \kappa_{w}\left(\pi_{t+1}^{w s}-\pi_{t}^{\iota_{w}} \pi^{1-\iota_{w}}\right) \frac{\left(\pi_{t+1}^{w s}\right)^{2}}{\pi_{t+1}}+\left(1-\epsilon_{t}^{l}\right) l_{t}^{s}+\epsilon_{t}^{l} \frac{\left(l_{t}^{s}\right)^{(1+\phi)}}{w_{t}^{s} \lambda_{t}^{s}}
$$

Goods retailers. Goods retailers, owned by patient households, are monopolistically competitive and just buy the wholesale good produced by the entrepreneurs at price $P_{t}^{W}$ before selling slightly differentiated products at price $P_{t}$. The demand for final goods is aggregated in the same vein as deposits or loan demands $y_{t}(j)=\left(\frac{P_{t}(j)}{P_{t}}\right)^{-\epsilon_{t}^{y}} y_{t}$. Retail prices depend on a sticky inflation index parametrized by $l_{p}$ and are subject to Rotemberg-type quadratic adjustement cost $\kappa_{p}$ to adjust beyond the price index. Each good retailer chooses $P_{t}(j)$ in order to maximise its profits $J_{t}^{R}(j)$, and the aggregate profits in real terms is obtained after recognising that they have a mass one:

$$
J_{t}^{R}=\frac{1}{P_{t}}\left[P_{t} y_{t}-P_{t}^{W} y_{t}-P_{t} y_{t} \frac{\kappa_{p}}{2}\left(\frac{P_{t}}{P_{t-1}}-\pi_{t-1}^{\iota_{p}} \pi^{\left(1-\iota_{p}\right)}\right)^{2}\right]
$$

Capital goods producers. Capital goods producers buy undepreciated capital left after the production and replenish those capital units by investing $I_{t}^{k}$ and transforming new consumption goods subject to adjustment costs into new productive capital sold back to entrepreneurs at the end of the period.

The intertemporal problem of capital goods producers, which are owneds by entrepreneurs, can be written as:

$$
\max _{\left\{q_{t}^{k}, I_{t}^{k}\right\}} \mathbb{E}_{0} \sum_{t=0}^{\infty} \Lambda_{0, t}^{E} P_{t}\left[q_{t}^{k} k_{t}-q_{t}^{k}\left(1-\delta^{k}\right) k_{t-1}-I_{t}^{k}\right]
$$

subject to the production technology

$$
k_{t}^{E}=\left(1-\delta^{k}\right) k_{t-1}^{E}+\left(1-\frac{\kappa_{i k}}{2}\left(\frac{\epsilon_{t}^{i k} I_{t}^{k}}{I_{t-1}^{k}}-1\right)^{2}\right) I_{t}^{k}
$$

where $\epsilon_{t}^{i k}$ is an exogenous disturbance to capital goods production. Capital goods producers redistribute per-period profits $J_{t}^{h}$ to the shareholders. 
Housing goods producers. In analogy to capital goods production, housing goods producers buy the undepreciated housing stock left after consumption and replenish those housing units by investing $I_{t}^{h}$ and transforming new consumption goods subject to adjustment costs into new dwellings sold back to households at the end of the period.

The intertemporal problem of housing goods producers, which are owned by patient households, can be written as:

$$
\max _{\left\{q_{t}^{h}, I_{t}^{h}\right\}} \mathbb{E}_{0} \sum_{t=0}^{\infty} \Lambda_{0, t}^{P} P_{t}\left[q_{t}^{h} h_{t}-q_{t}^{h}\left(1-\delta^{h}\right) h_{t-1}-I_{t}^{h}\right]
$$

subject to the production technology

$$
h_{t}=\left(1-\delta^{h}\right) h_{t-1}+\left(1-\frac{\kappa_{i h}}{2}\left(\frac{\epsilon_{t}^{i h} I_{t}^{h}}{I_{t-1}^{h}}-1\right)^{2}\right) I_{t}^{h}
$$

where $\epsilon_{t}^{i k}$ is an exogenous disturbance to production of new housing, and with, by market clearing, $h_{t}=$ $h_{t}^{P}+h_{t}^{I}$. Housing goods producers redistribute per-period profits $J_{t}^{h}$ to the owners.

Market clearing. The markets for labor, credit and consumption goods clear. It follows that combining the budget constraints of the three agents we find,

$$
y_{t}-\delta^{b} \frac{k_{t-1}^{b}}{\pi_{t}}-A d j_{t}^{R}-A d j_{t}^{b}=c_{t}+I_{t}^{h}+I_{t}^{k}
$$

where

$$
A d j_{t}^{R}=\frac{\kappa_{p}}{2} y_{t}\left(\pi_{t}-\pi_{t-1}^{\iota_{p}} \pi^{\left(1-\iota_{p}\right)}\right)^{2}
$$

are the resources lost in the production of retail goods and

$$
\begin{aligned}
A d j_{t}^{b}= & \frac{\kappa_{k b}}{2}\left(\frac{k_{t-1}^{b}}{B_{t-1}}-\nu_{t-1}\right)^{2} k_{t-1}^{b} \\
& +\frac{\kappa_{b I}}{2}\left(\frac{r_{t}^{b I}}{r_{t-1}^{b I}}-1\right)^{2} r_{t}^{b I} b_{t}^{I}-\frac{\kappa_{b E}}{2}\left(\frac{r_{t}^{b E}}{r_{t-1}^{b E}}-1\right)^{2} r_{t}^{b E} b_{t}^{E}-\frac{\kappa_{d}}{2}\left(\frac{r_{t}^{d}}{r_{t-1}^{d}}-1\right)^{2} r_{t}^{d} d_{t}+\epsilon_{t}^{k b}
\end{aligned}
$$

are the resources lost in banking activity. Output is consumed, invested (in either productive or housing capital), or lost in banking activity and in retail good production.

\section{A.2.2 Model solution and parametrization}

We use a linear approximation of the policy functions around the deterministic steady state to characterize the likelihood. We then estimate the model with Bayesian techniques. 


\section{A.2.2.1 Estimation on French data}

We calibrate the parameters that pin down the deterministic steady state of the model, while we estimate the remaining parameters that determine the equilibrium dynamics of the model, including the 10 exogenous state variables.

Data We use 10 quarterly time series of French data over the period 1993-2015. The observable time series that are matched to their theoretical counterparts are the year-on-year growth rates of GDP, CPI, residential house prices and stock market index, the Basel III credit-to-GDP gap, the 3-month Euribor, the interest rate on 3-month deposits and lending rates on mortgages and corporate loans, and asset-weighted aggregate bank total capital ratio. ${ }^{41}$

Arguably these variables constitute the minimal set of observables necessary to restrict the behavior of the model features we are directly interested in. In particular, spreads and the capital ratio provide information on the core transmission mechanism of the model of a change in the capital target ratio, while we also have information on the transmission of monetary policy to the macroeconomy as well as on the relation between credit and GDP, and between bank capital levels and the main macro-financial factors, including house and stock valuations. Our information set is quite different from the one used by Gerali et al. [2010] reflecting our focus on the transmission mechanism of a shock to the capital target.

Calibrated parameters The discount factor for patient households $\beta_{P}$ is set to 0.9943 , so the annualized steady-state interest rate $r_{d}$ equals the average rate on deposits in France. Both impatient and entrepreneurs' discount rates are set to 0.9975, in the range used in Iacoviello and Neri [2010]. The external habit parameters are set to a value close to 1 to generate sufficient volatility in model-implied stock prices without generating counterfactually large volatility in real variables such as GDP. The frictionless capital share of output $\alpha$ and capital and housing depreciation rates $\delta^{k}$ and $\delta^{h}$ are set respectively to 0.25 , 0.025 and 0.010. Values for price- and labor-elasticities $\epsilon^{y}$ and $\epsilon^{l}$ are set to 5 and 6 as we assume a markup of 20 percent in the good market and a markup of 15 percent in the labor market. We use a loan-to-value ratio for constrained households equal to 0.7, respectively, which corresponds to the mortgage evidence quoted by Gerali et al. [2010]. To calculate loan-to-value ratios of liquidity constrained entrepreneurs, we calculate the ratios of loans to the value of shares and other equities for non-financial corporation and find values of $0.23 .^{42}$

The labor input parameter for the Cobb-Douglas function $\mu$ is defined to 0.8 to replicate the labor income share of non-constrained households reported by Iacoviello and Neri [2010]. Parameters related to banking system are calibrated to match some stylized facts in our dataset. We compute the average monthly spreads using series for the deposit interest rates on loans to firms and households and the 3month Euribor. Since the deterministic steady-state equations give a direct relationship between moments of these time series and elasticities of substitution, we set accordingly $\epsilon^{d}, \epsilon^{b I}$ and $\epsilon^{b E}$. Finally, the cost of

\footnotetext{
${ }^{41}$ The aggregate bank capital ratio is available only at annual frequency and covers only a part of the sample. Estimation proceeds at quarterly frequency, with the missing data constituting additional degrees of freedom.

${ }^{42}$ We picked as the relevant rate the lending rate to firms with original rate fixation above one year.
} 
managing bank capital $\delta^{b}$ is set to 0.076 so as to obtain a long-run capital-to-loan ratio of $13.6 \%$, equal to the average, aggregate total capital ratio observed in France during the post-crisis period (2009-2014). ${ }^{43}$

Table 11 lists the calibrated parameters.

Table 11: Calibrated Parameters

\begin{tabular}{clc}
\hline Parameters & Description & Value \\
\hline$\beta_{P}$ & Patient households' discount factor & 0.9943 \\
$\beta_{I}$ & Impatient households' discount factor & 0.9750 \\
$\beta_{E}$ & Entrepreneurs' discount factor & 0.9750 \\
$\phi$ & Inverse Frisch elasticity & 1.0000 \\
$a^{P}$ & Patient households' habit parameter & 0.9000 \\
$a^{I}$ & Impatient households' habit parameter & 0.9000 \\
$a^{E}$ & Entrepreneurs' habit parameter & 0.9000 \\
$\epsilon^{h}$ & Steady-state weight on housing in preferences & 0.2000 \\
$m^{I}$ & Households' LTV ratio & 0.7000 \\
$m^{E}$ & Entrepreneurs' LTV ratio & 0.2300 \\
$\mu$ & Share of unconstrained households & 0.8000 \\
$\alpha$ & Capital elasticity in the production function & 0.2500 \\
$\delta^{k}$ & Depreciation rate of physical capital & 0.0250 \\
$\delta^{h}$ & Depreciation rate of housing stock & 0.0100 \\
$\delta^{b}$ & Costs for managing banks' capital position & 0.0760 \\
$\omega^{b}$ & Share of profits distributed to patient households (bankers) & 0.0000 \\
$\pi$ & Steady-state inflation rate & 1.0000 \\
$r$ & Steady-state interest rate & 0.0092 \\
$\frac{\epsilon^{y}}{\epsilon^{y}-1}$ & Steady-state markup in the goods market & 6.0000 \\
$\frac{\epsilon^{l}}{\epsilon^{-}-1}$ & Steady-state markup in the labor market & 5.0000 \\
$\frac{\epsilon^{b I}}{\epsilon^{b I}-1}$ & Steady state markup on rate on loans to households & 1.7900 \\
$\frac{\epsilon^{b E}}{\epsilon^{b E}-1}$ & Steady state markup on rate on loans to firms & 1.5500 \\
$\frac{\epsilon^{\frac{\epsilon}{\epsilon^{d}}}-1}{}$ & Steady state markdown on deposit rate & 0.6200 \\
\hline & &
\end{tabular}

Prior specification and posterior distributions. For most of the parameters we use standard prior distributions, mostly in line with estimated DSGE models for the Euro Area [e.g., Gerali et al., 2010, Darracq-Paries et al., 2011]. Prior distributions are reported in Table 12 along with the resulting posterior distribution of the structural parameters.

The rich parametrization of the model is able to match reasonably well the dynamic autocovariance matrices of the vector of observables. Table 13 shows the ability of the model to reproduce the unconditional volatilities of the observable time series. Figure 12 shows the full set of dynamic correlations to gauge the

\footnotetext{
${ }^{43}$ We consider the average ratio in the post-crisis period, as the recent crisis prompted a change in regulation that can be interpreted as a regime-switch in the long-run capitalisation level of banks.
} 
Table 12: Parameter Estimates

\begin{tabular}{|c|c|c|c|c|c|c|}
\hline & prior mean & post. mode & st.dev. & $90 \%$ prob. interval & prior distr. & prior st.dev. \\
\hline$\kappa_{p}$ & 50.000 & 48.6528 & 10.0379 & {$[23.347,50.934]$} & gamma & 10.0000 \\
\hline$\kappa_{w}$ & 25.000 & 34.2868 & 9.6574 & {$[32.218,72.000]$} & gamma & 10.0000 \\
\hline$\kappa_{i k}$ & 5.000 & 7.9490 & 1.9793 & {$[5.2565,11.832]$} & gamma & 3.0000 \\
\hline$\kappa_{i h}$ & 5.000 & 2.1640 & 0.3154 & {$[1.7379,2.7957]$} & gamma & 3.0000 \\
\hline$\kappa_{d}$ & 5.000 & 0.6357 & 0.3441 & {$[0.2687,2.2006]$} & gamma & 2.0000 \\
\hline$\kappa_{b E}$ & 5.000 & 4.1129 & 1.3385 & {$[2.8339,7.5108]$} & gamma & 2.0000 \\
\hline$\kappa_{b I}$ & 5.000 & 3.2689 & 1.0367 & {$[2.2653,5.3162]$} & gamma & 2.0000 \\
\hline$\kappa_{k b}$ & 15.000 & 9.1223 & 2.0046 & {$[6.4908,13.076]$} & gamma & 3.0000 \\
\hline$\phi_{\pi}$ & 2.000 & 2.1951 & 0.1129 & {$[2.0367,2.3951]$} & gamma & 0.1000 \\
\hline$\phi_{y}$ & 0.000 & 0.6260 & 0.1234 & {$[0.4551,0.8506]$} & norm & 0.2250 \\
\hline$\phi_{r}$ & 0.500 & 0.8461 & 0.0176 & {$[0.8208,0.8731]$} & beta & 0.1500 \\
\hline$\iota_{p}$ & 0.500 & 0.0323 & 0.0377 & {$[0.0064,0.1395]$} & beta & 0.2250 \\
\hline$\iota_{w}$ & 0.500 & 0.2795 & 0.3208 & {$[0.0261,0.6234]$} & beta & 0.2250 \\
\hline$\rho_{z}$ & 0.500 & 0.7583 & 0.0846 & {$[0.5987,0.8628]$} & beta & 0.1500 \\
\hline$\rho_{a}$ & 0.500 & 0.9286 & 0.0211 & {$[0.8965,0.9593]$} & beta & 0.1500 \\
\hline$\rho_{h}$ & 0.500 & 0.4237 & 0.0431 & {$[0.3674,0.4877]$} & beta & 0.1500 \\
\hline$\rho_{d}$ & 0.500 & 0.7590 & 0.0482 & {$[0.5551,0.8107]$} & beta & 0.1500 \\
\hline$\rho_{b i}$ & 0.500 & 0.4949 & 0.1718 & {$[0.2929,0.8415]$} & beta & 0.1500 \\
\hline$\rho_{b e}$ & 0.500 & 0.7766 & 0.0610 & {$[0.6419,0.8538]$} & beta & 0.1500 \\
\hline$\rho_{k}$ & 0.500 & 0.6605 & 0.0691 & {$[0.5409,0.7587]$} & beta & 0.1500 \\
\hline$\rho_{i k}$ & 0.500 & 0.7872 & 0.0537 & {$[0.6625,0.8585]$} & beta & 0.1500 \\
\hline$\rho_{i h}$ & 0.500 & 0.9989 & 0.0006 & {$[0.9977,0.9996]$} & beta & 0.1500 \\
\hline$\rho_{n u}$ & 0.500 & 0.8868 & 0.0380 & {$[0.8169,0.9366]$} & beta & 0.1500 \\
\hline$\sigma_{z}$ & 0.030 & 0.0450 & 0.0071 & {$[0.0365,0.0603]$} & invg2 & Inf \\
\hline$\sigma_{a}$ & 0.030 & 0.0119 & 0.0015 & {$[0.0089,0.0136]$} & invg2 & Inf \\
\hline$\sigma_{h}$ & 0.030 & 0.8537 & 0.0934 & {$[0.7022,0.9814]$} & invg2 & Inf \\
\hline$\sigma_{d}$ & 0.030 & 0.1054 & 0.0168 & {$[0.0883,0.1616]$} & invg2 & Inf \\
\hline$\sigma_{b i}$ & 0.030 & 0.1007 & 0.0182 & {$[0.0898,0.1634]$} & invg2 & $\operatorname{Inf}$ \\
\hline$\sigma_{b e}$ & 0.030 & 0.0093 & 0.0049 & {$[0.0046,0.0226]$} & invg2 & $\operatorname{Inf}$ \\
\hline$\sigma_{k}$ & 0.030 & 0.0144 & 0.0013 & {$[0.0129,0.0175]$} & invg2 & $\operatorname{Inf}$ \\
\hline$\sigma_{i k}$ & 0.030 & 0.0256 & 0.0049 & {$[0.0182,0.0309]$} & invg2 & $\operatorname{Inf}$ \\
\hline$\sigma_{i h}$ & 0.030 & 2.0552 & 0.3175 & {$[1.2248,2.3191]$} & invg2 & Inf \\
\hline$\sigma_{n u}$ & 0.030 & 0.0083 & 0.0015 & {$[0.0068,0.0120]$} & invg2 & $\operatorname{Inf}$ \\
\hline$\sigma_{m}$ & 0.030 & 0.0014 & 0.0001 & {$[0.0012,0.0017]$} & invg2 & $\operatorname{Inf}$ \\
\hline
\end{tabular}


ability of the model to capture the Wold representation of the observed time series, thereby clarifying all dimensions along which the model is likely to have counterfactual implications.

Table 13: Unconditional standard deviations

\begin{tabular}{|c|c|c|c|}
\hline Observable & Model st.dev. & Data st.dev. mean & [90\% confidence interval] \\
\hline GDP yoy growth & $0.59 \%$ & $0.40 \%$ & {$[0.35 \% ; 0.47 \%]$} \\
\hline Credit-to-GDP gap & $4.92 \%$ & $5.31 \%$ & {$[4.65 \% ; 6.28 \%]$} \\
\hline CPI yoy inflation rate & $0.45 \%$ & $0.19 \%$ & {$[0.17 \% ; 0.23 \%]$} \\
\hline 3 -month interest rate & $0.52 \%$ & $0.25 \%$ & {$[0.22 \% ; 0.30 \%]$} \\
\hline Lending spread (mortgages) & $0.38 \%$ & $0.19 \%$ & {$[0.16 \% ; 0.23 \%]$} \\
\hline Lending spread (corporates) & $0.36 \%$ & $0.15 \%$ & {$[0.13 \% ; 0.18 \%]$} \\
\hline Deposit spread & $0.27 \%$ & $0.26 \%$ & {$[0.22 \% ; 0.31 \%]$} \\
\hline House price yoy growth & $2.07 \%$ & $1.87 \%$ & {$[1.63 \% ; 2.20 \%]$} \\
\hline Stock price yoy growth & $11.48 \%$ & $5.78 \%$ & {$[5.07 \% ; 6.83 \%]$} \\
\hline Capital ratio & $2.19 \%$ & $2.63 \%$ & {$[1.99 \% ; 4.29 \%]$} \\
\hline
\end{tabular}

Table 14 reports the approximate variance decomposition of the main macro-financial variables of the model. As in Gerali et al. [2010], technology shocks are the most important driver of economic activity. Credit is driven in particular by shocks to households' appetite for housing as well as by housing investment shocks, which are key to generate the observed negative correlation (contemporaneous as well as at up to one year leads and lags) between GDP and the credit-to-GDP gap. Shocks to productive capital investment are the main drivers of stock prices, while financial shocks (including own shocks to bank capital and shocks to the capital target) drive primarily the lending spreads. Deposit spreads are driven strongly by technology shocks beside by movements in the deposit demand curve. Movements in mortgage loan demand play virtually no role; this limited role they play can in part be attributed to the absence of an empirical counterpart to the intra-bank lending spread, which could provide more information to identify loan demand shocks.

\section{A.2.3 Macroprudential policy experiments}

After having estimated the role of financial shocks in shaping the business cycle (table 14), we are now able to set the estimated parameters at their posterior mode to conduct counterfactual policy analysis and to study two main questions related to the macroeconomic effect of shocks originating in the banking system: i) the impact on the macroeconomy of an unanticipated increase in bank capital requirements; and ii) the effect of the introduction of a capital buffer rule on the credit and output cycles conditional on the main macroeconomic shocks that drove the endogenous variables historically.

Unexpected (permanent) increase in regulatory capital ratios When deriving the response of the economy to shocks, it is important to remind the reader that our solution method based on the linearization of the model around the deterministic steady state precludes the study of some phenomena 

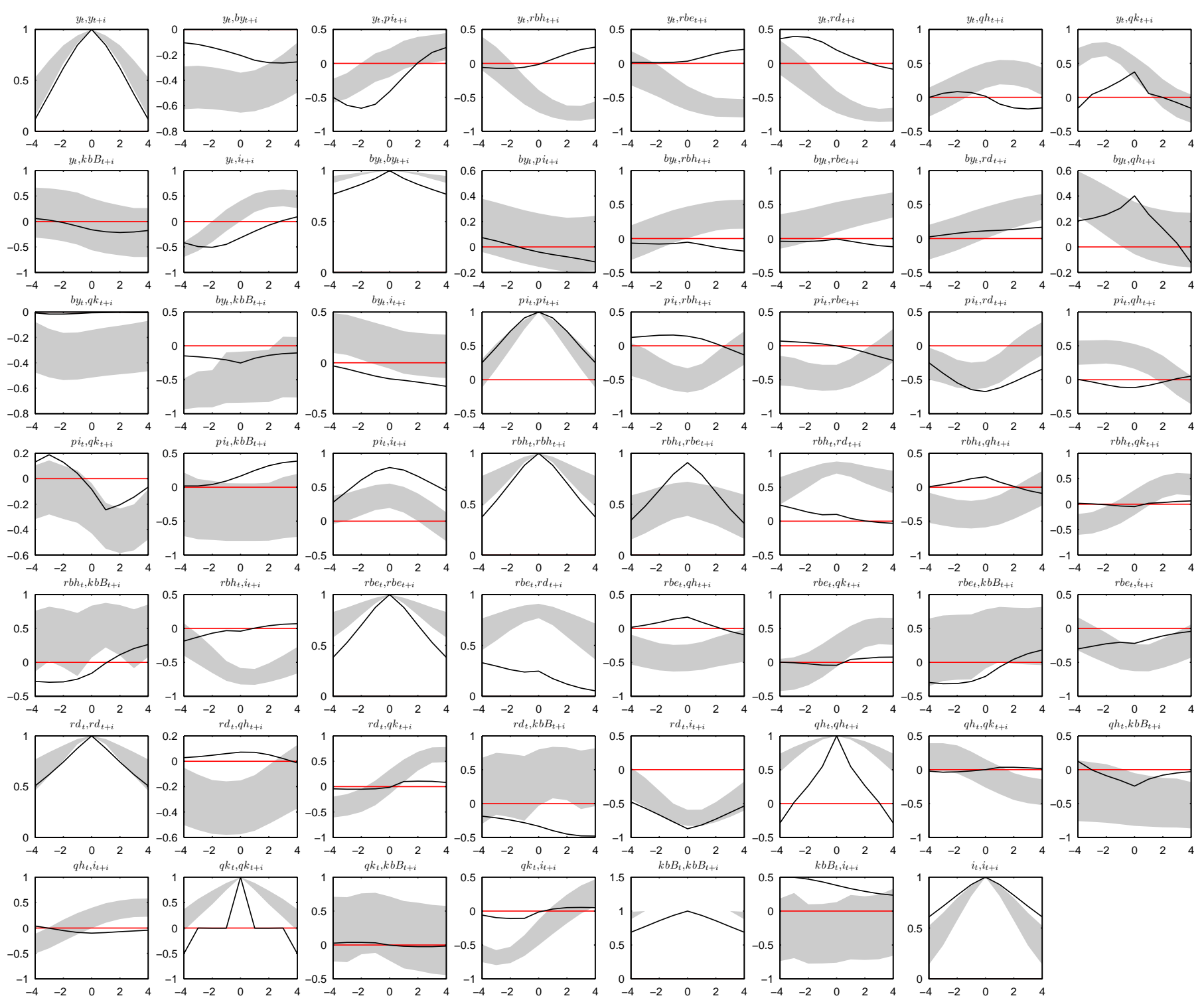

Figure 12: Dynamic cross-correlations of the observable variables: empirical $90 \%$ confidence intervals (shaded areas) and model-implied mode (solid black lines). 

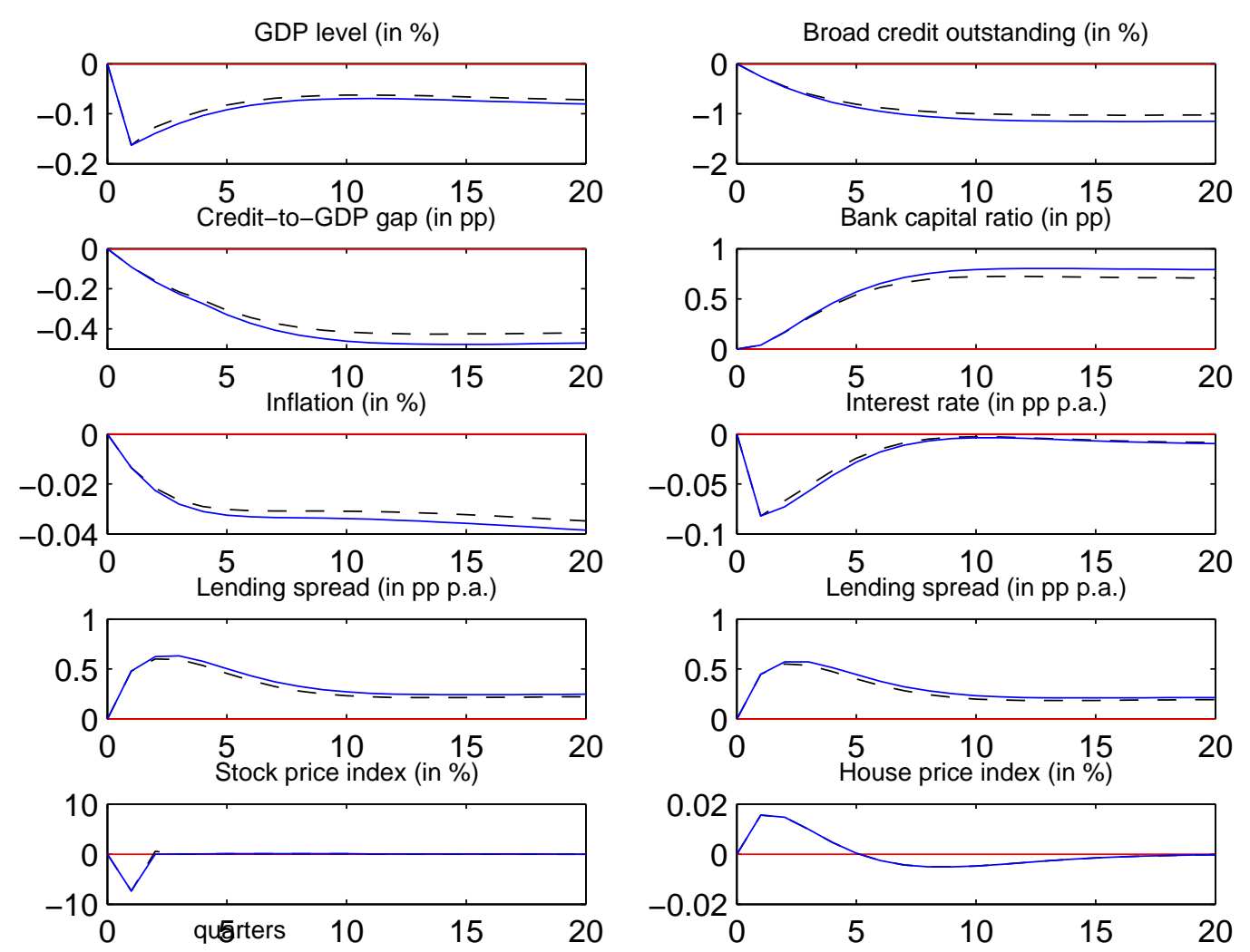

Figure 13: Reaction of the main variables to a 100bp permanent increase in regulatory capital ratio target; dashed lines represent counterfactual responses in the presence of a $\mathrm{CCyB}$ (slope of reaction to the broad credit gap $\left.\phi_{\nu}=.25\right)$. Impulse responses are computed using a parametrization at the posterior mode. 

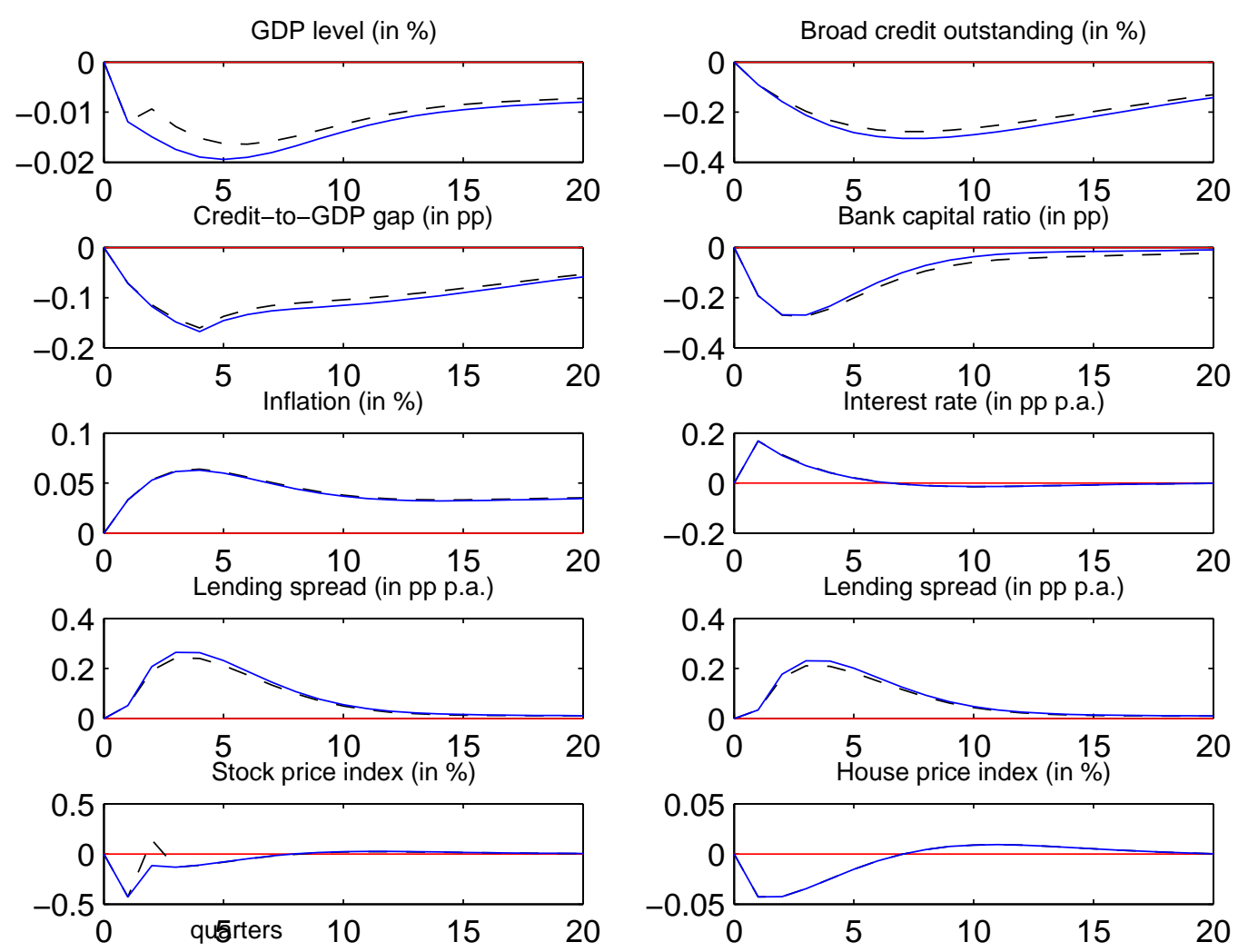

Figure 14: Reaction of the main variables to a 1-s.d. unexpected loss suffered by the banking system; dashed lines represent counterfactual responses in the presence of a CCyB (slope of reaction to the broad credit gap $\phi_{\nu}=.25$ ). Impulse responses are computed using a parametrization at the posterior mode. 
Table 14: Variance decomposition

\begin{tabular}{lrrrrrrrrrrr}
\hline variance decomp. & $\epsilon^{z}$ & $\epsilon^{a}$ & $\epsilon^{h}$ & $\epsilon^{d}$ & $\epsilon^{b E}$ & $\epsilon^{b I}$ & $\epsilon^{k}$ & $\epsilon^{\nu}$ & $\epsilon^{m}$ & $\epsilon^{i k}$ & $\epsilon^{i h}$ \\
\hline GDP yoy growth & 7.64 & 49.20 & 8.25 & 1.44 & 0.20 & 0.00 & 4.91 & 1.21 & 5.83 & 13.54 & 7.77 \\
credit gap & 5.61 & 3.02 & 30.19 & 0.16 & 0.16 & 0.00 & 1.04 & 1.65 & 0.58 & 1.57 & 56.02 \\
CPI infl. & 5.15 & 59.33 & 5.16 & 3.21 & 0.06 & 0.00 & 0.42 & 0.08 & 13.53 & 0.60 & 12.46 \\
3-month rate & 13.30 & 31.39 & 5.51 & 5.80 & 0.11 & 0.00 & 1.09 & 0.24 & 4.39 & 2.14 & 36.02 \\
mortgage spread & 1.39 & 4.80 & 6.72 & 5.52 & 1.78 & 0.01 & 14.12 & 50.01 & 3.44 & 1.11 & 11.11 \\
corporate spread & 2.04 & 4.42 & 5.32 & 6.28 & 8.65 & 0.00 & 11.68 & 45.83 & 3.82 & 1.04 & 10.91 \\
deposit spread & 7.47 & 19.05 & 3.02 & 44.39 & 0.07 & 0.00 & 0.88 & 0.17 & 3.98 & 1.76 & 19.22 \\
house price & 0.26 & 1.71 & 59.10 & 0.31 & 0.00 & 0.00 & 0.02 & 0.00 & 0.56 & 0.01 & 38.04 \\
stock price & 0.01 & 2.68 & 0.02 & 1.01 & 0.73 & 0.00 & 0.02 & 3.48 & 8.42 & 83.26 & 0.37 \\
bank capital ratio & 4.95 & 6.11 & 5.27 & 6.51 & 0.56 & 0.00 & 6.51 & 45.51 & 0.87 & 0.31 & 23.41 \\
\hline
\end{tabular}

of interest, including asymmetric responses to shocks, precautionary behavior, the occasionally-binding nature of some constraints such as the zero lower bound and LTV constraints, and convergence properties away from the steady state. Similarly, this observation will be relevant in our subsequent counterfactual analysis of cyclical macroprudential policies, as our characterization of the model solution is unable to uncover potentially asymmetric effects or the effects of policies in abnormal states of nature.

Figure 13 describes the impact of a 100bp-increase in the target capital buffer faced by the banking system. We assume the target increase to be permanent, akin to a permanently higher macroprudential tightening not anticipated by the economy.

Output and inflation fall on impact before picking up and stabilizing to the new steady state that associates with the higher capital target, in which economic activity is permanently depressed by about $0.1 \%$. Credit drops by about $1 \%$ and sticks to this lower level in the long run. Capital on the other hand adjusts slowly to the higher target and reaches its new steady state level after about two years. The pass-through of the higher target level to the capital ratio is imperfect as it is transferred in part on higher intra-bank lending spreads. Retail lending spreads widen as banks look more aggressively for profits in order to move to a higher leverage ratio, and similarly settle to a permanently higher long-run level.

Systematic macroprudential reaction to credit developments In our model, the target capital level determines the spread between borrowing and lending rates,

$$
r_{t}^{b}-r_{t}=-\kappa\left(\frac{K_{t}}{B_{t}}-\nu_{t}\right) \frac{K_{t}^{2}}{B_{t}^{2}}
$$

through its effect on the capital adjustment cost function of the bank. The movements in the implicit leverage target picked up in estimation are most likely a mixture of market and regulatory bank leverage requirements, depending on whichever of the two turned out to bind more on any given period; arguably, moreover, most high frequency movements cannot be attributed to non-cyclical changes in microprudential requirements, as the available sample predates the introduction of dynamic capital requirements. Con- 
sistent with our modeled structure, we nonetheless rely on the estimated reaction to a movement in the capital target as a description of the reaction to a dynamic change in regulatory capital requirements. In the benchmark case, bank capital requirements are a constant, up to an exogenous disturbance, $\epsilon_{t}^{\nu} \sim A R(1)$, $\nu_{t}=\nu+\epsilon_{t}^{\nu}$, which is pinned down by the steady-state level of the spread. Conversely, once we include a $\mathrm{CCyB}$, bank capital requirements are allowed to vary in a systematic fashion.

The adoption of a quasi-structural form of bank capital adjustment costs is reasonably standard in the literature [e.g., Curdia and Woodford, 2009, 2010, Gerali et al., 2010, Darracq-Paries et al., 2011, Jermann and Quadrini, 2012, Woodford, 2012, Justiniano et al., 2014, Suh, 2014] and Angelini et al. [2014] even use it normatively. However, the absence of an explicit microfoundation for the adjustment cost function implies that its use for normative purposes must be taken with caution. For this reason we limit its use to describe the effects of a particular $\mathrm{CCyB}$ rule but we refrain from using the model to rank alternative $\mathrm{CCyB}$ rules. We therefore turn to a simple and arguably policy-relevant specification for a systematic $\mathrm{CCyB}$ rule [BCBS, 2010b], and rely on the credit-to-GDP gap as an indicator for the activation/deactivation of the $\mathrm{CCyB}$ :

$$
\nu_{t}=\nu+\phi_{\nu}\left(\frac{b_{t}^{I}+b_{t}^{E}}{\sum_{j=0}^{3} y_{t-j}}-\frac{b^{I}+b^{E}}{4 y}\right)+\epsilon_{t}^{\nu}
$$

with $b^{I}+b^{E}$ and $y$ being respectively credit and output at the deterministic steady state.

By construction, our $\mathrm{CCyB}$ is not exactly identical to the instrument envisaged on paper [BCBS, 2010b]. First, we implement a CCyB without lower and upper bounds. Nevertheless, to get magnitudes consistent with the actual CCyB, for equation (A.2.35) we choose $\phi_{\nu}=0.25$, that is to say a deviation of the credit-to-GDP gap of $10 \%$ from its long-term trend is associated to 2.5 percentage points of additional capital. Second, the rule is symmetric so that the CCyB can be negative. However, this version of the $\mathrm{CCyB}$ is the closest to the prudential rules set by the regulator.

In this context, figures 13 and 14 include a counterfactual analysis describing the reaction of the economy after a shock to bank capital in the presence of a rule for the CCyB characterized by equation (A.2.35). In the case of these financial shocks that originate in the banking sector the effect of the different shocks on credit is generally dampened by the $\mathrm{CCyB}$ rule, in line with the declared objective. In the case of the permanent increase in the capital target, the economy eventually converges to the higher capital target but does so with smoother transitional dynamics. The dampening effect of the CCyB is quite limited, in particular due to the estimated small adjustment cost parameter $\kappa_{k b}$, which controls primarily the transmission mechanism of macroprudential policy.

\section{Annex 3 DSGE models comparison}

The GNSSFr builds on a framework originally proposed by Gerali, Neri, Sessa, and Signoretti [2010]. The 3D model builds on a framework originally proposed by [Clerc, Derviz, Mendicino, Moyen, Nikolov, Stracca, Suarez, and Vardoulakis, 2015]. We estimate both models on French macroeconomic data to focus on the following question: What is the impact on the macroeconomy of an unanticipated increase in bank capital 
requirements and, given the limited past experience with macroprudential policies, how can we build counterfactual aggregate dynamics of the economy in the presence of systematic rules driving dynamic capital requirements? In this context, dynamic stochastic general equilibrium models that incorporate a banking sector and time-varying prudential capital requirements are natural measurement tools to answer the quantitative questions at hand.

Similar to Angelini et al. [2014], Mendicino et al. [2016], we augment the models by including a countercyclical capital buffer $(\mathrm{CCyB})$ as a way to assess what its dynamic effects would be and their role in optimizing a policy objective criterion. By carrying out this exercise in a DSGE framework we circumvent the major difficulty of assessing the potential effectiveness of macroprudential tools via a reduced-form approach, given the lack of data and experience in applying these policies. Moreover, the GNSSFr coincidentally allows for gauging the relationship between macroprudential and monetary policies, and explicitly accounts for a monopolistic structure of the banking sector, which seems appropriate to describe the French case; whereas then 3D model is a real model that explicitly models defaults.

Table 15 sketches a comparison of the two structural models.

Table 15: Comparative table of two available DSGEs

\begin{tabular}{ll}
\hline 3D & GNSSFr \\
\hline Real model & Nominal model \\
Instantaneous adjustment to required capital ratio & Accounts for implementation lags \\
Long-run benefits to macroprudential intervention & No long-run benefits to macroprudential intervention \\
Long-run costs to macroprudential intervention & Long-run costs to macroprudential intervention \\
Captures limited amount of dynamic correlations & Captures several dynamic correlations \\
Models default probabilities & No default \\
\hline
\end{tabular}

\section{Annex 4 Stress-testing tool}

This annex describes our top-down stress testing tool that aims at calibrating macro-prudential instruments building on Henry and Kok [Eds.] and [Alessandri et al., 2009]. Top-down stress testing tools measure the impact of macro-financial shocks on individual and system-wide capital ratios. Macro stress tests aim at identifying vulnerabilities to specific macroeconomic shocks and quantify these vulnerabilities before the adverse events materialize.

The quantitative framework consists of several buiding blocks. Figure 4 represents the macro stress testing module graphically. The first stage designs the macroeconomic scenario as described in section 3 .

Second, we estimate satellite predictive models that connect the projected macroeconomic and financial variables with other financial variables that are directly relevant to model the balance sheet of banks (e.g., the probability of default on the different loan categories, the interest rate on distinct deposit and lending categories at different maturities, the return on net trading assets). Satellite models rely on a Bayesian Model Averaging estimation method (BACE) [see Sala-i Martin et al., 2004, Henry and Kok , Eds.]. We 
can thus use the projections from the VAR model to develop a forecast for credit and market risks over the stress test horizon.

Third, forecasts from stage two are used to model projections for core tier 1 equity (CET1) and riskweighted assets (RWA) for six major French credit institution. To make sure that the distress is systemic rather than concentrated on a single bank we aggregate individual bank capital ratios before comparing them with a predefined threshold and derive a capital shortfall of the banking sector as a whole (see section 4.3).

Fourth, we use the potential capital shortfall as an indication for calibration of the $\mathrm{CCyB}$ and revise the scenario to include the contractionary effect of such an activation of additional capital requirements. In case the stress test exercise is used in the context of the hybrid approach, we then use the new scenario to update the prescribed calibration, and repeat the process until convergence.

To estimate the stress testing module we rely on several data sources, including aggregate macroeconomic and financial variables (INSEE, SNL), credit risk variables (such as realized corporate default frequency and returns on different lending and deposit classes from EBA stress test) and market risk variables (Bloomberg).

\section{A.4.1 Macroeconomic scenario design}

Step one builds a macroeconomic adverse scenario by projecting aggregate French variables over a twelvemonth horizon as described in section 3.

Following Henry and Kok [Eds.], these aggregate dynamics may include a projection for aggregate bank credit, which will form the basis to model dynamics in individual banks' balance sheets-aggregate and individual credit dynamics will thus be reconciled.

\section{A.4.2 Satellite models}

Macroeconomic aggregates modeled in step one must be linked to credit and market risk variables in order to estimate the impact of a given macroeconomic scenario on the banking system. Satellite models allow us to connect projections from the economic scenario to variables affecting balance sheets.

We model credit risk for four assets classes: lending to corporates, SMEs, mortgages and consumers. Two time series are estimated for each asset class: the spread between interest rates and 3-month Euribor rates and the probability of default (PD).$^{44}$ Moreover, we also model the cost of deposits for three different maturities - overnight, three-month and one-year - by relying on the asset valuation model proposed by

\footnotetext{
${ }^{44}$ Our proxies for PDs and losses given default (LGDs) are constructed as follows: we use realized corporate default rates (available publicly in France for non-financial firms since 2006, monthly) and we assume constant LGDs (e.g., as in Alessandri et al., 2009). Then, given the average risk weight for each asset class under the standard approach, LGDs and PD of nonfinancial corporates, we build PDs of consumer and mortgage loans and on SMEs using the F-IRB formula (BIS Internal Ratings-Based). The underlying assumption we make is that the risk-weight under F-IRB and the standard approach are consistent; also, we choose the remaining degree of freedom in the IRF formula for corporate PD - maturity-so that F-IRB corporate $\mathrm{PD}$ equals the average realized corporate default rate (such a calibrated maturity turns out to be of one year). Finally, the PD of sovereigns is proxied by estimates of CDS-implied PDs provided by Deutsche Bank Research.
} 
Drehmann et al. [2010] (see also Alessandri et al., 2009). Repricing of deposits with a maturity exceeding one year (five or ten years) do not need to be modeled in the stress-testing exercise as they do not mature during the stress test period.

The estimation method relies on a BACE approach applied to each satellite model using combinations of five regressors and four lags. ${ }^{45}$ Regressors were chosen among the variables included in the VAR model. Since BACE has an exponential complexity, adding lags to the model is time consuming. We choose a four-lag structure at a monthly frequency as it appears to be a good compromise between complexity and econometric requirements. We assume interest rates and probabilities of default to be stationary, in line with economic theory (e.g., the structural models in Annex 1 and Annex 2). Five regressors are chosen to model each dependent variable: 3-month Euribor rate $\left(i_{t}\right)$, 10-year to 3-month government bond spread $\left(i_{10, t}-i_{t}\right)$, CPI price inflation $\left(\Delta p_{t}\right)$, and the stationary dividend-price ratio $\left(d p_{t}\right)$ and dividend-output $\left(d y_{t}\right)$ ratios. Satellite models are estimated using monthly data from 2000m01 to $2015 \mathrm{~m} 12$.

We denote by $S_{t}$ the spreads between interest rates and 3-month Euribor (available from the ECB's Monetary Financial Institution Data) and $P D_{t}$ the probabilities of default for each asset class:

$$
S_{t}=\left[\begin{array}{c}
i_{s m e, t}-i_{t} \\
i_{\text {mort }, t}-i_{t} \\
i_{\text {cons }, t}-i_{t} \\
i_{\text {corp }, t}-i_{t}
\end{array}\right], \quad P D_{t}=\left[\begin{array}{l}
p d_{\text {sme }, t} \\
p d_{\text {mort }, t} \\
p d_{\text {cons }, t} \\
p d_{\text {cor }, t}
\end{array}\right]
$$

And by $D e p_{t}$ the deposit rate spreads for the three different maturities:

$$
\operatorname{Dep}_{t}=\left[\begin{array}{c}
i_{o n, t}-i_{t} \\
i_{3 m, t}-i_{t} \\
i_{1 y, t}-i_{t}
\end{array}\right]
$$

Let $y_{t}$ be a component of $S_{t}, P D_{t}$ or $D e p_{t}$. Then, we can write the relation linking $y_{t}$ to its regressors as:

$$
y_{t}=\sum_{i=1}^{4}\left(\alpha_{i} y_{t-i}+\beta_{i}^{\prime} X_{t-i}\right)+c+\epsilon_{t}
$$

where $X_{t}$ is a vector of 5 regressors out of the variables in the information set described in section $3, \epsilon_{t}$ is a white noise error term and $c$ is a constant.

Finally, to model returns on assets not held at historical value (broadly, the trading book), one approach is to model directly growth in net trading asset [e.g., Alessandri et al., 2009]. Due to scant available data on net trading assets along the time dimension we complement this approach with information from banks' stock valuations. In particular, we make the assumption that movements in the banks' stock valuations

\footnotetext{
${ }^{45}$ Frequencies between step one and step two may differ. In our application, VAR projections are at a quarterly frequency whereas the satellite models use monthly data. We linearly interpolate quarterly forecasts from step one to feed satellite models at a monthly frequency. Accordingly, losses and solvency ratios will be calculated on a monthly basis. Bayesian priors are set according to the following formula: $\mathbb{P}\left(M_{i} \mid Y, X\right)=\frac{\mathbb{P}\left(M_{i}\right) T^{-k_{i} / 2} S S E_{i}^{-T / 2}}{\sum_{j}^{N} \mathbb{P}\left(M_{j}\right) T^{-k_{j} / 2} S S E_{j}^{-T / 2}}$.
} 
reflect returns on net trading assets; more specifically, we assume that banks' stock returns are levered version of returns on their net trading assets. In this context, we assume a simple CAPM model of banks' stock returns in which the betas of stocks are scaled to reflect their leverage relative to movements in net trading assets. The market return $r_{t}^{m}$ is thus modeled as a function of market dividends $d_{t}$ and dividend yields $d p_{t}$ via the empirical Campbell-Shiller approximate identity:

$$
r_{t+1}^{m}=k-\rho d p_{t}+d p_{t}+\Delta d_{t+1}
$$

with estimated parameters $k=0.136$ and $\rho=0.970$.

Exposure to trading assets is specific to each bank $j \in\{1, \ldots, 6\}$ which has its own return $r_{t}^{j}$. We thus define and calculate a beta for each bank $j, \beta_{j}=\operatorname{cov}\left(r_{t}^{j}, r_{t}^{m}\right) / \operatorname{var}\left(r_{t}^{m}\right)$ and hence, by CAPM logic,

$$
r_{t}^{j}=i_{t}+\beta_{j}\left(r_{t}^{m}-i_{t}\right)
$$

When the scenario includes a negative return on the stock market of $-40 \%$ or less over a six-month period, we use the elasticity implicit in the long-run marginal expected shortfall (LRMES) measure by Acharya et al. [2013] instead of the CAPM beta. We proxy the CAPM beta of banks not publicly traded as the minimum of the CAPM betas of publicly traded banks in the sample. ${ }^{46}$

\section{A.4.3 Individual balance sheets}

Satellite models link the impact of macroeconomic shocks to individual bank losses through probabilities of default and interest rates. Step three paves the way for calculating the solvency ratio. It estimates first round losses and projections for CET1 and RWA using balance-sheet data from EBA 2015 transparency exercise data. Every P\&L component that we do not explicitly model is assumed to have remained at the cutoff date value.

Similarly, we model the evolution of risk weights related to credit risk but not the one related to market risk; hence,the risk-weighted assets for this part of the balance sheet is assumed to have remained at the cutoff date value.

For a bank $j$, let $N I_{j, t}$ be the monthly net income/losses. It is defined as the sum of net incomes from credit $\left(N I C_{j, t}\right)$, incomes from net trading assets $\left(N T I_{j, t}\right)$, losses due to deposit/short-term debt costs $\left(\operatorname{Depc}_{j, t}\right)$, provisions for trading asset, loans and bonds $\left(\operatorname{Prov}_{j, t}\right)$, and net incomes from government bond holdings $\left(N I B_{j, t}\right)$ :

$$
N I_{j, t}=N I C_{j, t}+N T I_{j, t}+N I B_{j, t}-\operatorname{Depc}_{j, t}-\operatorname{Prov}_{j, t} .
$$

Calculating first round losses requires information on banks' exposures. The EBA stress testing and transparency exercises provide this data. Loans are split into five asset classes (as a percentage of total loan exposure): consumers, mortgages, SMEs, corporates loans and the rest. Loan maturities are also given but only as a percentage of total loan exposures. We split maturities into five ranges (in line with available loan yield data from the ECB's MFI database): overnight, 0 to 3 months, 3 months to 1 year, 1 to

\footnotetext{
${ }^{46}$ LRMES measures for non-publicly traded banks suggest a lower riskiness of the returns on these banks' equity.
} 
5 years and above 5 years. We then assume that the loan maturity structure does not change for each asset class. Let $A_{l, j}$ denote the exposure vector of loans and $N t a_{t}$ the vector listing net trading assets. These vectors are assumed to be constant along the stress period-so-called static balance sheet assumption. ${ }^{47}$ We denote by Lstr $_{j}$ the loan structure of bank $j$. For example, considering a $m$-asset, $n$-maturity loan structure, we write

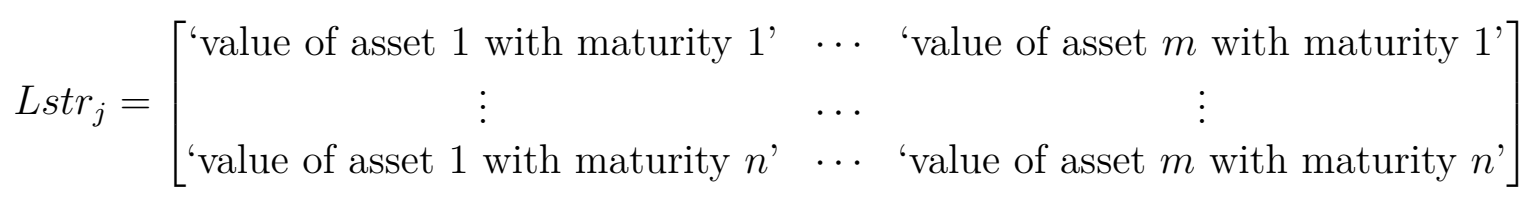

However, only maturities of up to 1 year are concerned by the stress tests and the interest rate of the remaining asset classes ("rest") is not modeled. Similarly, EBA stress test data provides data for deposits and the associated maturities for bank $j$, Depstr $_{j}$.

Credit incomes The calculation of $N I C_{j, t}$ requires the exposure to loans $A_{l, j}$, the loans structure $L s t r_{j}$ and the projections of spreads $\tilde{S}_{t}$. Net incomes on credit are defined in the following way [Drehmann et al., 2010]:

$$
N I C_{j, t}=A_{l, j} \operatorname{Lstr}_{j} \tilde{R}_{t}
$$

where $\tilde{R}_{t}=\left[\tilde{R}_{t}^{n, k}\right]$ is the conforming matrix of risk-adjusted returns on the $k$ th-class loan of $n$-period maturity,

$$
\tilde{R}_{t}^{n, k} \equiv \frac{1-D_{t+n}^{k}}{\sum_{j=1}^{n} D_{t+j}^{k}}
$$

with $n$-period discount rate

$$
D_{t}^{k}=\prod_{j=1}^{n} \frac{1-P D_{t+j}^{k} L G D_{t+j}^{k}}{1+i_{t+j}+S_{t+j}^{k}}
$$

The logic is that loan portfolios are treated as (risky) bonds with a fixed coupon $\tilde{R}$ each period for each unit of principal $A_{t}$ plus the principal repayment $A_{t}$ at maturity. The present discounted value of this security is $\sum_{j=1}^{n} D_{t+j} \tilde{R} A_{t}+D_{t+n} A_{t}$. Whenever the bank rolls over a loan, it reprices it by commanding a coupon rate $\tilde{R}$ such that $A_{t}$ equals the present value of the loan, consistent with risk-neutral pricing. ${ }^{48}$ It follows that a coupon reprices at time $t$ is $\tilde{R}_{t}=\left(1-D_{t+n}\right) / \sum_{j=1}^{n} D_{t+j}$.

\footnotetext{
${ }^{47}$ Retained earnings or losses are assumed to be imputed on cash holdings, whose variation has no bearing on the calculation of risk-weighted assets.

${ }^{48}$ Note that the re-priced interest rate (which are increasing in the probability of default, the loss-given-default, the riskfree rate and the spread) apply only to loans (and deposits, as discussed below) maturing within the stress-test horizon. It follows that long-duration asset and short-duration liabilities in a recession typically mean less income for the bank.
} 
Net trading income $N T I_{j, t}$, income on net trading assets $\left(N t a_{j, t}\right)$ is modeled using the stock return $r_{t}^{j}$. For bank $j, N T I_{j, t}$ and $N t a_{j, t}$ are set recursively as:

$$
\left\{\begin{array}{l}
N t a_{j, t}=N t a_{j, t-1} \exp \left(r_{t}^{j}\right) \\
N T I_{j, t}=N t a_{j, t-1}\left[\exp \left(r_{t}^{j}\right)-1\right] .
\end{array}\right.
$$

Income on sovereign bonds EBA data also provides information about banks' exposure to sovereign bonds. Probabilities of default of government bonds are assumed to be constant. We proxy their values using estimates from Deutsche Bank economic research that rely on CDS prices and a constant LGD at $60 \%$. We calculate income from sovereign bonds as:

$$
N I B_{j, t}=A_{b, j} \operatorname{Bstr}_{j} S_{b, t}^{\prime},
$$

where $A_{b, j}$ are the exposures in bonds for the bank $j, B s t r_{j}$ denotes the bond structure for each bank $j$, while $S_{b}^{\prime}$ expresses the projected spread.

Deposit/short-term debt costs Deposit rates are calculated using banks' exposures $A_{j, d}$, the deposit maturity structure Depstr ${ }_{j}$ and projected deposit spreads Dep $p_{t}^{\prime}$. Deposit costs are then computed as:

$$
\operatorname{Depc}_{j, t}=A_{j} \text { Depstr }_{j} \text { Dep }{ }_{t}^{\prime}
$$

It is precisely the difference in maturities between loans and deposits that may cause income losses on the banking book [see also Alessandri et al., 2009].

Provision losses In addition to income and losses from loans, sovereign bonds, trading incomes and deposits, banks have to make provisions as a function of their defaulted assets. Here, provisions are simply the defaulted assets for each loan class. We suppose that losses given default (LGD) are kept constant over the stress period:

$$
L G D=\left[\begin{array}{l}
l g d_{\text {sme }} \\
l g d_{\text {mort }} \\
l g d_{\text {cons }} \\
l g d_{\text {corp }}
\end{array}\right]=\left[\begin{array}{l}
0.84 \\
0.17 \\
1.00 \\
0.84
\end{array}\right]
$$

Denote by $A_{j}$ the exposure of bank $j$ to each asset class (SME, mortgage, consumer, corporate), regardless of their maturity.

$$
\operatorname{Prov}_{j, t}=A_{j}\left(\sum_{i=1}^{4} P D_{t}(i) L G D(i) A_{j}(i)\right) .
$$

Therefore, increased probabilities of default and losses-given-default force banks to set aside higher amounts of provisions. 
Equity projections There are many elements of the income statement that are not modeled, including operational costs; also, we have not yet modeled decisions to distribute dividends or issue new capital. To pin these elements down we make the assumption that they are invariant across different scenarios and are such that capital levels (and non-risk-weighted ratios) are constant if macroeconomic variables are at their long-run values. This hypothesis mimics standard DSGE logic and implies that banks' capital levels are constant at the mean value of macroeconomic factors.

There is a more general point here (and often an overlooked one in the top-down stress testing literature). Stress testing models always have implications for steady-state capital levels and ratios, and these implications have to be disciplined. These steady-state values are crucial, as they work as points of attraction for modeled capital ratios in the presence of mean reversion in the forecasting model for macro-financial variables.

Under our assumption, we are effectively saying that the current capital levels (and non-risk-weighted ratios) are our best guess for where they are going in the future and that, since baseline projections revert to a stationary point in the long run, that we are taking the current capital levels as the steady-state capital levels to which banks will converge as the economy reverts to its long-run value. Therefore, a natural diagnostic tool for whether a macro stress testing tool has reasonable implications is to look at the capital ratios that it forecasts in absence of shocks, as the economy reverts to its mean.

Formally, we can summarize our model as follows. We model demeaned macroeconomic variables $X$ as a stationary $\operatorname{VAR}(1)$ :

$$
X_{t}=A X_{t-1}+B \epsilon_{t}
$$

with $\epsilon_{t} \sim W N(0, I)$ and known matrices $A, B$. We model auxiliary variables $Y$ (excess returns in the factor model of returns on the trading book; spreads, probabilities of default and losses-given-default on loans in the banking book; and deposit and bond rates) as stationary variables:

$$
y_{t}=y+C X_{t}
$$

with known mean vector $Y$ and matrix $C$.

The $i$ th bank has unweighted exposures $A_{1, i}, \ldots, A_{J, i}$ to the $J$ different asset classes and $H$ types of debt $D_{1, i}, \ldots, D_{H, i}$. After-tax-and-distribution profits and losses $N I$ of bank $i$ are modeled as:

$$
N I_{i, t}=(1-\tau)\left(\xi_{i, t} A_{i, t}+\sum_{j=1}^{J} f_{j}\left(y, X_{t}\right) A_{i, j, t}-\sum_{h=1}^{H} g_{h}\left(y, X_{t}\right) D_{i, h, t}\right)
$$

for known functions $f_{j}$ and $g_{h}, A_{i, t} \equiv \sum_{j=1}^{J} A_{i, j, t}$, and a given share $\tau$ of net income devoted to taxes and profit distribution (interpreted as issuance of new equity in the event of a negative NI), and where $\xi_{i, t}$ is the unmodeled part of the $i$ th bank net income and that includes operating and personnel costs, operational-risk costs, extraordinary items, assets and debt whose returns are not explicitly modeled, etc., expressed as a fraction of total assets.

We make the assumption that $\xi_{i, t}=\xi_{i}$ is constant. Parameter $\xi_{i}$ is unknown at this stage. 
A static balance sheet assumption implies trivial dynamics in exposures and debts:

$$
A_{i, j, t}=e^{\mu} A_{i, j, t-1}=e^{t \mu} A_{i, j, 0}, \quad D_{i, j, t}=e^{\mu} D_{i, j, t-1}=e^{t \mu} D_{i, j, 0}
$$

for some trend growth rate $\mu$, where $A_{i, j, 0}$ and $D_{i, j, 0}$ are known initial exposures and debts.

Let $\rho_{i, t} \equiv \frac{N I_{i, t}}{A_{i, t}}$. Importantly:

$$
\rho_{i, t}=(1-\tau) \xi_{i}+(1-\tau) \frac{\sum_{j=1}^{J} f_{j}\left(y, X_{t}\right) A_{i, j, 0}-\sum_{h=1}^{H} g_{h}\left(y, X_{t}\right) D_{i, h, 0}}{A_{i, 0}}
$$

is a stationary variable, so $N I$ inherits the trend growth rate of assets. At the steady state:

$$
\rho_{i}=(1-\tau) \xi_{i}+(1-\tau) \frac{\sum_{j=1}^{J} f_{j}(Y, 0) A_{i, j, 0}-\sum_{h=1}^{H} g_{h}(Y, 0) D_{i, h, 0}}{A_{i, 0}}
$$

Let $\kappa_{i, t} \equiv \frac{K_{i, t}}{A_{i, t}}$, where $K_{i, t}$ is the capital level of bank $i$. Then:

$$
K_{i, t} \equiv K_{i, t-1}+N I_{i, t} \quad \Leftrightarrow \quad \kappa_{i, t}=e^{-\mu} \kappa_{i, t-1}+\rho_{i, t}
$$

so the capital level inherits the trend growth rate of assets. At the steady state:

$$
\kappa_{i}=e^{-\mu} \kappa_{i}+\rho_{i} \quad \Rightarrow \quad \rho_{i}=\left(1-e^{-\mu}\right) \kappa_{i}
$$

for a given steady-state unweighted capital ratio parameter $\kappa_{i} \in[0,1]$.

Therefore, for given parameters $\kappa_{i}$ (long-run unweighted capital ratio) and $\mu$ (trend growth rate), we can pin down $\rho_{i}$ via (A.4.38), and hence $\xi_{i}$ via (A.4.37). ${ }^{49}$

${ }^{49}$ The balance-sheet identity holds as:

$$
\sum_{j=1}^{J} A_{i, j, t} \equiv \sum_{h=1}^{H} D_{i, h, t}+D_{i, t}^{*}+K_{i, t}
$$

with $D_{i, 0}^{*}=0$, where $D_{i, t}^{*}$ represents amounts not included in $\left\{D_{i, h, t}\right\}_{h=1}^{H}$ owed to the central bank and remunerated at some interest rate $i_{t}^{*}$. Accordingly, $D_{i, t}^{*}>(<) 0$ counts as an increase (reduction) in the liabilities with the central bank. For simplicity, we assume $i_{t}^{*}=0$, so the term $i_{t}^{*} D_{i, t-1}^{*}$ does not affect $N I_{i, t}$ in equation (A.4.36).

It follows that $A_{i, j, t}=e^{\mu} A_{i, j, t-1}, D_{i, h, t}=e^{\mu} D_{i, h, t-1}$ and $K_{i, t}-K_{i, t-1}=e^{\mu} \rho_{i, t} A_{i, t-1}$ imply

$$
D_{i, t}^{*}=A_{i, t}-D_{i, t}-K_{i, t}=e^{\mu} D_{i, t-1}^{*}+\left[\left(e^{\mu}-1\right) \kappa_{i, t-1}-e^{\mu} \rho_{i, t}\right] A_{i, t-1}
$$

Note that at the steady state we have $D_{i, t}^{*}=0$ along a balanced growth path. 
RWA projections Using Interal rating-based approach (IRB) Basel II risk-weight functions, risk weighted assets (RWA) are defined according to the following rule:

$$
R W A_{j, t}=12.5\left(\sum_{i=1}^{4} \mathcal{K}_{t}(i) S t r_{j, t}(i) A_{j, t}\right),
$$

where $\mathcal{K}_{t}(i)$ is the weight associated to the asset $i$ according to IRB standard, $A_{j}$ is the total exposition in assets for bank $j$ while $S t r_{j, i}$ is the percentage allocation of bank $j$ in asset $i$. The weight $\mathcal{K}_{t}(i)$ is function of default probabilities, maturities and LGD. As assets classes face different risk profiles, the weight in the computation of the RWA will be different [BCBS, 2005]. ${ }^{50}$ According to this formula, in the computation of the asset side, each asset is rescaled according to its own risk profile. In our stress test exercise, the values for the weights $\mathcal{K}_{t}(i)$ evolve over the projection period according to the behaviour of the PDs, while the assets expositions remain at their cut-off values complying to the static balance sheet assumption.

Solvency ratio Once risk weighted assets (RWA) and equity projections have been estimated, it is possible to calculate the solvency ratio forecasts. The ratio is defined by:

$$
\text { ratio }_{j, t}=\frac{K_{j, t}}{R W A_{j, t}}
$$

The solvency ratios that we obtain at the end of the procedure can be confronted with the target ratio requested by the regulator and the mismatch coming out of the exercise can be used as a suggestion for the $\mathrm{CCyB}$. In case the stress test exercise is used in the hybrid application and the activation of the $\mathrm{CCyB}$ is triggered, second round effects coming out from the this activation can be computed. For future work, it will be interesting to allow banks to re-optimize the structure of their balance sheet under the different scenarios (i.e. a dynamic balance sheet).

\section{Annex 5 Contagion models}

This annex presents the contagion models used to assess financial contagion after a first round shortfall on individual banks' capital ratios. We use the frameworks developed in Gabrieli et al. [2015] and Idier and Piquard [2017]. The first paper focuses mainly on direct mechanisms of contagion. The second framework considers jointly direct and indirect channels of propagation. The two set up are shortly described in the following.

\footnotetext{
${ }^{50}$ For the sake of brevity, we do not report the formulas for the asset weights $\mathcal{K}_{t}(i)$, the interested reader can refer to [BCBS, 2005].
} 


\section{A.5.1 Contagion model by Gabrieli, Salakhova, and Vuillemey [2015]}

The network model developed in this paper allows analysis of the effect of financial interconnections between European banking groups on the risk of contagion. The model features the interaction of three contagion channels: (i) exposures to stress in the stock market; (ii) exposures to credit and counterparty risk in the interbank market; and (iii) exposures to short-term liquidity risk (inability to roll over a loan overnight or with a very short maturity). Following an initial shock to the system, the spread and consequences of financial contagion are measured by the number of banks in default and the capital losses suffered.

The paper considers a stress scenario consisting of a common shock to the stock market (a drop in banks' equity prices) and the exogenous default of one of the banks in the network. In the context of the hybrid approach for the calibration of the $\mathrm{CCyB}$ presented in this paper, the stress scenario consists of the initial capital shortfalls suffered by the six banks composing the national banking sector. Following such initial impact on banks' balance sheets, the amplification of losses is driven by the following mechanisms:

- Bank solvency contagion (via long-term bilateral credit obligations), and

- Bank liquidity contagion (via short-term bilateral obligations).

In the first form of direct contagion all banks exposed to the banks suffering the initial shortfall take losses (given an assumed recovery rate); these losses may trigger a cascade of defaults if the total losses suffered by one bank make its CET1 capital ratio go below the regulatory limit of $4.5 \%$ (under the assumption that external equity capital cannot be raised in the midst of a stress situation). The defaulting banks are removed from the system.

For the surviving banks, a sizeable aversion to lend excess liquidity over short horizons then appears (liquidity contagion channel). The larger the losses incurred, the more a bank becomes reluctant to roll over unsecured short-term loans to other institutions. The riskier institutions (those that have a higher leverage ratio) face greater funding strains. If it is impossible for a bank to roll over its short-term debt, it becomes illiquid and defaults. The bank's counterparties write the loan down as an additional loss and may themselves subsequently default. The contagion mechanisms continue to unfold until no additional bank defaults. Even in the absence of additional default, the algorithm computes the additional losses suffered by banks.

\section{A.5.2 Contagion model by Idier and Piquard [2017]}

This paper is one of the first to jointly include several channels of contagion:

- Bank solvency contagion (via cross holding of equity),

- Bank liquidity contagion (through collateralized interbank loans and margin calls),

- Fire-sales dynamics leading to market contagion (when banks suffer liquidity shortage). 


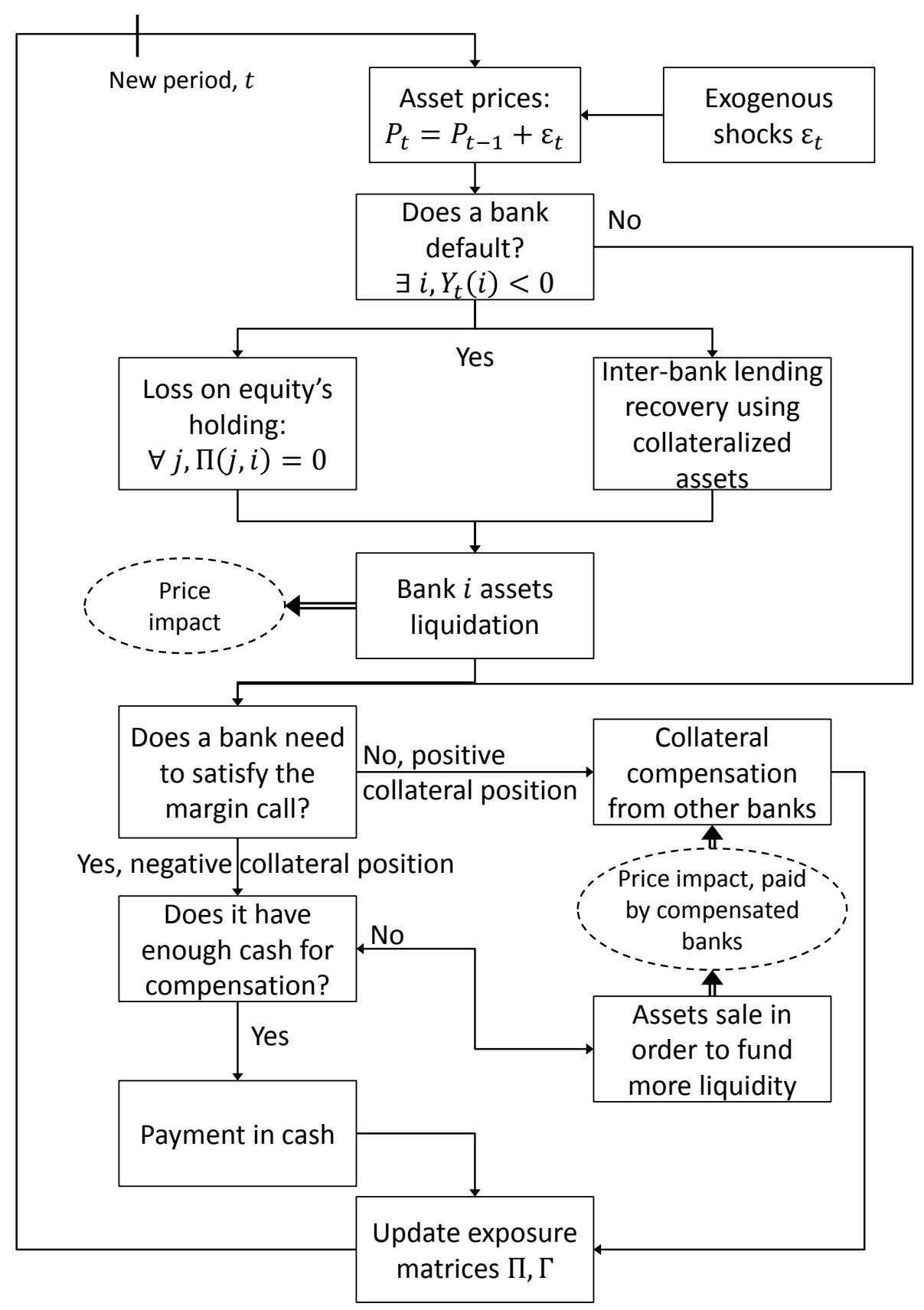

Figure 15: Idier and Piquard [2017] contagion model, framework 
We especially draw on two key papers that are Gourieroux et al. [2012] for the balance sheet stylization and on Greenwood et al. [2015] for firesales dynamics.

The general framework is presented in figure 15 and proceeds as follows:

Exogenous shock on asset prices corresponds to the initial shock from first round stress testing exercises. Asset prices then randomly move (with null mean and standard variance from financial time series) at the beginning of each round of contagion to allow for probabilistic distributions of banks' equity.

Default condition and assets liquidation If a bank goes bankrupt, all modelled banking counterparties lose their cross-holding of equity and recover their interbank liabilities with collateral of the defaulted bank, that is implicitly equally distributed among all classes of assets safe cash instruments. Remaining exposures are liquidated on markets. It induces a price impact as the market depth is finite, whom is to be borne by all remaining banks.

Margin calls on collateralized debt Initial shocks on asset prices in addition to the liquidation of defaulted banks change collateral needs to secure interbank lending contracts. We allow margin calls to ensure the same recovery value for lenders. In the advent of prices shortfall, the borrower has to pay the lender in cash. It must liquidate assets if it has not enough cash to meet margin calls. This additional channel of contagion expands the gap between fragile and safe banks, as the former needs to provide cash to the latter. Therefore, it amplifies contagion effects coming from initial shortfalls as fragile banks are more likely to fail as soon as they pay margin calls.

Exposures are updated and the system proceeds to a next round Cross-exposures from defaulted banks are deleted and we proceed to the next round, i.e. implement a new random shock on asset prices.

We use the banking balance sheet model from Gourieroux et al. [2012], as it allows to include as much granular data as we have.

\begin{tabular}{c|c} 
Assets $i$ & Liabilities $i$ \\
\hline$\Pi_{i} Y_{t}$ & $L_{i}^{I}$ \\
$\Gamma_{i} L^{I}$ & $L_{i}^{*}$ \\
$X_{i, t} P_{t}$ & \\
\hline$A_{i, t}$ & $L_{i}$
\end{tabular}

Table 16: Bank $i$ balance sheet

with $Y_{t} \in M_{n, 1}(\mathbb{R})$ the vector of equities; $A_{t}$ are assets and $L_{t}$ liabilities, as $n \times 1$ vectors. Liabilities split between interbank lending $L_{i}^{I}$ and other debts $L_{i}^{*}$ such as deposits for example. Both are considered at their nominal value provided bank $i$ does not go bankrupt. We do not differentiate maturities and seniority at the liability side. Matrices $\Pi$ and $\Gamma$ presents equity and debt cross-holdings. $X_{t}$ matrix 
represents exposure to exogenous, i.e. non banking assets, such as cash, loans to the non-banking sector, trading book, debt securities and derivatives. Interbank debt inter-linkages are roughly estimated with the following formula:

$$
\Gamma(i, j)=\frac{\operatorname{laons}(i)}{\sum_{k=1}^{\text {banks }} \operatorname{loans}(k)-\operatorname{loans}(j)}
$$

Although regulatory data allow us to access real bilateral debt networks, we use this formula as an example of a tiered interbank network.

The price impact from assets' liquidation is modelled using the Amihud [2002] statistics $A_{m}$ along with market correlation between the various types of assets $R$. The price impact is such that

$$
\Delta P=T V A_{m} R
$$

with $T V$ being the volume of liquidated assets. This formula holds for liquidations following both default and payment of margin calls.

Finally, margin calls are calculated as the price impact times the haircut on collateralized debt.

We take on the following calibrated values to simulate contagion effects. Trading assets volatility is at $15 \%$ yearly while loans portfolio one stands at $2 \%$. Correlation matrices $R_{\text {norm }}$ and $R_{\text {crisis }}$ are obtained by calculating correlations between eurostoxx50, corporate bonds and iTraxx indexes, considering that these correlations are doubled when a default event occurs. In line with empirical estimations, Amihud statistics is equal to $10^{-10}$.

\section{Annex 6 BCBS rule in the illustrative scenario}

In this box, we show a practical application of the BCBS buffer guide based on the observation of the aggregate credit-to-GDP gap. According to this rule, the CCyB is activated when the credit-to-GDP gap exceeds $2 \mathrm{pp}$ in a linear relationship with slope .3125 and a maximum value of $2.5 \mathrm{pp}$. The latest estimate of the credit-to-GDP gap is $1.7 \mathrm{pp}$ and is projected to reach 3.5pp by end-2019. If one believes in the threshold of 2pp as an indicator of abnormal credit expansion, then the CCyB should react now.

We calibrate the activation based on the projected values of the credit-to-GDP gap over 2017-2018. The strict application of the rule to this value gives an $0.65 \mathrm{pp}$ rise in the buffer. The year 2019 corresponds in our setting to an economic downturn episode during which the $\mathrm{CCyB}$, in accordance with its objectives, should be released regardless of the credit gap level. Note that this behavior of capital buffers constitutes a break in the rule described by equation (1) - the credit gap level is still above the activation threshold, yet the $\mathrm{CCyB}$ is released in response to the downturn episode. This stands in contrast with the structural analysis described by figure 6 according to which the macroprudential authority commits to the rule that dampens the credit cycle, despite discretionary incentives to respond to other objectives and release buffers during a downturn.

We use the GNSSFr model to simulate the effect on the scenario of an activation of magnitude $0.65 \mathrm{pp}$ in 2017Q1 and a release in 2019Q1. The impact on the scenario is plotted in figure 16. 
GNSSFr model:
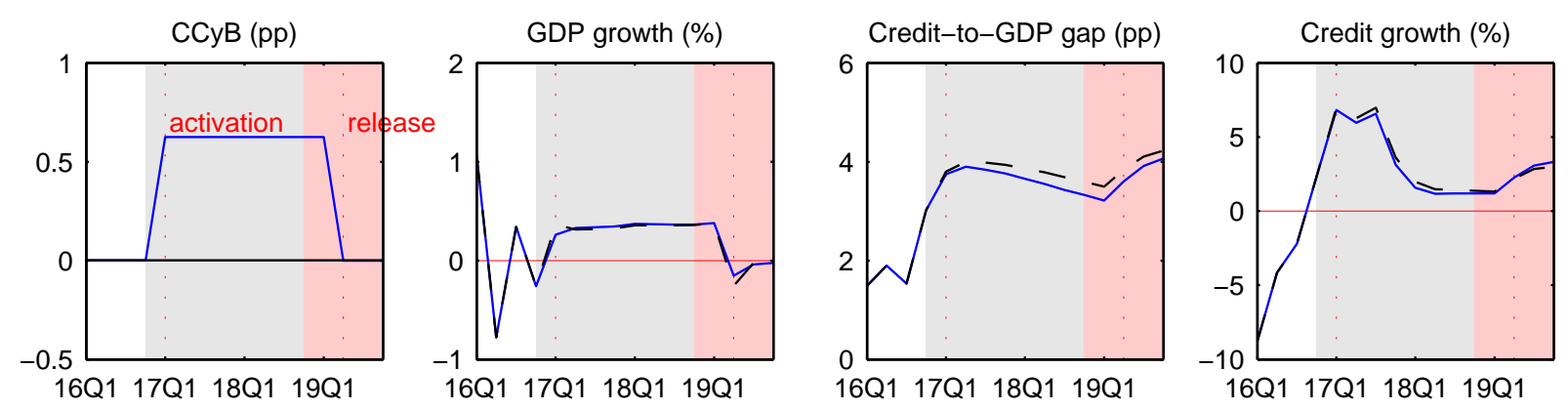

$3 D$ model:

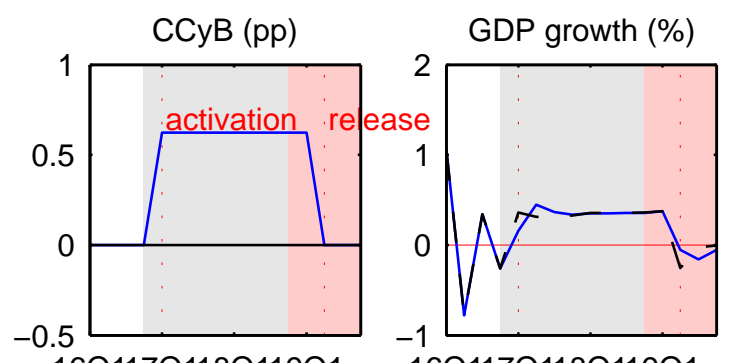

16Q117Q118Q119Q1

16Q117Q118Q119Q1

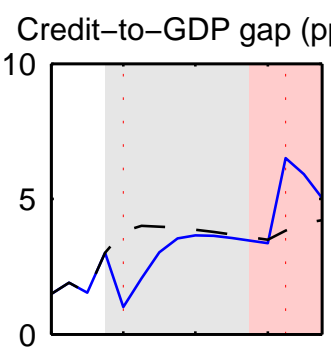

16Q117Q118Q119Q1

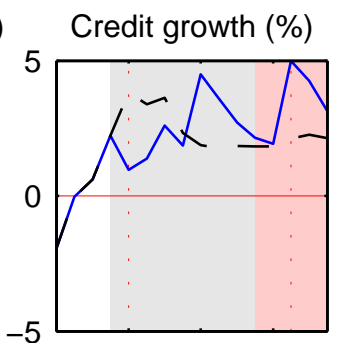

16Q117Q118Q119Q1

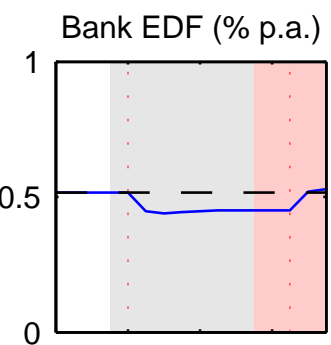

16Q117Q118Q119Q1

Figure 16: Counterfactual analysis under the BCBS approach in the illustrative scenario. 